\title{
The ability to invest in human capital
}

Citation for published version (APA):

Golsteyn, B. H. H. (2007). The ability to invest in human capital. [Doctoral Thesis, Maastricht University]. Researchcentrum voor Onderwijs en Arbeidsmarkt, Faculteit der Economische Wetenschappen. https://doi.org/10.26481/dis.20071217bg

Document status and date:

Published: 01/01/2007

DOI:

10.26481/dis.20071217bg

Document Version:

Publisher's PDF, also known as Version of record

\section{Please check the document version of this publication:}

- A submitted manuscript is the version of the article upon submission and before peer-review. There can be important differences between the submitted version and the official published version of record.

People interested in the research are advised to contact the author for the final version of the publication, or visit the DOI to the publisher's website.

- The final author version and the galley proof are versions of the publication after peer review.

- The final published version features the final layout of the paper including the volume, issue and page numbers.

Link to publication

\footnotetext{
General rights rights.

- You may freely distribute the URL identifying the publication in the public portal. please follow below link for the End User Agreement:

www.umlib.nl/taverne-license

Take down policy

If you believe that this document breaches copyright please contact us at:

repository@maastrichtuniversity.nl

providing details and we will investigate your claim.
}

Copyright and moral rights for the publications made accessible in the public portal are retained by the authors and/or other copyright owners and it is a condition of accessing publications that users recognise and abide by the legal requirements associated with these

- Users may download and print one copy of any publication from the public portal for the purpose of private study or research.

- You may not further distribute the material or use it for any profit-making activity or commercial gain

If the publication is distributed under the terms of Article $25 \mathrm{fa}$ of the Dutch Copyright Act, indicated by the "Taverne" license above, 


\section{The Ability to Invest in Human Capital}


(c) Bart Hendricus Hubertus Golsteyn, Maastricht 2007

All rights reserved. No part of this publication may be reproduced, stored in a retrieval system, or transmitted in any form, or by any means, electronic, mechanical, photocopying, recording or otherwise, without the prior permission in writing, from the author.

Published by ROA

Postbus 616

6200 MD, Maastricht

ISBN: 978-90-5321-461-9

Printed in the Netherlands by Océ Business Services 


\title{
The Ability to Invest in Human Capital
}

\author{
Proefschrift
}

ter verkrijging van de graad van doctor aan de Universiteit Maastricht, op gezag van de Rector Magnificus, Prof. mr. G.P.M.F. Mols

volgens het besluit van het College van Decanen, in het openbaar te verdedigen op maandag 17 december 2007 om 14.00 uur

door

Bart H.H. Golsteyn 
Promotor

Prof. dr. L. Borghans

Prof. dr. J.A.M. Heijke

Beoordelingscommissie

Prof. dr. A. de Grip (voorzitter)

Prof. dr. C. de Neubourg

Prof. dr. E.J.S. Plug 


\section{Acknowledgements}

Throughout the course of this dissertation, Lex Borghans has provided invaluable support. He has generously transferred his knowledge regarding the world of economic science on to me for which I am most grateful.

Many people have given their views on the ideas in this thesis. I thank them in the beginning of the chapters. Two of them deserve special attention: each paper I wrote has benefitted from the comments of Bas ter Weel and Arnaud Dupuy. Hans Heijke has provided valuable comments in the last phase of the research. In this respect, I also thank the members of the assessment committee.

Frank Cörvers and Lex helped me to acquire commissioned research projects in line with the topic of my thesis. Besides a solid financial basis for my research, this provided me with the opportunity to integrate my questions in large-scale school leaver surveys. ROA has supported me financially to write this thesis from May 2004 onwards, to travel to various conferences and to stay at the IIES in Stockholm for six months. ROA also has given me a very pleasant working atmosphere for which I would like to thank all my colleagues. Thanks especially to Sander Dijksman, Jos Sanders, Ben Kriechel, Charlotte Büchner, and Jan Sauermann.

Finally, I am deeply grateful to my mother Nelly, father Henk, sister Maud, my friends, and especially my girlfriend Johanna for listening to the developments in my research and for their support in the other areas of my life.

Maastricht, the Netherlands

Bart Golsteyn

October, 2007 


\section{Contents}

1 Introduction 1

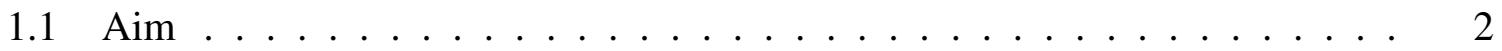

1.2 Time discounting, imagination and regret $\ldots \ldots \ldots$

1.2 .1 Time discounting . . . . . . . . . . . . . . 3

1.2 .2 Imagination . . . . . . . . . . . . . . 4

1.2 .3 Regret...................... 5

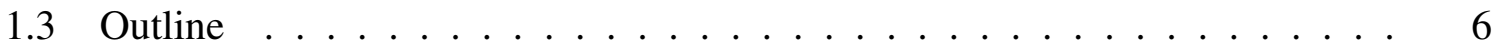

1.3.1 Time Discounting, Imagination and Human Capital Investments . . 7

1.3.2 Skill Transferability, Regret and Mobility . . . . . . . . . . . . . 8

1.3.3 Imagination and Investments in Skill-Deficiencies . . . . . . . . . . 8

1.3.4 Imagination and Investments in Health: the Body Mass Index . . . . 9

2 Time Discounting, Imagination and Human Capital Investments 11

2.1 Introduction . . . . . . . . . . . . . . . . . . . . . 12

2.2 The Model . . . . . . . . . . . . . . . . . . . . . . . 15

2.2.1 Imagination and time discounting . . . . . . . . . . . . . 15

2.2.2 Imagination and the length of stay in education . . . . . . . . . . 17

2.2.3 Regret of length of stay in education . . . . . . . . . . . . . . 22

2.3 Data and definitions . . . . . . . . . . . . . . . . . . 22

2.3.1 The Dutch educational system . . . . . . . . . . . . . . . 23

2.3 .2 Three data sets . . . . . . . . . . . . . . . . . . 24

2.3.3 Measuring time discounting . . . . . . . . . . . . . 28

2.3.4 Measuring imagination . . . . . . . . . . . . . . . . . 34

2.3.5 Measuring other attributes . . . . . . . . . . . . . . . 40

2.4 Results . . . . . . . . . . . . . . . . . . . . . . 43

2.4.1 Imagination and time discounting . . . . . . . . . . . . . 43

2.4.2 Imagination and length of stay in education . . . . . . . . . . . . . . 47

2.4.3 Regret of length of stay in education . . . . . . . . . . . . . 51

2.5 Conclusions . . . . . . . . . . . . . . . . . . 53

3 Skill Transferability, Regret and Mobility 55 


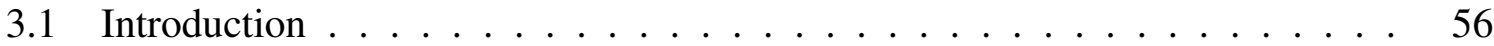

3.2 Contribution to the literature . . . . . . . . . . . . . . 57

3.3 The model . . . . . . . . . . . . . . . . . . . . . 59

3.4 Data description and definitions . . . . . . . . . . . . . 64

3.5 Empirical strategy . . . . . . . . . . . . . . . . . . . . 67

3.5.1 Switching between fields of education . . . . . . . . . . 68

3.5 .2 Duration of further education . . . . . . . . . . . . . . 69

3.5 .3 Wage ............................... 70

3.5.4 The second step: Identifying transferability . . . . . . . . . . . . 71

3.6 Results . . . . . . . . . . . . . . . . . . . . . . 72

3.6.1 Robustness and extensions . . . . . . . . . . . . . . . 74

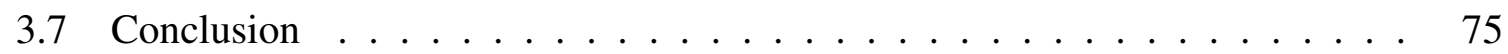

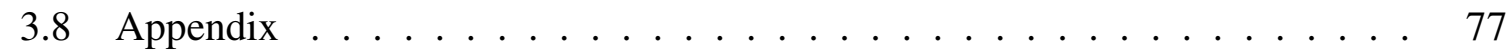

4 Imagination and Investments in Skill-Deficiencies $\quad 85$

4.1 Introduction . . . . . . . . . . . . . . . . . . 86

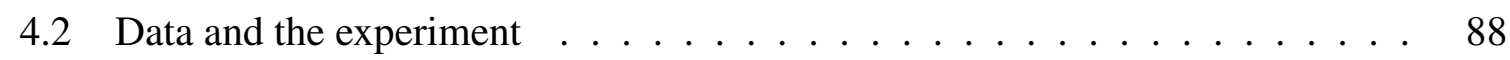

4.2.1 Skill-deficiency . . . . . . . . . . . . . . . . 88

4.2 .2 The experiment . . . . . . . . . . . . . . . . . . . . . 89

4.2 .3 Individual attributes $\ldots \ldots \ldots . \ldots \ldots 1$

4.3 Method ............................... 96

4.4 Results . . . . . . . . . . . . . . . . . . . . 97

4.4.1 Individual attributes . . . . . . . . . . . . . . . . . . . . . . . . 99

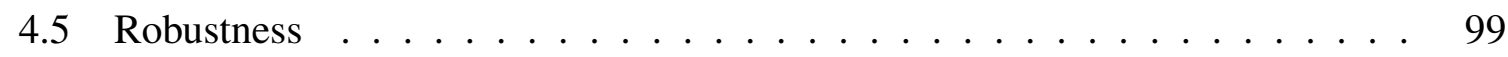

4.5.1 Linearity assumption of skill-deficiency variable . . . . . . . . . . . . 99

4.5.2 Selection bias . . . . . . . . . . . . . . . . . . 101

4.5.3 Incentives to invest per course . . . . . . . . . . . . . . . . . . . . . . . . . . 104

4.6 Conclusions . . . . . . . . . . . . . . . . . . . . 104

5 Imagination and Investments in Health: the Body Mass Index 107

5.1 Introduction . . . . . . . . . . . . . . . . . . . . 108

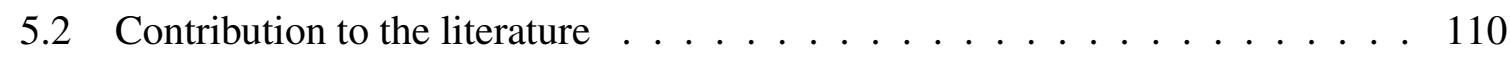

5.3 Time discounting and BMI . . . . . . . . . . . . . . . . . . . . . . . . . . . . . . . 112

5.4 Data and empirical strategy . . . . . . . . . . . . . . . . 115

5.4 .1 The data . . . . . . . . . . . . . . . . . . . . . . . . . . . . . . . 115

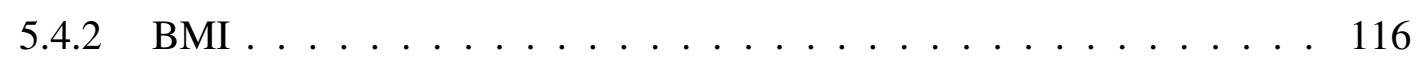

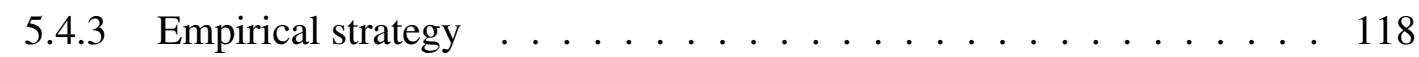

5.4 .4 Measuring time discounting . . . . . . . . . . . . . . . . 119

5.4 .5 Noncognitive skills . . . . . . . . . . . . . . . . 120

5.5 Cross-sectional relationship between noncognitive skills and time discounting and BMI . . . . . . . . . . . . . . . . . . . . . . 125

5.6 The relationship between noncognitive skills and BMI over time . . . . . . 128

5.7 Discussion and conclusions . . . . . . . . . . . . . . . 130 
6 Implications and future research 135

6.1 Main findings . . . . . . . . . . . . . . . . . . . 136

6.2 Implications . . . . . . . . . . . . . . . . . . 137

6.2.1 The case for interventions in behavior . . . . . . . . . . . . . . 137

6.2 .2 The costs of inadequate choices . . . . . . . . . . . 138

$\begin{array}{ll}\text { Summary in Dutch } & 155\end{array}$

$\begin{array}{ll}\text { Biography } & 161\end{array}$

$\begin{array}{ll}\text { ROA Dissertation Series } & 163\end{array}$ 
Contents 


\section{List of Figures}

2.1 Duration of education and the discount rate $\ldots \ldots \ldots$

4.1 Regression coefficients of dummies per skill-deficiency level . . . . . . . . . 101

4.2 Regression coefficients of the interaction of the default with dummies per skill-deficiency level . . . . . . . . . . . . . . . . . . . 102

5.1 The development of BMI, 1995-2004 . . . . . . . . . . . . . . . 117

5.2 Increase in BMI between 1995 and 2004 for different percentiles of the male and female BMI distribution . . . . . . . . . . . . . . . . . . 118

5.3 Development of MANAGE and PLAN as proxies for (budget) management skills and impulsiveness, 1995-2004 . . . . . . . . . . . . . . . . . 129

5.4 Development of the scores on FUTURE03-variable as a proxy for imagination, $1995-2004 \ldots \ldots \ldots$. . . . . . . . . . . . . . . . 129

5.5 Development of coefficients for MANAGE in annual regressions explaining BMI, 1995-2004 . . . . . . . . . . . . . . . . . 130

5.6 Development of coefficients for PLAN in annual regressions explaining BMI,

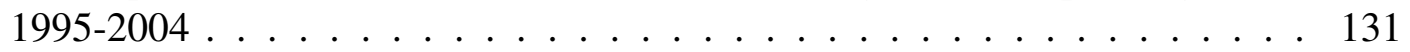

5.7 Development of coefficients for FUTURE03 in annual regressions explaining BMI, 1995-2004 . . . . . . . . . . . . . . . . . 131

5.8 BMI for high and low budget managing skills (based on MANAGE variable), 1995-2004 . . . . . . . . . . . . . . . . . . . 132

5.9 BMI for high and low impulsiveness (based on PLAN variable), 1995-2004 . 132 5.10 BMI for high and low imagination (based on FUTURE03 variable), 1995-2004 133 
List of Figures

viii 


\section{List of Tables}

2.1 A simple representation of the Dutch educational System . . . . . . . . . . 23

2.2 Sample characteristics . . . . . . . . . . . . . . . 26

2.3 Discount rate descriptives . . . . . . . . . . . . . . . . . 30

2.4 The relationship between the discount rate based on the vacation question and monetary measures of the discount rate . . . . . . . . . . . . . 32

2.5 Relationship between measures of the discount rate and indicators of risky

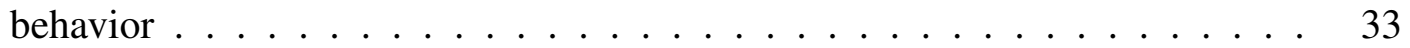

2.6 Imagination measures $\ldots \ldots \ldots \ldots \ldots \ldots \ldots$

2.7 Imagination descriptives $\ldots \ldots \ldots \ldots \ldots \ldots$

2.8 Measures about uncertainty related to the educational choice and imagination 39

2.9 Measurement of individual attributes . . . . . . . . . . . . . . . 42

2.10 Correlation between different measures of the discount rate and measures of imagination ............................. 44

2.11 Other explanatory variables of the discount rate and imagination . . . . . . 46

2.12 The discount rate and the clarity of the image in different domains of life . . . 47

2.13 Imagination and the length of the stay in education . . . . . . . . . . . . 49

2.14 Regret, duration of the stay in education for students who formed an image about their field due to family working in this field and those who did not gain from such information . . . . . . . . . . . . . . 51

2.15 Regret of length of stay in education . . . . . . . . . . . . 52

3.1 Distribution of respondents over disciplines in original education . . . . . . 65

3.2 Usage of skills acquired by the initial education in current profession . . . . . 66

3.3 Number of respondents continuing education in same or different field and mean duration of further education . . . . . . . . . . . . . . . 66

3.4 Regret of initial education and switching behavior . . . . . . . . . . . . 67

3.5 Correlation between transferability parameters (St. Error in parenthesis) . . . 73

4.1 Skill-deficiency question . . . . . . . . . . . . . . . . . . . . 89

4.2 The specific courses offered related to the skills . . . . . . . . . . . . 90

4.3 The choice of courses, average skill-deficiency per course and the percentage of respondents skill deficient in a course . . . . . . . . . . . . . . . 92 
4.4 Measuring individual characteristics . . . . . . . . . . . . . . . . . . . . 94

4.5 Correlations between measures of personal characteristics . . . . . . . . . . . 96

4.6 Default, skill-deficiency and the choice for courses . . . . . . . . . . . 98

4.7 Psychological attributes and the choice for the default and skill deficiency . . 100

4.8 Attitudes related to work . . . . . . . . . . . . . . . . . . 102

4.9 Default, skill-deficiency and the choice for courses for different values attached to challenge in job . . . . . . . . . . . . . . . . . . . 103

4.10 Default, skill-deficiency and the choice for courses for different values attached to career perspectives . . . . . . . . . . . . . . . . . . 103

4.11 Analysis per course . . . . . . . . . . . . . . . . . 105

$5.1 \quad$ BMI levels men and women, $2004 \ldots \ldots \ldots \ldots$

5.2 Percentages of the respondents choosing the option that gives them gratification sooner with the high and low monetary questions . . . . . . . . . . . . 120

5.3 Noncognitive skills . . . . . . . . . . . . . . . . . . . . . . 122

5.4 Relationship between time discounting and BMI as dependent variables and noncognitive skills as independent variables . . . . . . . . . . . . . 126

6.1 The costs of learning delay . . . . . . . . . . . . . . . . . . . 140 


\section{Introduction}




\subsection{Aim}

Activities in the present often affect future outcomes. Individuals who engage in these activities are trading off their present and future well-being. Some reveal a higher preference for present happiness while others deprive themselves of current pleasure in anticipation of the future. In the literature, the former are defined as having a high time discount rate. The consequences of heterogeneity in discount rates between persons have been investigated for a great variety of investment decisions. Higher time discounting has been associated with a lower willingness to invest in knowledge and health.

The observation that motivates the research in this thesis is that many activities related to high discount rates do not seem to reflect deliberate investment strategies. Dropping out of school, starting to smoke, or having unsafe sex are some examples. An important manifestation of the undeliberate nature of these decisions is that many people regret such choices later on. This raises the question whether attaching a relatively low value to the future reflects true preferences or whether investors with high discount rates have problems imagining the future consequences of their actions.

The aim of the thesis is to investigate whether people differ in the capacity to think about the future, and whether those who see the future less clearly will be more present oriented and will make less adequate investment decisions. The context of the analysis will be investments in human capital.

We approach this question by analyzing the theoretical implications of incorporating imagination in the human capital investment framework and by testing these implications empirically. In a model, we show that a lack of imagination partly affects investment decisions in a similar way as a traditional discount rate. Aspects further away in the future will be more highly discounted as a result of increased unclarity. But imagination has other implications which are different from the traditional discounted utility model.

First, while many authors have shown that people differ in the level of their discount rate, the relation between imagination and time discounting provides an important insight into the question why people are heterogenous with respect to intertemporal preferences. Moreover, for a given person, if certain results are imagined more vividly than other results, different discount rates will apply for different situations. We will show that the latter implication can explain paradoxical findings with respect to the correlation between time discounting and investment outcomes.

Second, those with less imagination have a higher probability to make less adequate investment decisions. The quality of investment decisions is a key aspect throughout the thesis. 
We show in various contexts and with various analytical tools that imagination improves the quality of investments in human capital. We focus also on the consequences of having made a low quality investment choice. One important consequence is that people who regret their choices have an incentive to correct their decisions. Repairing the initial choices can be very costly.

An implication of the idea that imagination affects the quality of investment decisions is that it provides a rationale for government interference in individuals' choices. In standard investment models, conclusions are drawn that people with high discount rates are involved more in present oriented behavior. From a policy perspective, this conclusion alone does not allow for interventions because if people with high discount rates are making conscious decisions in favor of the present and their decisions do not negatively affect other individuals' utility, there is no reason to discourage them from doing so. However, governments, parents, partners, friends, managers, and others often attempt to intervene in seemingly undeliberate choices and their interventions seem to have good cause. For instance many will agree that it is imperative that children under a certain age should be prohibited to drink alcohol or smoke. We argue that many present oriented decisions occur because people cannot imagine the future consequences of their decisions very well. Once they are confronted with these consequences, many state they would have made a different choice had they known this at the time they made the choice. This conclusion may encourage policy interventions.

\subsection{Time discounting, imagination and regret}

To analyze the empirical relevance of our theory, we designed measures for time discounting, imagination and regret which we included in several surveys. Here, we briefly review the concepts and introduce the way in which they are measured. The results and validation of the measures will be given in chapter 2 .

\subsubsection{Time discounting}

In the thesis, we will make a distinction between the concepts time preference and time discounting. Time discounting is in our view a composite of both the traditional preference for present relative to future utility and a lack of imagination. We will use the terms "time discounting" and "discount rate" to indicate any reason for valuing the future less - including having less imagination - and "time preference" for the traditional preference for immediate utility over delayed utility. An important matter is that because respondents have to estimate 


\section{Introduction}

their future utility when they make the trade-off, any measure for discount rates will be influenced by imagination.

Our measure for time discounting follows standard methods in psychological literature. Measures for discount rates are typically elicited from some sort of intertemporal trade-off. Frederick, Loewenstein, and O'Donoghue (2002) give an overview of empirical estimates of discount rates in various studies. Time discounting has been measured in two ways. Some authors attempt to measure discount rates by observations of real-world behaviors, while others derive their estimates from experimental elicitation procedures or hypothetical questions. Our main measure of discount rates falls in the hypothetical questions category. We ask:

Suppose you win a 10-day holiday trip to an interesting destination. To spread participation, you are asked if you can delay your trip with three years in exchange for a longer vacation. How many days should you be offered in addition to accept the offer in 3 years?

\subsubsection{Imagination}

Imagination reflects the ability to anticipate how one will appreciate aspects in the future. People with better imagination may have better information about future aspects, but even with the same quality of information we expect those with better imagination to make better choices. The reason is that people with better imagination are more able to understand the values they will attach to various situations in the future. The choice for an educational discipline provides an inspiring example. Students choose their education before they have any serious experience with working in a field related to their education. When they consider the variety of college disciplines they can study after high school graduation, they can gather information about the content of the education, the possibilities the education offers in the labor market, and the professions they can engage in after graduation. However, they cannot gather information about how they will value these aspects in the rest of their careers. Life and values of an 18-year old are very different from those of a 40-year old. It takes imagination to be able to accurately picture the value of future aspects.

Measures for imagination are not standard in the literature, but recently related concepts to imagination have gained substantial interest in psychology. Among others, Suddendorf and Busby (2005), Busby and Suddendorf (2005), Friedman (2005), Clayton, Bussey, and Dickinson (2003) use the term "mental time travel" for the ability to remember past experiences and 
to project oneself into the future. Our term "imagination" is similar to mental time travel into the future. To measure this concept, we ask respondents a battery of statements like "I have a clear image of what your life will look like in the next 2 years," and "My current life is very different from what I thought it would have been 3 years ago."

Other related concepts are "projection bias" which refers to the exaggeration of the degree to which future tastes will resemble current tastes (Frederick, Loewenstein, and O'Donoghue 2002). Caplin and Leahy (2001) give examples of psychological research concerning the measurement of feelings of anticipation. Ameriks, Caplin, and Leahy (2003) investigate the propensity to plan in the context of wealth accumulation. In psychological literature the term "temporal construal" is used to describe that people generally are less able to construct concrete images of aspects which have a larger "psychological distance" (Lewin 1951, Trope and Liberman 2003). Our concept measures the difference in the ability of people to form these images. With respect to visceral states, Loewenstein (1996) mentions "cold-to-hot empathy gaps." Such gaps are mispredictions of own behavior and preferences across affective states. When people are in a cold state, they fail to fully appreciate how hot states will affect their own preferences and behavior. In the context of investments in health, Loewenstein (2005) concludes that healthy people may expose themselves excessively to risks. Visceral factors also influence other intertemporal choices. This is related to our theory that a lack of imagination decreases the incentives to invest.

\subsubsection{Regret}

The consequence of being less able to imagine the future is that inadequate choices may occur. To be able to determine the ability to invest in human capital, we designed a question to measure the quality of choices regarding education.

In principle, a measure for quality of the educational choice could be related to the accuracy of the image of jobs which can be performed with the education. People could for instance be interviewed about the image they have of aspects of their future job and this image could be compared to actual aspects of the jobs. However, for two reasons such an approach is undesirable. First, in this case the researcher would determine which aspects are crucial for comparing image and reality. A person can have an inadequate image of the reward in a certain profession but if the reward does not interest him, it does not matter in the evaluation of the educational choice either. There can be other aspects (e.g. the amount of leisure or commuting time, the provision of child care facilities by the employer, etc.), which the researcher does not think of, which are crucial for the individual to decide to follow a certain education. Secondly, it is likely that many youngsters will not develop a very clear image of their future profession 


\section{Introduction}

(in part also because these professions are changing constantly). It is sufficient that one has enough information to make a responsible choice.

The idea underlying our measure of the quality of the educational choice is that a person makes an adequate choice if he makes the same decision based on the imperfect information, as he would make if he knew all the consequences of his decision. We ask

Would you choose the same education if you had the opportunity to choose again?

Those who answer they would - at the same or another institute - apparently made the right choice. If the respondents indicate they would have wanted to study another discipline (or no education at all), we consider they regret their educational choice, thus indicating a low adequacy of educational choice.

Of course, at the individual level there might be differences in the way people answer the question and unpredictable changes in circumstances and specific personal situations may affect the evaluation of the study chosen. Even people who were not well-informed might be very satisfied with their choice afterwards. Furthermore, people will not have experienced all facets of their job yet and will not have experienced alternative professions they did not choose. For that reason the knowledge of respondents to answer the question is not perfect. However, knowledge of the pros and cons of the choice made will be much better than when the initial educational choice was made. Therefore, we consider that the percentage of people who regret their choice is a good proxy of the adequacy of the choice in a certain group.

A stunning example of the relation between imagination and regret is that of young girls who apply for flight attendant school. For many of them, the reason to apply is the expected glamorous life while traveling around the world. This dream very often becomes a deception once these girls actually become stewardesses. The main reason is that they did not take into account that being away from home is not that attractive when having a family. At registration days, the flight attendant school in the Netherlands provides abundant information about this fact, but apparently this does not induce many students to reconsider their choice. As a result $60 \%$ of all flight attendants report to regret their choice of education. This is by far the highest level of regret of all disciplines.

\subsection{Outline}

This thesis consists of four self-contained chapters in which the consequences of having less imagination are investigated in a context of investments in human capital. Human capital 
incorporates a broad spectrum of aspects which people can acquire by investing in them, including knowledge and health.

The structure of the chapters is in accordance with the following line of thought. In chapter 2 , the imagination concept will be defined and it will be shown that having less imagination is related with a higher discount rate and a lower ability to invest. People with less imagination take more time to finish studies with the same nominal duration and have a larger probability to regret their longer stay in education. Less imagination is also related with more regret about the choice of an educational field. Chapter 3 shows the consequence of regretting the choice of an educational field. Students with regret attempt to correct their decision after graduation by continuing to study in a different field. While chapters 2 and 3 report cross-sectional evidence on the relation between imagination and the willingness and ability to invest, chapter 4 reports findings of an experiment in which we show that people with more imagination are more inclined to choose courses from which they can learn. Chapter 5 shows that imagination of the future is an important predictor of investments in health: people with more imagination have a lower body mass index. Chapter 6 concludes.

\subsubsection{Time Discounting, Imagination and Human Capital Investments}

In chapter 2 , we analyze the consequences of the idea that discount rates reflect an inability to adequately imagine the future. Differences in imagination provide a reason for heterogeneity of discount rates between and within people and for people with high discount rates to have a larger probability to regret investment decisions. In the context of educational decisions, we show that students with a larger mental distance between their study and working life will value working life less, and stay longer in education. When they enter the labor market, they will have a larger probability to regret this delay.

We measure imagination and the discount rate in three custom-designed Dutch surveys. We find a robust negative correlation between these concepts and confirm the predictions that students who have more problems imagining the future stay longer in college, and report more regret of having stayed longer.

Besides regret of the length of stay in education, people with less imagination also report more regret of their choice of educational field than those who had a better picture of their future. 


\subsubsection{Skill Transferability, Regret and Mobility}

We explore the consequences of regretting the choice of educational field in the third chapter. After graduation many students start working in sectors not related to their field of study or participate in training targeted at work in other sectors. In this chapter, we look at mobility between sectors immediately after graduation from the perspective that educational choices have been made when these pupils had little experience of the actual working life in these professions.

We develop a model where students accumulate human capital but also learn about their professional preferences at university and during the first years in the labor market. As a consequence of the newly acquired insights after graduation, these young workers might realize that working in another occupational field would better fit their preferences, although they are better equipped to work in their own field.

When they realize they made an inadequate educational choice, they have an incentive to leave their field of education. However, continuing education in another field is very costly because of foregone earnings. These costs indicate the importance of imagination. ${ }^{1}$

We show that besides regret, the trade-off between staying in the initial field or continuing to another field is determined by the possibility to transfer skills between sectors. If occupational mobility leads to a large loss of human capital (i.e. transferability is low) the probability that the graduate will switch is low. However, when graduates with a low skill transferability nevertheless decide to change occupations, they will invest more in education. Using data about Dutch graduates from the CHEERS survey, we have tested our model. Consistent with our model we find that, conditional on the level of regret, higher skill transferability induces switching and reduces the wage loss and the duration of the training followed after the initial education.

\subsubsection{Imagination and Investments in Skill-Deficiencies}

Chapter 4 reports findings of an experiment in which we investigate whether people with more imagination are more inclined to choose courses from which they can learn. The experimental character of the analysis provides important additional evidence on the relation between imagination and the ability to invest.

The participants in the experiment are workers. The aim of the research is to investigate whether they choose courses to reduce work-related skill-deficiencies, and whether they choose these courses deliberately. We analyze which personal characteristics determine the

\footnotetext{
${ }^{1}$ We will elaborate on these costs in chapter 6.
} 
outcome of their choices.

We measure the skill-deficiency for six skills and perform an experiment in which workers hypothetically are asked by their employers to participate in a program of three courses related to these skills. They can accept the courses but can also exchange them for other courses. Randomizing the package of courses offered by the employer, we identify the deliberateness of their choice. The basic idea is that people will consider the courses offered as the employer's advise about the choice. The actual choice will be based on a combination of this implicit information and the perceptions in the mind of the respondent.

We find that people choose the default courses more often, especially when these courses match their skill-deficiencies. When workers make their own choice however, they generally do not choose courses with which they can reduce their skill-shortages. This suggests that managers can have an important role in an efficient development of workers' human capital. Workers with a more developed capacity to imagine the future invest more in their skilldeficiencies. Better imagination, less anxiety, lower risk aversion, and more cognitive skills increase the probability of making a deliberate choice.

\subsubsection{Imagination and Investments in Health: the Body Mass Index}

Chapter 5 investigates whether imagination affects investment decisions in health. In many Western countries, the average weight of people (relative to their height) - measured by the Body Mass Index (BMI) - has attracted much attention because it increased substantially in recent years. A high BMI has often been related to a high discount rate. Komlos, Smith, and Bogin (2004) argued that the average discount rate has increased in recent years and proposed that this may have caused the increase in BMI.

We analyze this claim from the perspective that time discounting is an aggregate of several psychological attributes. Many obese people are trying to lose weight, suggesting that they regret having gained weight previously. For this reason, we expect a lack of imagination to be an important predictor for overweight. Other attributes we investigate are impulsiveness, risk aversion, sacrificing for the future, and managing expenditures. We expect that BMI and these psychological attributes can be related but at the same time we think it is very unlikely that psychological attributes underlying time discounting, such as imagination, can have changed rapidly over the course of a few years.

The approach of this chapter consists of four steps. First, we analyze whether BMI is related to time discounting. We then investigate whether noncognitive skills such as imagination, impulsiveness, and risk aversion relate to time discounting and whether these noncognitive skills can explain differences in BMI. Fourth, we analyze whether a trend in the noncognitive 
skills can account for changes in BMI over time.

We find surprisingly little evidence for a positive correlation between the standard measure of time discounting and BMI. The explanation we pursue for this finding is that time discounting is related to a variety of noncognitive skills. These noncognitive skills may have different correlations with BMI. We find that there is significant correlation between certain noncognitive skills and time discounting and between these noncognitive skills and differences in BMI between people. The most significant correlations are found with proxies for imagination and impulsiveness although the relationship depends strongly on the choice of the proxy.

Giving the hypothesis that noncognitive skills have affected the increase in average BMI the best chance, we analyze the development of the proxies that are shown to be most strongly related to BMI. We find no evidence for a change of these proxies over time. Our main conclusion therefore is that overweight might be related to imagination or impulsiveness, but the increase in BMI over the last decade has to be explained by shifts in other parameters that determine the intertemporal decisions regarding the trade-off between current and future health and satisfaction.

In chapter 6 the main findings of the thesis are reviewed and we discuss the implications of the conclusion that imagination is an important individual attribute for making adequate investment decisions. We argue that this conclusion provides a rationale for governmental intervention in persons' behavior. Taking investments in education as an example, we show that the potential benefits of helping people to make adequate decisions are substantial. 
2 Time Discounting, Imagination and Human Capital Investments 


\subsection{Introduction}

Early writers on intertemporal choice considered that part of the variations in the preference for the present relative to the future may be due to differences in people's abilities to imagine the future (Rae 1835, Böhm-Bawerk 1891). Empirical evidence for this relation and an investigation of the consequences of this postulate have been the main lacuna ever since.

This chapter analyzes the consequences of an inability to adequately imagine the future for investments in education. ${ }^{1}$ Since students have very limited experience with working life, many will have difficulties forming an image of the consequences of their choices. For instance, at age 18 when most students choose a field of study in higher education, it will be very difficult for them to imagine what it will be like to work in an occupation related to that field of education.

The idea that a more developed ability to foresee the future is related to a higher value attached to future outcomes has three implications which are different from the traditional discounted utility model: (1) Variation in imagination between people can explain heterogeneity in discount rates. ${ }^{2}$ And for a given person, if certain results are imagined more vividly than other results, different discount rates will apply for different goods. (2) Students with less imagination will be less able to imagine working life than college life and will therefore discount working life more than college life. As a consequence, they have an incentive to procrastinate entrance to the labor market. (3) When the students enter the labor market, they receive a clear image of what it is like to be working. At this point in time, they can evaluate their choice to stay longer in education from a perspective in which imagination does not play a role. If the students stayed longer because they discounted working life more, those with less imagination will have a higher probability to regret delaying their entrance to the labor market. $^{3}$

\footnotetext{
${ }^{1}$ This chapter is a joint work with Lex Borghans. We thank Gary Becker, Arnaud Dupuy, Armin Falk, Shane Frederick, Nicola Gennaioli, Jonathan Guryan, Jim Heckman, Hans Heijke, Caroline Hoxby, Larry Katz, Ben Kriechel, David Laibson, Erzo Luttmer, Casey Mulligan, David Mundel, Kevin Murphy, Joan Muysken, Gerard Pfann, Erik Plug, Erik de Regt, Steve Rivkin, Inge Sieben, Bas ter Weel, Thomas Ziesemer, Fabrizio Zilibotti and seminar participants at IZA, the Dutch Education Inspection, IIES and SOFI at Stockholm University, Tjalling Koopmans Institute in Utrecht, Maastricht University, the 2004 meeting of the European Association of Labour Economists, the 2004 meeting of the Society of Labor Economists, the 2005 meeting of the NBER Education Program, and the 2006 Nordic Summer Institute meeting at Uppsala for valuable comments. We thank CentER Data for providing the DNB Household Survey. Golsteyn thanks the IIES where he worked on part of this research for its hospitality.

${ }^{2}$ We will use the term "discount rate" to indicate any reason for valuing the future less, including having less imagination, and "time preference" for the traditional (and as we will argue unmeasurable) preference for immediate utility over delayed utility. We use "imagination" as a term for the ability to foresee the future.

${ }^{3}$ This last result provides a new insight in the claim that people with high discount rates make deliberate decisions which are detrimental for their future health, career or other investment outcome. In rational addiction
} 
To investigate the empirical validity of these implications, we measure imagination and the discount rate in three custom-designed Dutch surveys: two college graduate surveys and one representative sample of the Dutch population. These surveys each contain distinct questions which enable us to test specific predictions of the model but in addition the surveys also partly hold questions in common which allows us to test the robustness of our findings. To our knowledge, there are no other surveys with data rich enough to test our hypotheses.

The design of our measures for the discount rate and other individual attributes follows standard methods in psychological literature. Measures for imagination are not standard, but recently related concepts to imagination have gained substantial interest in psychology. Among others, Suddendorf and Busby (2005), Busby and Suddendorf (2005), Friedman (2005), Clayton, Bussey, and Dickinson (2003) use the term "mental time travel" for the ability to remember past experiences and to project oneself into the future. Our term "imagination" is similar to mental time travel into the future. We ask respondents a battery of questions like "Do you have a clear image of what your life will be like in the next 2 years?," and "Is the image you had five years ago about your current situation in line with your current life."

The empirical analysis consists of three parts. (1) We provide evidence that imagination is part of the discount rate by showing that the correlation between different measures of the discount rate and imagination is significant and robust. We show that the correlation between these variables is much greater than the correlation between these measures and other individual attributes. Furthermore, we show that the same person invests more in future prospects for which he has a clearer view by measuring the quality of the image related to four different domains of life and the willingness to invest in these domains. (2) We find evidence that college students with better imagination stay shorter in education. Additional evidence for our model is that graduates who plausibly obtained less information about their future working life because their parents are immigrants or as a result of having no family members working in a related field report less satisfaction with their choice of study and stay in education longer. (3) We find that people with more imagination report less regret of the length of the period they stayed in school.

This chapter contributes to the literature on endogenous discount rates. Frederick, Loewenstein, and O'Donoghue (2002) give an overview of the history of the literature on intertemporal choices. They describe that before the discounted utility model was formalized by Fisher

models (Becker and Murphy 1988, Orphanides and Zervos 1995) individuals choose to risk addiction and reach outcomes which they sometimes regret. In contrast, non-rational addiction models Akerlof (1991), Bernheim and Rangel (2004) have argued that the use of substances among addicts is based upon a mistaken view of the future. Our result obviously falls in the latter category. A new feature of our model is that it relates explicitly the discount rate to regret by showing that imagination is related to regret and to the discount rate. 
(1930), Samuelson (1937) and Koopmans (1960), early writers such as Böhm-Bawerk (1891) and Rae (1835) noticed that intertemporal choices may be related with or formed by psychological attributes, in particular by imagination. In the discounted utility model, these underlying psychological concepts were compressed into a single parameter, the discount rate. This has provided economists with a very strong analytical tool, but at the same time also results have been reported which are non-trivial to explain with the traditional discounted utility model (such as the variation in the discount rate across different goods for a given person ${ }^{4}$ ). The interest among economists in the underlying psychological motives of intertemporal decisions revived notably because of Becker and Mulligan (1997), who explore the efforts of individuals to spend resources to make future consumption seem less remote. An example they give is that a person "may spend additional time with his aging parents in order to better appreciate the need for providing for his own old age" (p. 735). In terms of their framework, our concept of imagination is the marginal productivity of reducing remoteness. The main lacuna in this literature is empirical evidence to confirm the relation between the discount rate and imagination. We measure and analyze the relation between these concepts. ${ }^{5}$ Other contributions are that we investigate the consequences in the context of investments in education and that we show that when imagination is part of the discount rate, this provides an explanation for the relation between the discount rate and regret.

This chapter is also closely related to the work on dynamically inconsistent preferences, which started by the work of Strotz (1956). The influential work by Ainslie (1992), Thaler (1981), Loewenstein and Prelec (1992) and Laibson (1997) has given rise to the idea that discount rates are generalized hyperbolas, implying that people generally discount the distant future at lower levels than they discount the near future. An endogenous discount rate can provide an alternative explanation for inconsistent dynamic behavior: people may be less able to imagine the distant future than the near future. ${ }^{6}$ An imagination theory of the discount rate can provide a wider variety of observations than the theory of hyperbolic discounting since it can predict that different situations which may happen at the same time can be discounted at different rates if their level of difficulty to imagine differs.

Imagination is a concept which reflects uncertainty about future utility. We want to make explicit that imagination does not only refer to wages, but to a complete package of utility related to working. The way we think about imagination is not about the amount of facts

\footnotetext{
${ }^{4}$ Loewenstein, Weber, Flory, Manuck, and Muldoon (2001) report close to zero correlation between behaviors which have an important intertemporal component.

${ }^{5}$ Regarding the empirical relation between time discounting and uncertainty, van Dijk and Zeelenberg (2003) provide experimental evidence that people discount ambiguous information.

${ }^{6}$ This is in line with the theoretical work by Azfar (1999), who shows that uncertainty about discount rates can generate similar results as those generated by hyperbolic discounting functions.
} 
about a future situation one has acquired, it is about being able to anticipate how one will appreciate these facts in the future. It is not that complicated for an 18-year old to find out that in certain professions the wage is higher than in other professions, or that with some educations one will have a much larger chance of finding an attractive job after graduation, but what is complicated for the 18-year old is to find out how much he will value these aspects in the future. To give an example, young girls often dream of becoming flight attendants when they grow up. However, the dream to travel around the world often becomes a deception once these girls actually become stewardesses. The main reason is that they did not take into account that being away from home is not that attractive when having a family. At registration days, the flight attendant school in the Netherlands provides abundant information about this fact, but apparently this does not induce many students to reconsider their choice. As a result $60 \%$ of all flight attendants report to regret their choice of education. This is by far the highest level of regret of all disciplines. By regarding uncertainty in a wider context than ability to predict a wage, we relate the literature on uncertainty in investments to the literature on the effect of non-cognitive skills on labor market outcomes (Mueser 1979, Bowles, Gintis, and Osborne 2001, Heckman, Stixrud, and Urzua 2006).

Section 2.2 gives the model. Section 2.3 introduces the Dutch educational system, the data for our analysis, and describes how we measure and validate time discounting and imagination. Section 2.4 consists of the empirical results. Section 2.5 concludes.

\subsection{The Model}

In this section, we explain why we expect imagination to be related with regret about choices and with the discount rate. Then, we apply the idea that imagination is part of the discount rate to the decision students have to make about how long they want to invest in education. We give a graphical illustration of the model, then show the formal relation between imagination and length of stay in education and discuss why less imagination is related to more regret about the length of stay.

\subsubsection{Imagination and time discounting}

People with a more developed ability to imagine future situations will be less uncertain about future situations. We will show here how being more uncertain about the future is related with more regret of choices and to higher discount rates. We will follow the model by Harrison and March (1984). 
Suppose a student chooses between a number of studies. The educations differ with respect to the utility the student can derive from these studies. Ex ante, this utility is not known with certainty but can be estimated. The student evaluates some educations and chooses the one he thinks will provide him with maximum utility. The utility he ex ante thinks an education will provide has a normal distribution $X \sim N(0,1)$, and is observed with uncertainty $\varepsilon \sim N(0,1)$.

$$
E U\left(X_{i}\right)=U\left(X_{i}\right)+\varepsilon_{i}
$$

The student observes the expected utility of the educations $i \in(0, n)$. Harrison and March (1984) show that higher $E U\left(X_{i}\right)$ is associated with greater $U\left(X_{i}\right)$. Hence, it is sensible for the student to choose an education which seems to have the highest utility because this will, on average, produce higher utility. However, because the covariance between $E U\left(X_{i}\right)$ and $\varepsilon_{i}$ is also positive, ${ }^{7}$ educations with relatively high estimated values will on average have a large positive error. The net effect is that choosing the education with a high estimated error will lead to disappointment. ${ }^{8}$ This result is known as "the winner's curse." 9 In the data section, for the purpose of validation of our measure of imagination, we will test the relation between imagination and regret.

This decision making model does not include behavioral features. Much like in "regret theory" it is assumed that individuals will incorporate in their utility functions the possible feelings of regret when they are making their decision (Loomes and Sugden 1982, Bell 1982), it can be expected that people who are more uncertain about their future will also take this uncertainty into account when they make decisions.

One way to take this into account is that people can deflate expectations. It is probable that people know their ability to imagine outcomes of difficult choices based on experiences in the past. To reduce potential regret, people with less imagination will deflate expectations more. This is the reason that we expect less imagination to be related with less commitment to the future, and hence with higher discounting. We will test this central assumption in our model empirically.

\footnotetext{
${ }^{7}$ For a proof of this, see Harrison and March (1984).

${ }^{8}$ Disappointment is not exactly the same as regret. Disappointment occurs when the outcome is less than the expected outcome, while regret occurs when the outcome of a choice turns out to be less than the outcome of a foregone alternative. We show in the data section that imagination is related to both regret and disappointment.

${ }^{9}$ The name winner's curse stems from Capen, Clapp, and Campbell (1971) who observed that in oil-lease bidding the winner tended to be the player who most overestimates true tract value.
} 


\subsubsection{Imagination and the length of stay in education}

\section{A graphical illustration}

This section will give a graphical illustration of the formal model in the next section.

In traditional investment models, agents trade off current and future consumption by a discount rate (Samuelson 1937). With a positive discount rate, a unit of future consumption is valued less than a unit of current consumption. A higher discount rate yields a lower relative value of future consumption. In Graph $1, \Delta_{1}(t)$ depicts the present value of a unit of consumption over time for an individual. $\Delta_{1}(t)=V_{t} e^{-\delta t}$, where $V_{t}$ is the value of consumption at time $t$ and $0<\delta<1$ is the discount rate, which determines the slope of $\Delta_{1}(t)$.

\section{Graph 1}

Time discounting and imagination

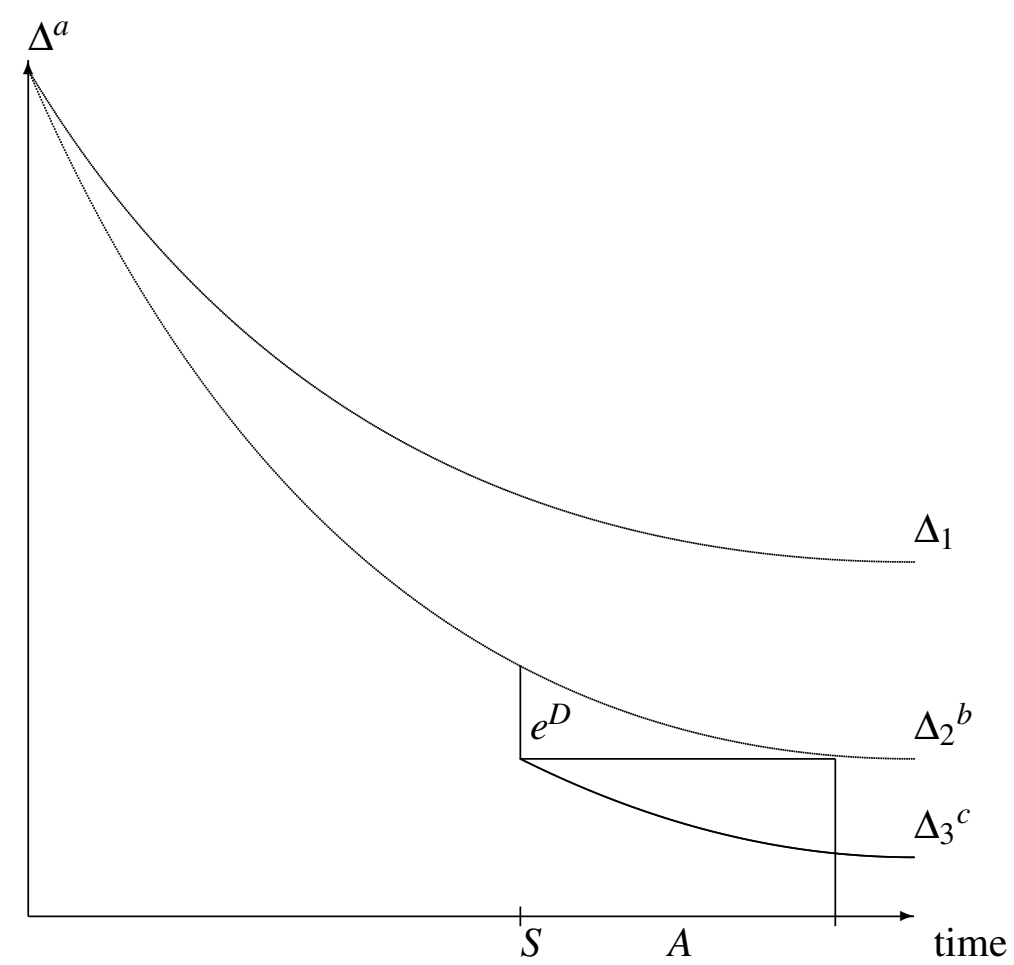

\footnotetext{
${ }^{a} \Delta$ is the present value of a unit of consumption over time.

${ }^{b} \Delta_{2}$ describes the discounted value of consumption over time if an individual is uncertain of his future consumption.

${ }^{c} \Delta_{3}$ is the discounted value of consumption over time of an individual who faces not only uncertainty about the future in general but who also is especially uncertain about the state of the world after $t=S$. $D$ is the associate decrease in utility.
} 
Intertemporal choices may not only be driven by a preference for the future relative to the present, but also by the ability to imagine the future. Imagination influences intertemporal choices in two ways: (1) Aspects further away in the future are more difficult to imagine than those in the present and will as a consequence be discounted more heavily, (2) Situations which differ in level of difficulty to imagine are discounted at different rates, while they may have the same distance in time.

In the graph, the difference between $\Delta_{2}(t)$ and $\Delta_{1}(t)$ shows the consequence of the first relation between intertemporal choice and imagination: as long as no large changes occur in the agent's world, he will know to a large extent what he can expect based on his current situation. When the time interval becomes longer, current experiences will be a less valuable indicator for future utility and therefore consumption further away in time will be discounted more heavily. ${ }^{10}$

The graph shows also the second consequence of a lack of imagination. Suppose that the agent with the discounted pattern $\Delta_{2}(t)$ knows or expects that his world will change drastically at some point. Then, as a consequence, the clarity of the image of the future will decrease instantaneously at the point in time where he leaves his current state for the next state. In the graph such a change occurs at point $S$, decreasing the expected value of utility beyond $S$ with the factor $e^{D}$. The discount pattern in this case is indicated by $\Delta_{3}(t)$. D indicates the size of this instantaneous decrease in expected utility, which depends on the unfamiliarity with the new situation $A$. Comparing this immediate fall in discounted value, with the normal gradual discount rate, reveals that $A$ can be interpreted as a time equivalent of the extra unclarity associated with this change in circumstances: a mental time distance. The day after $S$ feels $A$ years further away.

\section{The model}

We apply this idea to an investment in education. First, we show the traditional human capital model without unclarity. An agent maximizes an intertemporal utility function $Y$, with a discount rate $\delta$. During the time the agent studies he receives intrinsic utility (plus perhaps some financial support) $U{ }^{11}$

\footnotetext{
${ }^{10}$ This higher discount rate can be interpreted in terms of a risk premium, but can also reflect the consequences of suboptimal choices. If the agent can choose between alternatives $C_{1}, C_{2}, \ldots, C_{n}$, but observes the utility of each alternative with some error, the difference between the best choice $\operatorname{Max}_{i} U\left(C_{i}\right)$ and the expected utility when choosing with uncertainly $E\left\{U\left(\operatorname{Arg} \operatorname{Max}_{i} U^{\exp }\left(C_{i}\right)\right)\right\}$ will increase when uncertainty increases.

${ }^{11}$ In this model, we assume effort is similar per time unit. For future research, an interesting extension of the model could be to include effort to study the effect of imagination on effort during various phases in education.
} 


$$
Y=\int_{0}^{S} U e^{-\delta t} \mathrm{~d} t
$$

where $S$ is the total time in education. After graduation, the agent will receive utility from working on the labor market $H_{s}$. This utility is increasing in the time a person spent in education. We assume $H_{s}$ to be twice differentiable and concave, i.e. $H_{s}^{\prime}>0$ and $H_{s}^{\prime \prime}<0$. The standard human capital model without uncertainty can then be given as:

$$
Y=\int_{0}^{S} U e^{-\delta t} \mathrm{~d} t+\int_{S}^{\infty} H_{s} e^{-\delta t} \mathrm{~d} t
$$

Now we add unclarity to this theory as explained above. The discount rate $\delta$ is replaced by the composite discount rate:

$$
\text { Composite discount rate }=(\delta+\eta) t+\eta A,{ }^{12}
$$

where $\delta$ represents traditional time preference, $\eta(t+A)$ represents the inability to imagine the future, $t$ is the normal change associated with a unit of time, $A$ is the extra change associated with a move to an uncertain situation, and $\eta$ represents the discounting of the extra time the outcome appears to be in the future because of its uncertainty: a mental time discount rate. ${ }^{13}$ In the graph, $\eta A$ is represented by $D$.

The point in time when the student graduates and enters the labor market, he will be faced with a new situation that he might know very little about. We therefore treat the transition between college and work as a moment of large unclarity. A lack of imagination will produce an instantaneous increase in the discount rate at point $S$. Assuming for mathematical convenience that people stay in the work force forever, utility may then be written as

\footnotetext{
${ }^{13}$ Imagination is different from information. Giving more information is similar to the effect of reducing $A$. In our empirical analysis, we will use this aspect by analyzing decisions made by immigrants who plausibly have less information about the labor market than natives.
} 


$$
Y=\int_{0}^{S} U e^{-(\delta+\eta) t} \mathrm{~d} t+\int_{S}^{\infty} H_{S} e^{-(\delta+\eta) t-\eta A} \mathrm{~d} t
$$

We treat the time the student chooses to graduate, $S$, as endogenous:

$$
\frac{\partial Y}{\partial S}=U-H_{S} e^{-\eta A}+\frac{H_{S}^{\prime}}{\delta+\eta} e^{-\eta A}=0 .
$$

From which it follows that if $U>0$ :

$$
H_{s}(\boldsymbol{\delta}+\eta)-H_{s}^{\prime}>0
$$

Solving $\frac{\partial Y}{\partial S}$ for $S$ yields

$$
\hat{S}=s(\delta, \eta)
$$

The effect of traditional time preference $\delta$ on the length of study can be investigated by taking the derivative of $\hat{S}$ :

$$
\frac{\partial \hat{S}}{\partial \delta}=\frac{H_{s}^{\prime}}{(\delta+\eta)\left(H_{s}^{\prime \prime}-H_{s}^{\prime}(\delta+\eta)\right)}<0
$$

which clearly shows the standard prediction of the human capital theory that a higher traditional time preference is related with a shorter period in school. 
The effect of the imagination component of the composite time discount rate $\eta$ on the length of study is:

$$
\frac{\partial \hat{S}}{\partial \eta}=\frac{H_{s}^{\prime}+A(\delta+\eta)\left(H_{s}^{\prime}-H_{s}(\delta+\eta)\right)}{(\delta+\eta)\left(H_{s}^{\prime \prime}-H_{s}^{\prime}(\delta+\eta)\right)}
$$

From this function it follows that the effect of imagination on the length of stay in college is ambiguous. When $A$ is close to zero, this derivative is negative and therefore larger composite time discounting leads to lower investments, measured in years of education. The addition provided by the imagination theory is that when $A$ is sufficiently large, i.e.

$$
A>\frac{H_{s}^{\prime}}{(\delta+\eta)\left(H_{s}(\delta+\eta)-H_{s}^{\prime}\right)},
$$

a higher $\eta$ and hence a larger lack of imagination will lead to longer periods in college. This presents our first main empirical question, which will be to investigate whether people with less imagination decide to stay longer in education.

Since $\eta$ is part of the composite discount rate, with large enough $A$, the effect of the composite discount rate on $S\left(\frac{\partial \hat{S}}{\partial \delta}+\frac{\partial \hat{S}}{\partial \eta}\right)$ may occur. This paradoxical result complements the predictions of human capital theory. In the context of an investment in education, individuals choose to study for a certain time period before starting to work. During their study, their income will be lower than the wage they would get while working but of course this investment in human capital increases their future wages. Depending on their discount rate, the individual will choose how much to invest in education. Obviously a higher discount rate would lead by this reasoning to a longer period of studying (Becker 1964, Wilkinson 1966). Our model shows that when imagination is important, the opposite result may appear. The intuition behind this is that a lack of knowledge about working life increases the relative value of being in college and therefore leads to a delay of the transition from college to work. We will investigate empirically whether higher discount rates are related with longer stay in education. 


\subsubsection{Regret of length of stay in education}

Secondly, it is important to note that $A$ is unstable. Ex ante $A$ can be large, but ex post $A$ will decrease very rapidly, i.e. when people go to the labor market, their uncertainty associated with it decreases immediately. So, the day after $S$ feels $A$ years further away ex ante, but ex post $A$ is less far away. People with less imagination will experience a larger decrease in $A$. This unstable $A$ has the important consequence that ex post people would time their labor market entrance $S_{1}$ differently than their actual entrance to the labor market $S_{0}$. This difference is our measure of regret of staying too long in college, which can be defined as

$$
\frac{S_{0}}{S_{1}}>1
$$

People with a higher $\eta A$, will regret their length of stay in education more. So students with low imagination who stay longer will when they graduate and enter the labor market quickly become more certain about the labor market. Looking back at their decision to stay longer in education, we expect them to state more often that they would have wanted to graduate earlier.

This result is the second main prediction of our model. In the context of thinking about other explanations for our findings, we think this prediction is even stronger than the first prediction of our model. I.e. we interpret $\eta$ as a lack of imagination in our model. However, $\eta$ may also represent other personal attributes which are related with time discounting and with the length of stay in education, such as risk aversion, or having fun in education. We agree that the period people stay in education can be influenced by factors related to time discounting other than imagination. However, we think these factors cannot produce regret of longer stay in education. For instance, risk aversion or enjoying the time in school may be attributes related to both time discounting and length of stay in education. But if people are ex ante risk averse or have a good time in school, there is no reason to expect them to regret the consequences of that ex post. Impulsiveness can be related with regret, but this is not likely in the context of an investment in education.

\subsection{Data and definitions}

This section contains four parts. First, we explain features of the Dutch educational system. Second, we give an overview of the data sets we use. Third, we describe how we measure and 
Table 2.1: A simple representation of the Dutch educational System

\begin{tabular}{l|l}
\hline \hline High school & Further education \\
\hline $\begin{array}{l}\text { High level (VWO) } \\
6 \text { years }\end{array}$ & $\begin{array}{l}\text { University } \\
4 \text { years }\end{array}$ \\
Intermediate level (HAVO) & $\begin{array}{l}\text { Professional college } \\
\text { 5 years }\end{array}$ \\
& Voars \\
Low level (VMBO) & Vocational school \\
4 years & $1-3$ years \\
\hline \hline
\end{tabular}

validate the discount rate. And in the last section we describe the measurement and validation of imagination.

\subsubsection{The Dutch educational system}

In the Dutch educational system pupils attend primary school up to the age of 12. At the age of 13, pupils are selected (based on a test and the judgment of the teacher) to go to different levels of high school. These levels are called VMBO, HAVO and VWO. A VMBO diploma gives access to vocational schools (MBO). With a diploma from HAVO, one can continue education at a professional college (HBO). With a VWO diploma one is entitled to enrol at university (WO), leading to a master degree. In practice, graduates from VWO go either to university or to a professional college, graduates from HAVO continue at a professional college or a vocational school and most graduates from VMBO continue in vocational education or apprenticeships. The nominal duration of VMBO is 4 years, HAVO 5 years and VWO 6 years. Each year in high school there are exams and students can pass or fail. Those who fail have to repeat class, but often decide to continue at a lower level. It is very difficult to go to a higher level before graduating. There is however a substantial group that takes a VWO after graduation from $\mathrm{HAVO}$, or HAVO after graduating from VMBO at the cost of one additional year (compared to a regular student at the higher level). Although graduates from HAVO and VWO are at least 17 years of age and therefore beyond compulsory education (16 years of age), almost all students will continue education. In addition, many students attend HBO after graduating from $\mathrm{MBO}$, and few go to University after graduating from HBO. Table 2.1 gives an overview of the educational system.

Dutch universities are public and tuition fees are low compared to US standards. Students attending college have to pay an annual tuition fee of 1,496 euros. ${ }^{14}$ This fee is equal for all

\footnotetext{
${ }^{14}$ All mentioned amounts concern the net amounts in the year 2005.
} 
universities and fields of study.

In the first four years of their education, students receive a stipend from the government which depends on the income of their parents and whether they are living at their parents' place or in a dormitory. This stipend is a loan which will be converted into a gift if the student graduates within 10 years. The minimum monthly grant of a student living at his parents' home is 76 euros, that of a student living in a dormitory is 233 euros. The maximum grants students with low income parents can get are respectively 299 euros and 476 euros. Students can take generous additional loans (259 Euros per month) at low interest rates (3.1\%) from the government. The stipend, the loan and/or the financial help from parents can cover living and studying expenses. ${ }^{15}$ While students can receive the stipend for four years only, they can get loans for up to 7 years. In the last 3 years these loans can be extended to 787 Euros per month. All loans have to be paid back within 15 years after graduation if people have a job.

Besides that Dutch students face hardly any credit constraints to study, the Dutch educational system has three other specific features. (i) Upon college entrance, Dutch students have to choose a specific education (comparable to a major in the U.S., e.g. they have to choose between economics and econometrics), (ii) the quality standard of Dutch colleges is very homogeneous ${ }^{16}$, (iii) during their education students can choose most courses themselves and can take additional courses. These features create a climate in which the human capital theory optimally applies: students are assumed to think about their future at an early age and are given the freedom to invest in it without binding credit constraints.

\subsubsection{Three data sets}

To analyze the empirical relevance of our model, we use three samples of the Dutch population. All three surveys were custom designed in the sense that we were able to include some questions in the first survey, and a comprehensive set of questions in the second and third survey. Table 2.2 gives some descriptives of the samples.

\section{ROA School leaver survey (2003)}

The first data we use are taken from the Research Centre for Education and the Labour Market's 2003 school leaver survey. In this survey Dutch graduates from high school and pro-

\footnotetext{
${ }^{15}$ The stipend for students with low income parents living in a dormitory who take a full loan is 733 euros. For comparison: the Dutch minimum net monthly wage of a person who is older than 22 years and works full-time is 1144 euros per month. The minimum net wage for people below 23 is considerably less.

${ }^{16}$ Oosterbeek, Groot, and Hartog (1992) show that selection corrected wage differentials of students from different economics departments in the Netherlands are small.
} 
fessional college are approached 1.5 years after graduation. From the approached graduates, 3,879 high school graduates (54\%) and 15,601 college graduates (36\%) responded.

There are more women than men in the sample. The nominal age to graduate is 17 for the HAVO students, and 18 for the VWO students. The table shows that most respondents graduated around that age, since the average age at the time the graduates are approached (1.5 years after graduation) is 18.9 years of age. For the college graduates this is very different. The nominal age to graduate from HBO is 21 . At the time they graduated, the respondents were on average 4 years older. This does not imply they took 8 years to finish their education. Graduates may start their college education at a later age than 17 years because of longer pre-college tracks.

$13 \%$ of the high school graduates and $11 \%$ of the college graduates is immigrant. Following the definition of Statistics Netherlands, people are immigrant if they are born abroad (first generation), or if at least one of their parents is born abroad (second generation). Most immigrants in our sample are second generation immigrants from Turkey, Morocco, Surinam, and the Dutch Antilles.

1.5 years after graduation most college graduates are working, while only a very small portion of the high school graduates is working. Moreover, in general - when working - the high school graduates work in part-time jobs of about 1.5 days per week.

The survey contains questions related among others to the education and the job the graduate is occupied with. In this large scale survey, we had limited possibilities to add questions. We will give details about the questions we included below. 


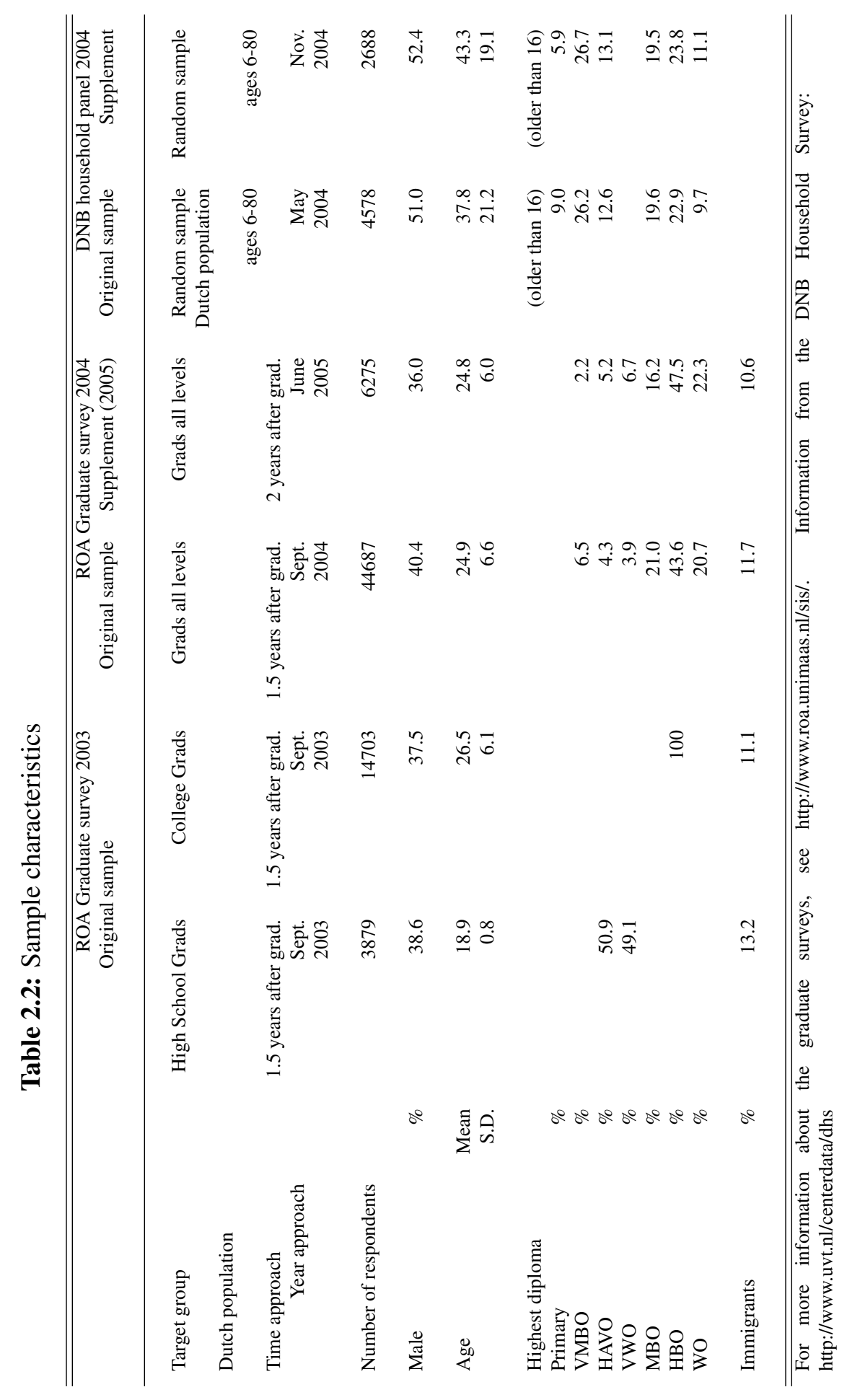




\section{ROA 2005 graduate survey supplement}

In 2004, a similar survey was held among people who graduated in 2003 . We approached a subsample of the respondents of the 2004 survey again in the spring of 2005 with a comprehensive set of questions to measure our key variables imagination and time discounting, and other psychological attributes. ${ }^{17}$

Respondents were approached by e-mail to fill out a questionnaire called "Dealing with difficult choices" on the internet. In the mail, we explained that the aim of the research is to increase understanding of how young people deal with difficult decisions, especially those related to educational choices. We explained that knowledge about these processes is of great societal and scientific importance since e.g. $20 \%$ of all graduates indicate that they regret their educational choice in retrospect. To stimulate participation and deliberate answers, we promised the respondents upon completion of the questionnaire a personal profile regarding several individual attributes. In the mail we did not state which personal factors were included in the profile. The respondents received a profile and an explanation of the terms in the profile regarding their discount rate, the quality of the image of the future, and several other attributes. We will give details about these measures below.

Table 2.2 shows that 6,275 graduates responded from all educational levels except primary school. We want to test with this sample the relation between imagination and the delay of labor market entrance. Many graduates with a diploma below HBO, are continuing their education after graduation and hence do not enter the labor market. We therefore include in our analysis only graduates from HBO and WO (which we will refer to as college graduates).

\section{Supplement to DNB household Survey}

Our third survey is the 2004 DNB household Survey, formerly known as the CentER Savings Survey, collected by CentER Data (Tilburg, the Netherlands). In this survey all members of the household are requested to fill out a questionnaire. The children are however excluded from most of the survey questions when they are below 16. The survey includes psychological variables to measure imagination, the discount rate and other psychological attributes. The sample is representative for the Dutch population of 16 and older, and provides information about sex, age, educational attainment, and income. Table 2.2 shows that respondents are on average around 40 years of age and have a diverse educational background.

In October 2004, we carried out a supplementary survey, targeted at the same respondents

\footnotetext{
${ }^{17}$ In this sample, graduates from all levels were asked to fill out the survey. However, we restrict the analysis to the college graduates only.
} 
as the basic DNB household Survey of 2004. The question we included in this supplement is a measure for regret of the time people stayed in college. We asked the respondents the following two questions:

In which year did you finish your last education?

If you could plan the educations you followed in your life again, in which year would you have liked to have finished your education in retrospect?

We used the difference between these two questions as a measure for regret of the timing of graduation. We find that $28 \%$ of the respondents rather would have graduated earlier, i.e. they regret having stayed in college too long. $37 \%$ indicate that they would like to have graduated at the same time and $35 \%$ indicate that they would like to have graduated later. Those who want to have graduated later appear to be mostly people who rather would have continued at a higher level. Because higher educations take a longer time to finish, the endpoint of the education moves to a later point in time. In our analysis, we exclude people who rather would have wanted to finish later from our analysis. To exclude outliers, we exclude also those who wanted to have graduated more than 5 years earlier than their actual age of graduation.

\subsubsection{Measuring time discounting}

Measures for discount rates are typically elicited from some sort of intertemporal trade-off. Frederick, Loewenstein, and O'Donoghue (2002) give an overview of empirical estimates of discount rates in various studies. Time discounting has been measured in two ways. Some authors attempt to measure discount rates by observations of real-world behaviors, while others derive their estimates from experimental elicitation procedures or hypothetical questions. Important to note is that because respondents have to estimate their future utility when they make the trade-off, any measure for discount rates will be influenced by imagination or other noncognitive skills. In the terminology of our model, these measures for discount rates therefore proxy $\delta+\eta$, not $\delta$ only. Measuring pure time preference is impossible. The goal in this chapter is to analyze whether intertemporal trade-offs are influenced by imagination. Therefore, we need an estimate for composite discount rates. Our measure of discount rates falls in the hypothetical questions category. We ask: 
Suppose you win a 10-day holiday trip to an interesting destination. To spread participation, you are asked if you can delay your trip with three years in exchange for a longer vacation. How many days should you be offered in addition to accept the offer in 3 years?

We included this measure in the three surveys. In the 2003 sample, the results vary from zero (meaning a very high preference for delayed utility) to more than 300 days (or a very high preference for immediate utility) both for high school and college graduates. The mean value is 16.1 days and 19.1 days for high school graduates and college graduates respectively. $97.6 \%$ of the high school observations and $96.5 \%$ of the college observations are in the $0-50$ days interval. This applies similarly to the other two surveys. In the supplement of the 2004 graduate survey we find that $95 \%$ of the respondents filled out between 0 and 30 days. On average people answered 12.0 days (st.dev. 9.3).

We truncate our measure at 50 days and calculate the discount rate as $\left(\frac{\text { days }+10}{10}\right)^{1 / 3}-1$. The resulting average discount rate for the high school graduates is $27.8 \%$, for the college graduates $30.9 \%$, for the supplement of the 2004 graduate sample $28.0 \%$, and $25.5 \%$ for the 2004 DNB Household panel. Compared with an interest rate at a bank this average is therefore very high but a rather stable average score. In the literature (Frederick, Loewenstein, and O'Donoghue 2002), measured discount rates of this size are often reported. It is well-known that the level of the discount rate is strongly influenced by anchoring effects but that some people consistently score higher or lower on these measures.

Table 2.3 gives information about the measurement of discount rates in the samples. Across the three surveys, we find that the average discount rate is in the same range, and we find consistently that women score higher than men and immigrants score higher than natives. Surprisingly, we do not find that more highly educated respondents have lower discount rates in any sample. We find no relationship between discount rates and age, in contrast with findings of e.g. Chaloupka (1991) and Lawrance (1991). This is probably due to the small variation of age in our sample. 


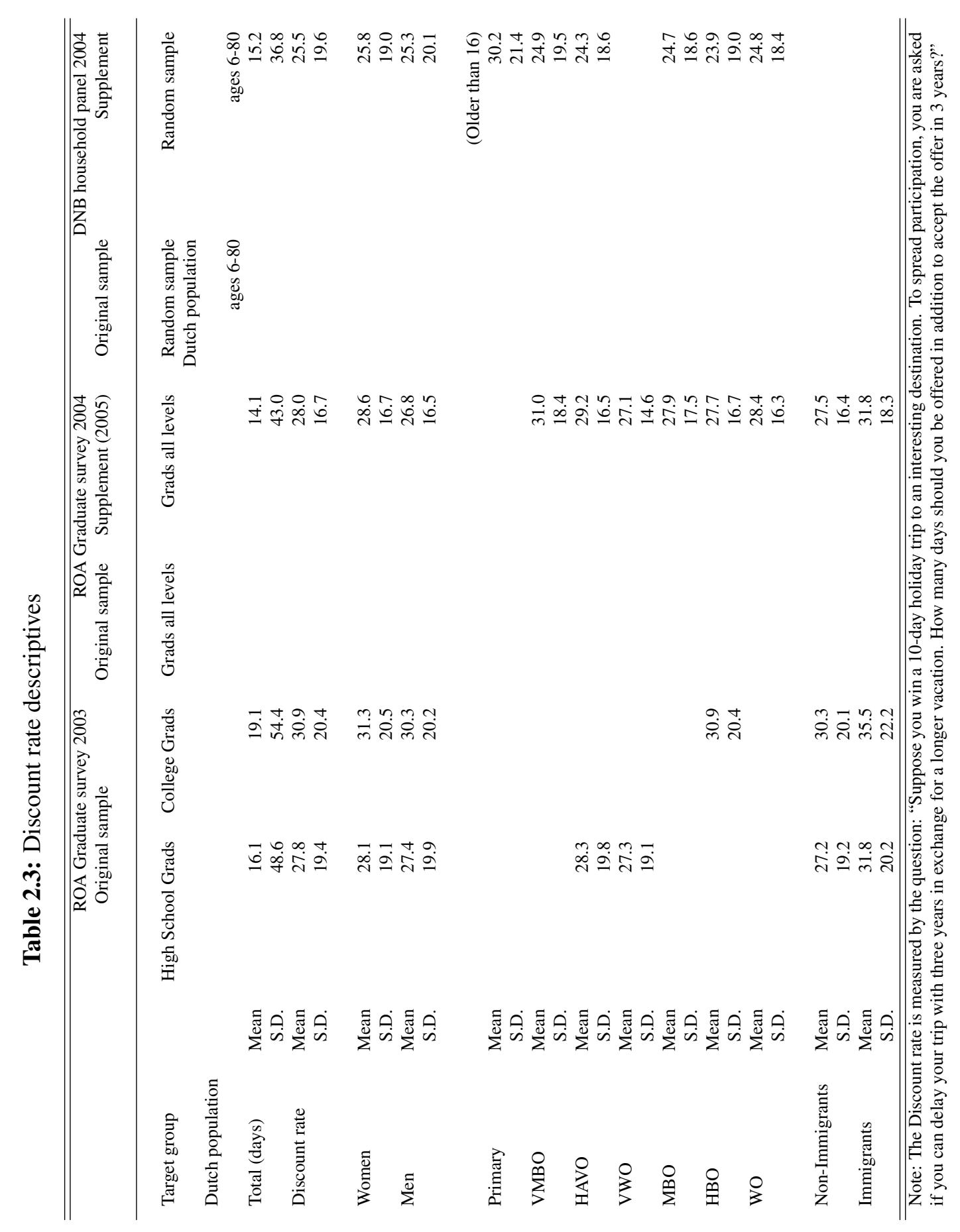




\section{Validation}

In all three surveys we included questions to validate our measure of time discounting. These variables are either other measures typically used in the literature to measure discount rates or typical outcomes of high discount rates.

For a limited group of the 2003 graduate survey, time discounting was measured by a similar question as the vacation question, replacing the vacation for a car worth 15,000 Euros. We find that although the level in the question related to the car is lower, the correlation between the two measures is high (0.295) and very significant (t-value: 7.720$)$.

The ROA 2005 graduate survey supplement includes many possibilities to validate our measure with plausible proxies. First, we use a measure often used in psychological research (Rachlin, Raineri, and Cross 1991). We asked the graduates to answer the following question: "What would you prefer: 800 Euros now or 1200 euros in one year?" To deduce information most efficiently, we made a tree of follow-up questions depending on the answer they gave. If they e.g. chose 800 euros, they received a similar question with the amounts 800 and 1400 euros. If they chose 1200 euros, they had to choose between 800 and 1000 euros. Depending on these choices, they received one more question in which we again varied the answer possibilities. Three sets of such monetary discount rate questions were included in the survey. The average resulting discount rate was $31.1 \%$ (with st. dev. 21.5). Table 2.4 shows that the measures correlate very significantly with our discount rate measure. A correlation of about .15 reveals however that there is substantial measurement error in these measures of discount rates. In psychological literature correlations between measures of individual attributes of this size are not uncommon.

Another part of the survey focuses on typical outcomes related to high discount rates. We use these outcomes to validate our measure. People with high discount rates value present consumption more than future consumption. Psychological studies, e.g. Sykes, Evans, and McCrum (1990), have shown that as a result, compared with those with low time discount rates, they would be more willing to trade pleasant but detrimental consumption now for a better health in the future. Bad health, and especially smoking is therefore associated with high discount rates. Also, in economic literature (e.g. Fuchs (1982), Evans and Montgomery (1994), Chevalier and Walker (2001) and Munasinghe and Sicherman (2006)) smoking is used as a proxy for time discounting. Table 2.5 shows that the correlations between discount rates and forms of risky behavior are significant and in the expected direction with most of these measures. 
Table 2.4: The relationship between the discount rate based on the vacation question and monetary measures of the discount rate

\begin{tabular}{|c|c|}
\hline \multicolumn{2}{|c|}{ Standardized coefficient } \\
\hline Average of the monetary questions ${ }^{a}$ & $\begin{array}{l}0.168 * * * \\
(0.012)\end{array}$ \\
\hline Monetary question $1^{b}$ & $\begin{array}{l}0.147 * * * \\
(0.013)\end{array}$ \\
\hline Monetary question $2^{c}$ & $\begin{array}{l}0.132^{* * *} \\
(0.013)\end{array}$ \\
\hline Monetary question $3^{d}$ & $\begin{array}{l}0.158^{* * *} \\
(0.012)\end{array}$ \\
\hline \multicolumn{2}{|c|}{$\begin{array}{l}\text { Source: Research Centre for Education and the Labour Market } 2005 \text { graduate survey } \\
\text { supplement. } \\
* \mathrm{p}<0.10, * * \mathrm{p}<0.05, * * * \mathrm{p}<0.01 \\
\text { The dependent variable is the discount rate which is measured by the following subjective } \\
\text { question: Suppose you win a } 10 \text {-day holiday trip to an interesting destination. To spread } \\
\text { participation, you are asked if you can delay your trip with three years in exchange for a } \\
\text { longer vacation. How many days should you be offered in addition to accept the offer in } \\
3 \text { years? The regressions have been run separately per monetary question. All regressions } \\
\text { are OLS. Standardized errors are reported in parenthesis. }\end{array}$} \\
\hline
\end{tabular}

${ }^{a}$ This is the average value of the answers to the three monetary questions below.

${ }^{b}$ We asked the people to answer the following question: What would you prefer 800 Euros now or 1200 euros in one year. We made a tree of follow-up questions depending on the answer they gave. If they e.g. chose 800 euros, they got a similar question with the amounts 800 and 1400 euros. If they chose 1200 euros, they had to choose between 800 and 1000 euros. Depending on these choices they got one more question in which we again varied the answer possibilities.

${ }^{c}$ The second tree of questions has the same mechanism but started with the question: What would you prefer 1000 Euros now or 4000 euros in four years?

${ }^{d}$ The third tree of questions has the same mechanism but started with the question: What would you prefer 800 Euros in one year or 1200 euros in two years? 


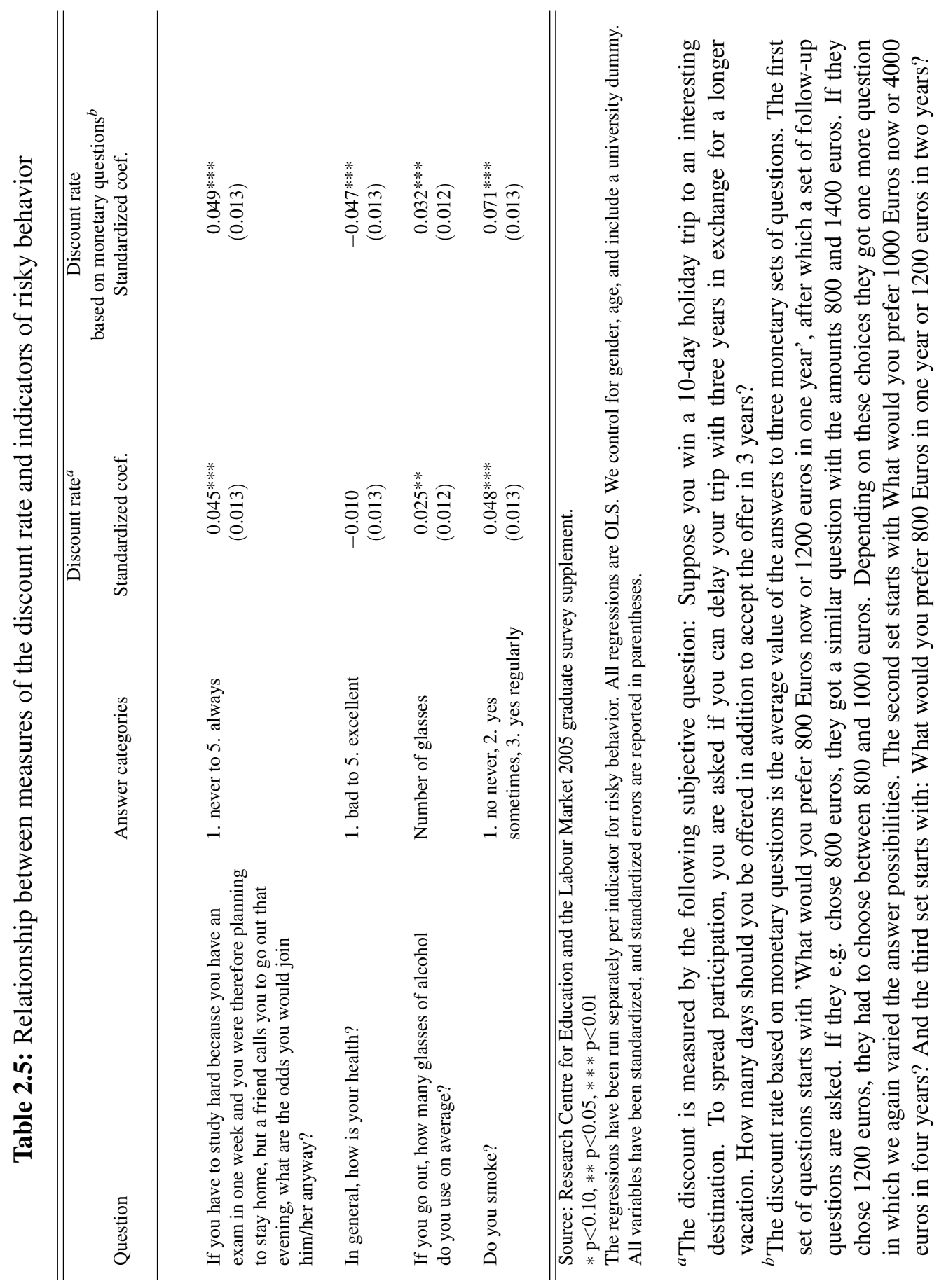


In the DNB supplementary sample, there are also many possibilities for validating our measure. We find significant correlations in this sample with a similar set of trade-offs between amounts of money now and in the future as in the 2005 supplement (Correlation coef: -0.108 , t-value: -5.560 ). The original sample also includes many proxies for discount rates. In Borghans and Golsteyn (2006b), we show that there is a high correlation between these proxies and our measure of time discounting.

\subsubsection{Measuring imagination}

The concept of imagination is less well studied as discount rates but related concepts have recently gained substantial interest in psychological literature.

Suddendorf and Busby (2005), Busby and Suddendorf (2005), Friedman (2005), Clayton, Bussey, and Dickinson (2003) use the term "mental time travel" for the ability to remember past experiences and to project oneself into the future. We define imagination as the ability to form mental pictures of the future. People with a better imagination are more able to see what their future will be like. Our term "imagination" is therefore similar to mental time travel into the future. D' Argembeau and van der Linden (2006) measure mental time travel by the Vividness of Visual Imagery Questionnaire, in which participants were asked to imagine and describe events which may reasonably happen to them in the future. Our measure of imagination is related to this. We ask people to imagine their life in general and aspects of their life (such as their jobs) in the future.

Other related concepts are "projection bias" which refers to the exaggeration of the degree to which future tastes will resemble their current tastes (Frederick, Loewenstein, and O'Donoghue 2002). And Caplin and Leahy (2001) give examples of psychological research concerning the measurement of feelings of anticipation. Ameriks, Caplin, and Leahy (2003) investigate the propensity to plan in the context of wealth accumulation. And in psychological literature "temporal construal" is used to describe that people generally are less able to construct concrete images of aspects which have a larger "psychological distance" (Lewin 1951, Trope and Liberman 2003). Our concept measures the difference in the ability of people to form these images.

With respect to visceral states, Loewenstein (1996) mentions "cold-to-hot empathy gaps." Such gaps are mispredictions of own behavior and preferences across affective states. When people are in a cold state, they fail to fully appreciate how hot states will affect their own preferences and behavior. In the context of investments in health, Loewenstein (2005) concludes that healthy people may expose themselves excessively to risks. Visceral factors also influence other intertemporal choices. This is related to our theory that a lack of imagination decreases 
Table 2.6: Imagination measures

\author{
ROA GRADUATE SURVEY 2003 \\ HAVO/VWO SURVEY \\ Ex ante imagination \\ Everyone sometimes has to make an important decision in his/her life. When you face such a decision, \\ what kind of image do you form of the consequences of the decision (1. no image to 5. a complete image) \\ Ex post imagination \\ And if you have taken such a decision, does the reality confirm the image you had on beforehand \\ (1. Almost always very similar to 5. Almost never similar) (-)

\section{ROA 2005 GRADUATE SURVEY SUPPLEMENT} \\ Ex ante imagination (1. Totally disagree to 7. Totally agree): \\ If I have to make an important decision, I form a clear image of the consequences of that decision \\ I can imagine well what my next job looks like \\ I clearly see what I can expect from the coming year \\ I sometimes imagine what my life will look like in 15 years \\ I have a clear image about what my life looks like in 10 years \\ Ex post imagination (1. Totally disagree to 7 . Totally agree): \\ If I have taken an important decision, the result is usually in line with the image I had \\ My life now is totally different from what I expected 3 years ago (-) \\ My life now is very different from what I imagined 5 years ago (-) \\ Last year has been quite different from what I expected on beforehand (-)
}

\title{
DNB HOUSEHOLD PANEL 2004
}

\section{SUBSAMPLE}

Ex ante imagination (1. Totally disagree to 7. Totally agree):

I sometimes imagine what my life will look like in 15 years

I have a clear image of my life in 10 years

Ex post imagination (1. Totally disagree to 7. Totally agree):

My life is very different now than I imagined five years ago (-)

COMPLETE SAMPLE (1. Totally disagree to 7. Totally agree):

I think about how things can be in the future and try to influence these in my every day life

I am often occupied with things that will have an effect in several years

I am only occupied with the present, assuming that things will be alright in the future (-)

With everything I do, I only think about the immediate consequences of these actions (days or weeks) (-)

I think it is important to take warnings about negative consequences of my actions seriously, even if these

consequences would appear in the far future

I think it is more important to be occupied with things which will have important consequences in the future,

than with things which have immediate but less important consequences

Note: The minus sign indicates that in the calculation of the imagination measure, we reversed the answer categories.

the incentives to invest.

Table 2.6 gives information about the questions we use to measure imagination in the various surveys.

An important aspect when measuring imagination is that ex ante people may think they have a good picture about their future, but ex post this picture may turn out not to be correct. To see if answers differ ex ante from ex post, we distinguish therefore between ex ante and ex post measures for imagination. Ex ante imagination measures how well the respondent makes pictures of his future. Ex post imagination ${ }^{18}$ evaluates the accuracy of the pictures of

\footnotetext{
18“Ex post imagination" could be seen as a contradiction in terms. We use this term because we want to stress
} 
the future.

In the 2003 high school graduate survey, we included one ex ante and one ex post question to measure imagination about life in general.

In ROA 2005 graduate survey supplement, we were able to include a battery of 9 subjective questions to measure the power of imagination as precisely as possible. Five of these questions have an ex ante and four an ex post nature. An example of the former is a statement like "I can imagine well what my next job will look like," while the latter is of the type "My life now is totally different from what I expected it to be 3 years ago." Cronbach's Alpha for these statements equals 0.60 .

Ex ante and ex post measures of imagination correlate very highly. We find correlation coefficients between the average of the ex ante and the average of the ex post questions of 0.27 (t-value: 17.248) and 0.28 (t-value: 22.846) in the 2003 and 2004 graduate surveys respectively. We use the average value of ex ante and ex post questions as our measure of imagination.

In the 2004 DNB household panel, our measures of imagination include for a limited sample the same questions as those we included in the 2004 supplement to the graduate survey. In the complete sample, several questions were added which very closely correspond to our imagination measure, like "I think about how things can be in the future and try to influence these in my every day life." These measures correlate significantly with the imagination questions we added in the subsample (Correlation: 0.077, t-value: 2.400). We use the questions from the complete sample in our analysis.

Table 2.7 shows descriptives of imagination for the three surveys. The table shows that in all surveys higher educated people, men and non-immigrants have a higher power to imagine their future.

that ex post imagination is measuring the same concept as ex ante imagination, but from a different perspective. 


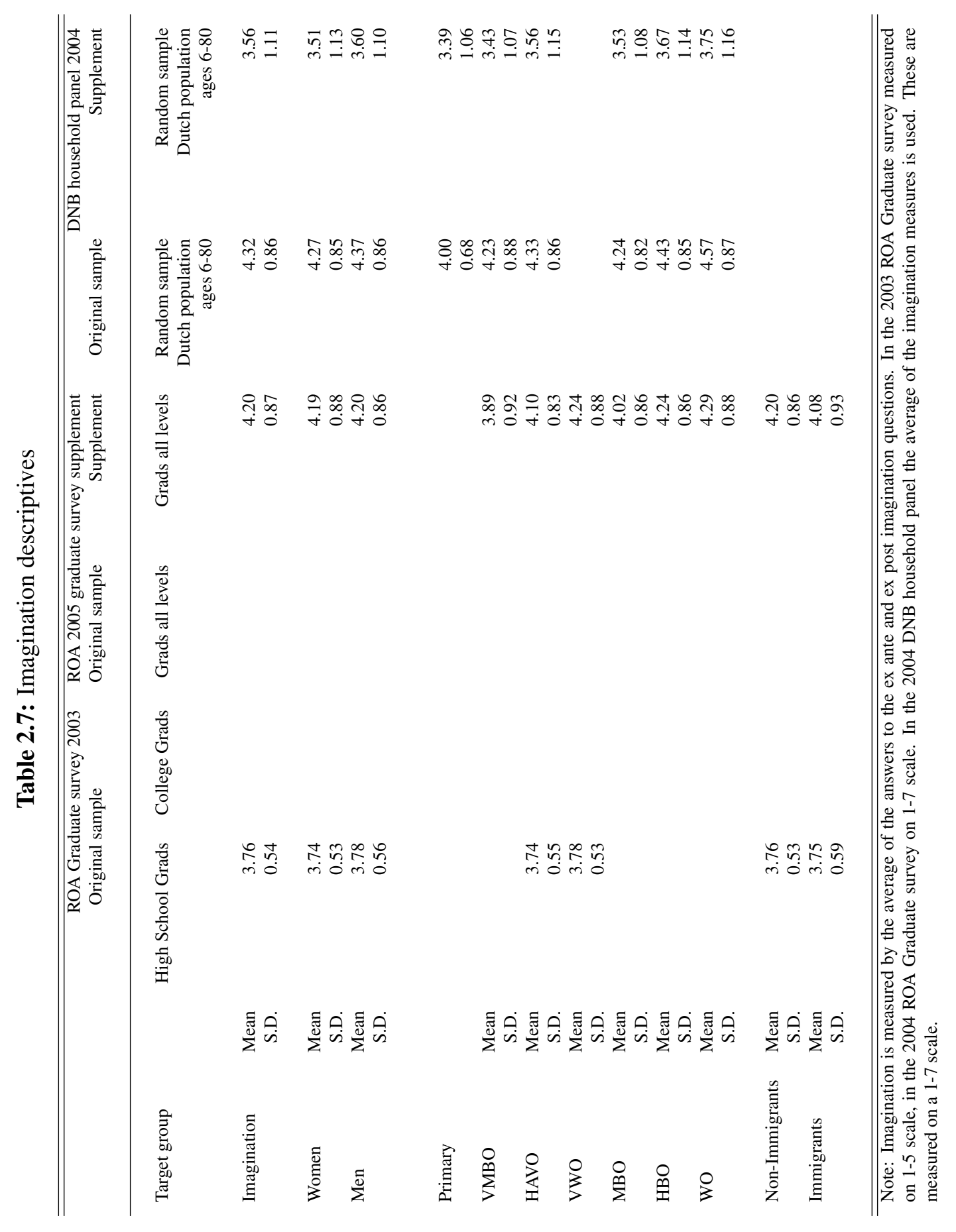




\section{Validation}

Like in the validation procedure of discount rates, we use outcomes which can be associated with low imagination to validate our measure of imagination.

We use the evaluation of a real life choice as a typical outcome of imagination. Here the important distinction needs to be made between daily and once-in-a-life-time choices. The evaluation of choices involving day-to-day issues with no consequences for the future will not necessarily be correlated with the quality of imagination. People have a lot of experience with these choices and they do not need to imagine how they in the future will value their current choices because the future value will be similar to the current value.

Instead, people who cannot picture their future very well, will have many difficulties making choices with which they have hardly any experience and which have important outcomes in the far future. Such choices involve once-in-a-lifetime issues such as a choice for a partner, a house, and having children. A key aspect of these choices is that people need to be aware not only of the value they currently give to outcomes of the choice, but - much more importantly also need to estimate how their future selves will value the choices they currently are making. Because - especially in our graduate surveys - our respondents are very young, we cannot ask them to evaluate most of such choices yet. However, the once-in-a-life-time choice they have made and can evaluate is their choice of educational discipline. ${ }^{19}$

We use questions about the trouble people had to choose the education and about the evaluation of the choice of the educational discipline to validate imagination. Table 2.8 shows the questions we added in the graduate surveys and how they are related to imagination.

The ultimate consequence of unforeseen aspects of a choice is that people face a higher probability to discover afterwards that they would have preferred an alternative educational field, had they known these consequences in advance. Of course there can always be unforeseen circumstances but people who have an incomplete picture of the future utility of a specific investment will regret their choice more often than those who have a better picture. To measure regret with respect to the choice of the educational discipline, we ask:

Would you choose the same education if you had the opportunity to choose again?

\footnotetext{
${ }^{19}$ Note that the choice for an educational discipline is more a once-in-a-life-time choice than in other countries, because as explained before, in the Dutch educational system students have to make a very specific educational choice at the start of their education. Because the educations are very specific, it is also difficult to switch between educational disciplines after one has chosen to follow an education. As a consequence, at age 18, students have to choose an education based on how they imagine they will value the specific field in a large part of their careers.
} 


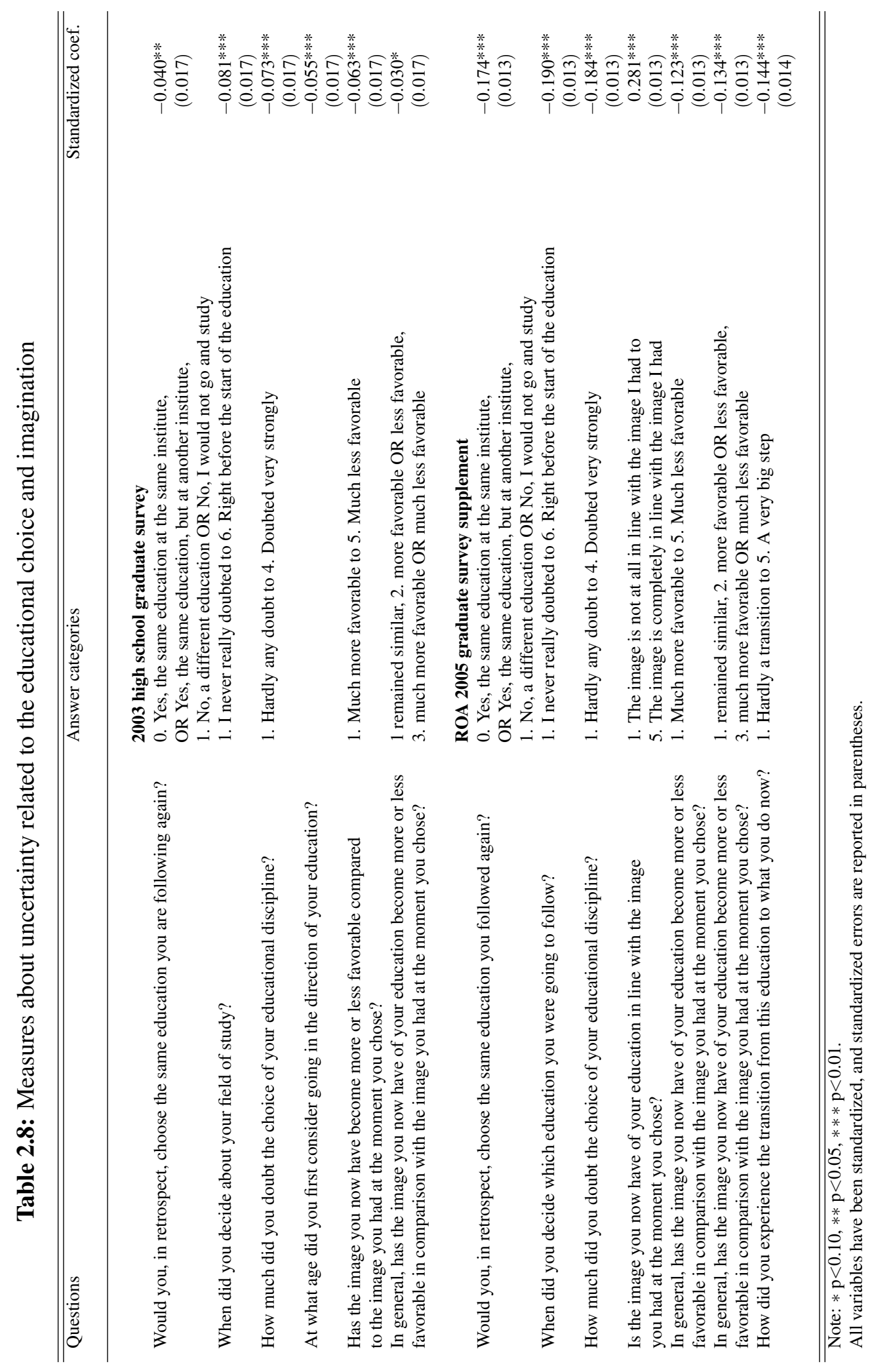


Answers are 1. "yes, same education at same college," 2. "yes, same education but at different school," 3. "no, a different education," 4. "no, I would not go and study." In both graduate samples, we find that people with better imagination regret their choice of educational discipline less. ${ }^{20}$

Next to this, we find in both samples that graduates with high imaginative powers indeed choose early what they will study, and doubted less the choice of the educational discipline. An important further consequence is that the probability increases that after a choice has been made unforeseen factors appear. The table shows that the image graduates with a low power to imagine have of their education has become worse after they left college. This implies that they overestimated the benefits of the discipline they chose. The table shows also that the image of the education remained more similar for people with better imagination and that they experienced a smaller transition from the education to what they do now.

Note that in the 2003 college graduate survey, there are no questions to measure imagination. However, two questions were included about the results of low imagination: doubt about the choice of their educational discipline ex ante and the evaluation of the educational choice ex post. ${ }^{21}$ In our analyses for the 2003 HBO graduates, we will use doubt as proxy for a lack of imagination.

\subsubsection{Measuring other attributes}

An important issue is that there may be other attributes which can provide alternative explanations for our findings. In the ROA 2005 graduate survey supplement and in the 2004 DNB Household panel, we measured several other attributes besides discount rates and imagination to analyze whether they drive the results. We selected psychological attributes which plausibly may be related with on the one hand a higher reluctancy to leave the safe or pleasant state of education, and on the other hand with imagination.

In both samples, we added the same questions related to anxiety, self-image and selfconfidence. Anxiety indicates to what extent people are afraid of things they do not have experience with. It is measured by 3 statements such as "I often think back about unpleasant experiences." Cronbach's Alpha equals 0.47. Self-image is measured by 3 statements like "In

\footnotetext{
${ }^{20}$ The correlations are higher in the 2005 sample probably because of larger measurement error in the 2003 sample. In 2005 imagination is measured with more questions and the 2005 sample is larger than the 2003 sample.

21 "How much did you doubt the choice of your educational discipline?" 1. Hardly doubted to 4. Doubted very strongly. And: "Would you, in retrospect, choose the same education you followed again?" 1. Yes, the same education at the same institute, 2. Yes, the same education, but at another institute, 3. No, a different education, 4. No, I would not go and study.
} 
general I have a clear idea about who and what I am." Cronbach's Alpha equals 0.58. Selfconfidence is measured by 3 statements such as "I think I have enough reason to be proud of myself." Cronbach's Alpha for these three statements equals 0.67.

We added in the supplement to the 2004 graduate survey the following questions to measure risk aversion. We offer the respondents one amount of money they can get for sure or a higher amount of money with a chance of getting it and a chance of not getting it. We asked 6 questions in which we varied the amounts of money and the chance of getting the money. To deduce information most efficiently, we used follow-up questions. An example is the question: "What would you choose: 800 Euros, or 50\% chance on nothing, 50\% chance on 2000 Euros?" If the respondent chose 800 Euros, he would get the question: What would you choose: "800 Euros, or 50\% chance on nothing, 50\% chance on 2400 Euros?" A respondent who chose 2000 Euros in the first question would get the question: "What would you choose: 800 Euros, or $50 \%$ chance on nothing, $50 \%$ chance on 1600 Euros?"

In the survey we also added 8 questions taken from Frederick (2005) to measure cognitive skills. An example of these questions is

"Together, a ball and a cap cost 1.10 Euros. The ball costs 1.00 Euros more than the cap. How much does the cap cost?"

Cronbach's Alpha equals 0.77 for these questions. Frederick (2005) shows that scores on this Cognitive Reflection Test are correlated with SAT-scores and scores on several other IQ tests and with the ability to make choices. We find significant correlations between the average number of correctly answered questions and high school grades for nearly all subjects taught in high school and with the average college grade. This indicates that the measure for cognitive skills plausibly reflects some general type of cognitive skills.

Besides these psychological characteristics we asked people how much they enjoyed their time in education.

In the 2004 DNB Household panel, we added one question to measure impulsiveness. And we added a measure for risk aversion being the answer of a set of six statements. Cronbach's Alpha for these three statements equals 0.71 .

The comprehensive list of the questions measuring these personal characteristics is shown in table 2.9. 


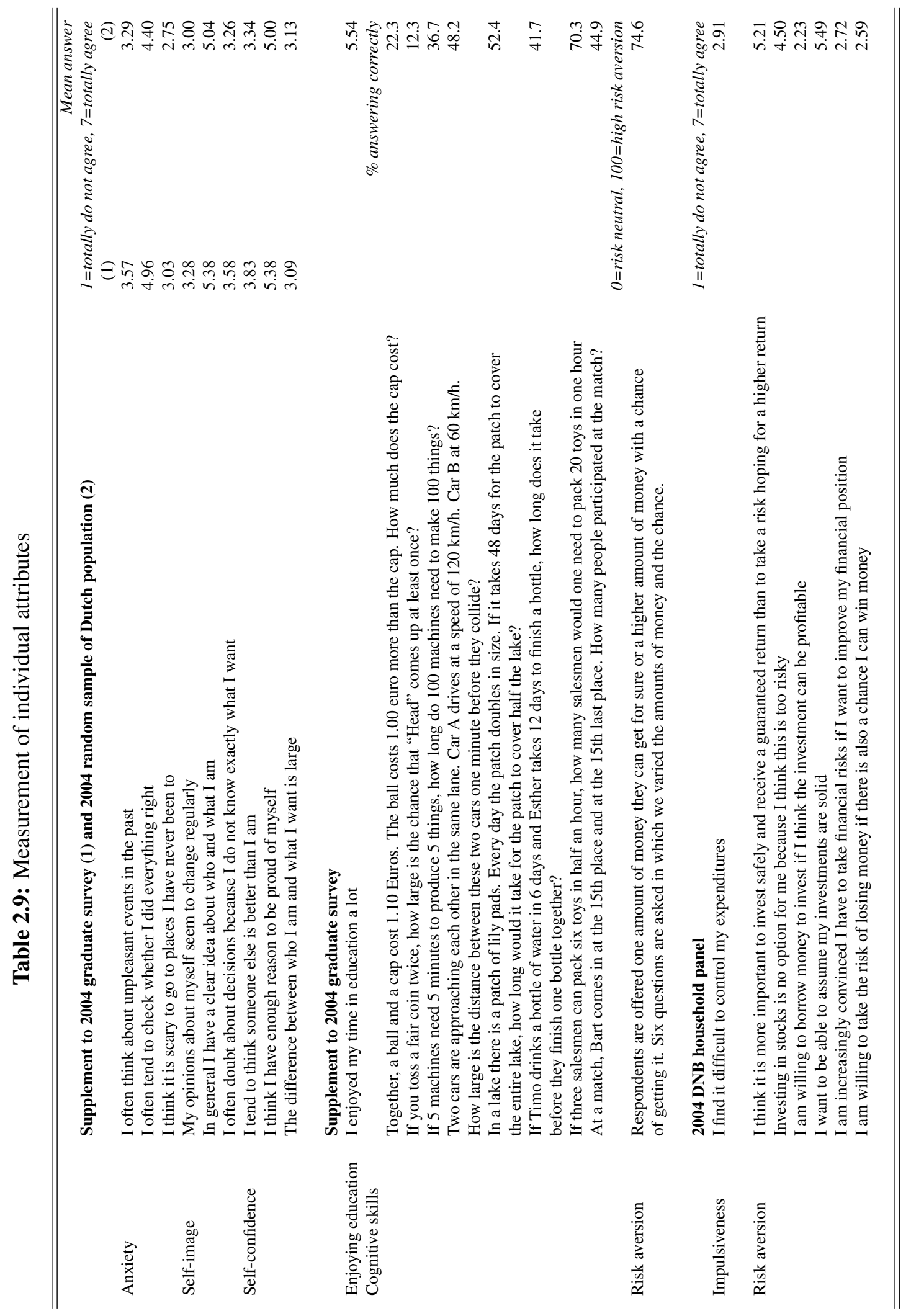




\subsection{Results}

This section consists of three parts. First we analyze the correlation between imagination and time discounting, then we analyze our main hypotheses whether imagination is related negatively with length of stay in education and regret of the length of stay.

\subsubsection{Imagination and time discounting}

\section{Between people}

The first empirical question we want to answer is whether the power of imagination is related to the discount rate. To that aim in table 2.10 we relate the power of imagination to time discounting. We find in all surveys that these concepts are negatively related, as expected. Other measures which we used to validate discount rates are also negatively correlated with imagination.

The model predicts that when time discounting reflects power of imagination, this would imply that those with high discount rates are more likely to make inadequate educational choices. The table shows also that graduates who have high discount rates are more likely to regret their choice of education and that they reported more doubt about their educational choice ex ante.

Using the ROA 2005 graduate survey supplement, we analyze many potential other explanations which may be confounding the relation between imagination and the discount rate. Table 2.11 shows that imagination is not related to enjoying college life, but is related to anxiety, self-image, self-confidence, cognitive skills and risk aversion.

Comparing the results in table 2.11 with those in 2.10 we find that the correlation between discount rates and imagination is not reduced by the inclusion of other attributes. In fact, imagination has the highest correlation with the discount rate. In the table, we also report the regressions of the other attributes on discount rates. Self-image, self-confidence, and cognitive skills are also related to discount rates. 


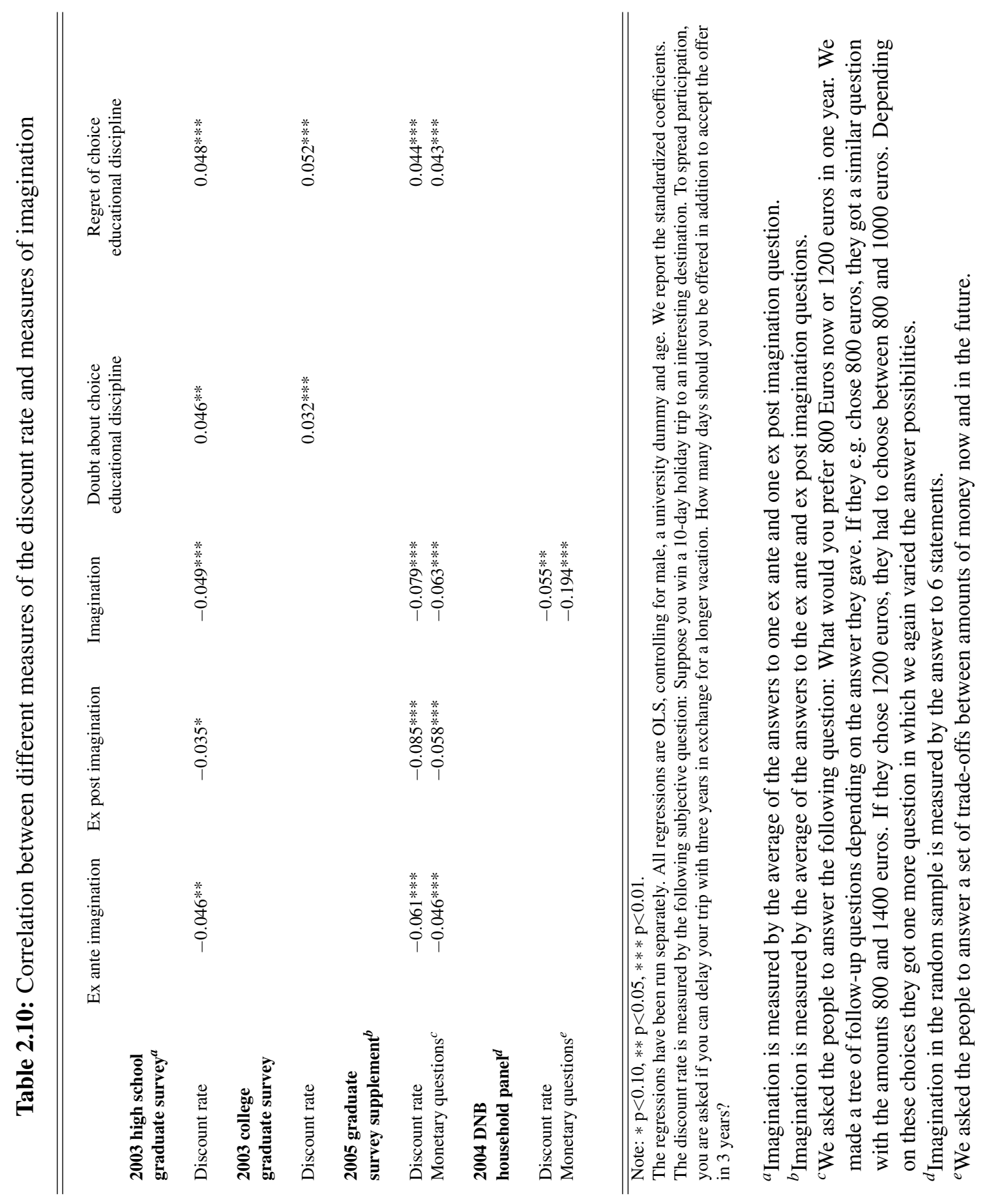




\section{Within people}

The evidence we provided above supports the prediction of the model that people with high discount rates have a low ability to imagine the future. In addition to this variation in investment behavior between people, the theory also predicts that the same person will invest more in aspects for which he has a clearer view about the future.

To test this we include a small experiment in the ROA 2005 supplement sample. We obtain a measure for the clarity of the image by asking:

"Often people get children at a certain moment in their lives. Do you often think about what it would be like to have children?"

The answers are on a 1 (never) to 7 (often) scale. Similar questions were asked with respect to three other domains of life: buying a house, being ill, and being retired.

To measure the willingness to invest we asked later in the survey:

"Suppose the government wants to stimulate that people save money for events later in their life. For instance, there could be a fund in which money is put which you may spend on expenses when you have got children, e.g. for child care. The money is invested as long as you do not need it, hence the amount grows over time. If you do not have children when you are 40 years of age, you receive the amount of money including interest. If you may choose between receiving 1000 euros in cash now or having a larger amount of money invested in the fund, how much money would at least have to be invested in the fund before you would agree with this destination?"

Again, similar questions were asked with respect to having a house, being ill, and being retired. We replaced the age at which the amount of money was to be received for the question about the house with 50 years of age and for the questions about illness and pension with 65 . The idea behind this question is that people who are more willing to invest in the aspect of their life, will accept a lower minimum amount of money.

We pooled the data for these 4 sets of questions. We excluded those who already had children, a house or a serious disease. Some of the respondents answered an amount lower than 1000 euros. This would imply a negative discount, which is not plausible. It could imply 
Table 2.11: Other explanatory variables of the discount rate and imagination

\begin{tabular}{|c|c|c|c|}
\hline & Imagination $^{a}$ & $\overline{\text { Discount rate }}{ }^{b}$ & Discount rate \\
\hline Constant & $\begin{array}{c}-0.054 \\
(0.098)\end{array}$ & $\begin{array}{l}0.439 * * * \\
(0.105)\end{array}$ & $\begin{array}{l}0.433 \text { *** } \\
(0.105)\end{array}$ \\
\hline Male & $\begin{array}{c}-0.021 \\
(0.033)\end{array}$ & $\begin{array}{c}-0.089 * * \\
(0.035)\end{array}$ & $\begin{array}{c}-0.090^{* *} \\
(0.035)\end{array}$ \\
\hline Age & $\begin{array}{c}-0.005^{* *} \\
(0.003)\end{array}$ & $\begin{array}{c}-0.012 * * * \\
(0.003)\end{array}$ & $\begin{array}{c}-0.013 * * * \\
(0.003)\end{array}$ \\
\hline Educational level father ${ }^{c}$ & $\begin{array}{l}0.021 * * \\
(0.009)\end{array}$ & $\begin{array}{c}-0.013 \\
(0.009)\end{array}$ & $\begin{array}{c}-0.011 \\
(0.009)\end{array}$ \\
\hline Educational level mother & $\begin{array}{c}0.000 \\
(0.009)\end{array}$ & $\begin{array}{c}0.014 \\
(0.009)\end{array}$ & $\begin{array}{c}0.014 \\
(0.009)\end{array}$ \\
\hline Immigrant $^{d}$ & $\begin{array}{c}-0.118^{* * *} \\
(0.048)\end{array}$ & $\begin{array}{l}0.189 * * * \\
(0.051)\end{array}$ & $\begin{array}{l}0.180^{* * * *} \\
(0.051)\end{array}$ \\
\hline Level high school ${ }^{e}$ & $\begin{array}{c}0.009 \\
(0.038)\end{array}$ & $\begin{array}{c}0.064 \\
(0.040)\end{array}$ & $\begin{array}{c}0.065 \\
(0.040)\end{array}$ \\
\hline Average grade ${ }^{f}$ & $\begin{array}{l}0.042^{* * * *} \\
(0.013)\end{array}$ & $\begin{array}{c}-0.032^{* *} * \\
(0.014)\end{array}$ & $\begin{array}{c}-0.028^{* *} \\
(0.014)\end{array}$ \\
\hline Dummy university & $\begin{array}{c}0.012 \\
(0.040)\end{array}$ & $\begin{array}{c}0.030 \\
(0.043)\end{array}$ & $\begin{array}{c}0.031 \\
(0.042)\end{array}$ \\
\hline Anxiety & $\begin{array}{l}0.108^{* * * *} \\
(0.017)\end{array}$ & $\begin{array}{c}-0.029 \\
(0.019)\end{array}$ & $\begin{array}{c}-0.020 \\
(0.019)\end{array}$ \\
\hline Self-image & $\begin{array}{l}0.295^{* * *} * \\
(0.020)\end{array}$ & $\begin{array}{c}-0.076^{* * * *} \\
(0.022)\end{array}$ & $\begin{array}{c}-0.053^{* *} \\
(0.022)\end{array}$ \\
\hline Self-confidence & $\begin{array}{l}0.123^{* * * *} \\
(0.021)\end{array}$ & $\begin{array}{l}0.045^{* *} * \\
(0.022)\end{array}$ & $\begin{array}{l}0.055^{* * *} \\
(0.023)\end{array}$ \\
\hline Cognitive skills & $\begin{array}{l}0.031^{*} \\
(0.017)\end{array}$ & $\begin{array}{c}-0.064 * * * \\
(0.018)\end{array}$ & $\begin{array}{c}-0.062^{* * * *} \\
(0.018)\end{array}$ \\
\hline Risk aversion & $\begin{array}{l}0.034 * * \\
(0.015)\end{array}$ & $\begin{array}{c}-0.030^{*} \\
(0.016)\end{array}$ & $\begin{array}{c}-0.028^{*} \\
(0.016)\end{array}$ \\
\hline Enjoying education & $\begin{array}{c}0.018 \\
(0.016)\end{array}$ & $\begin{array}{c}0.016 \\
(0.018)\end{array}$ & $\begin{array}{c}0.017 \\
(0.018)\end{array}$ \\
\hline Imagination & & & $\begin{array}{c}-0.078 \text { *** } \\
(0.017)\end{array}$ \\
\hline
\end{tabular}

Note: Source: Research Centre for Education and the Labour Market 2005 graduate survey supplement.

$* \mathrm{p}<0.10, * * \mathrm{p}<0.05, * * * \mathrm{p}<0.01$.

All regressions are OLS. The measures imagination, the discount rate, Anxiety, self-image, self-confidence, cognitive skills, risk aversion, and enjoying education are standardized.

${ }^{a}$ Imagination is measured by the average of the answers to the ex ante and ex post imagination questions.

${ }^{b}$ Discount rate is measured by the following subjective question: Suppose you win a 10-day holiday trip to an interesting destination. To spread participation, you are asked if you can delay your trip with three years in exchange for a longer vacation. How many days should you be offered in addition to accept the offer in 3 years?

${ }^{c}$ The educational level of the father and the mother are reported by the respondent. There were 7 categories varying from primary school to university.

${ }^{d}$ A person is defined to be an immigrant if he is not born in the Netherlands or one or both of his parents are not born in the Netherlands.

${ }^{e}$ Level high school is a dummy variable with the value 1 if the person had followed a high level high school and 0 if he followed a low level high school.

${ }^{f}$ This is the average grade the person scored during the professional college education or the university. 
Table 2.12: The discount rate and the clarity of the image in different domains of life

\begin{tabular}{l}
\hline \hline Constant \\
Clear image ${ }^{a}$ \\
\\
Disease \\
\end{tabular}

that they did not understand the question, or that they thought they had to give the extra amount of money they wanted on top of the 1000 euros. We excluded these observations.

Calculating the extra discount rate as $\left(\frac{\text { amount }+1000}{1000}\right)^{1 /(X-a g e)}-1$, where $X$ equals 40 for the question regarding children, 50 for the question about having a house and 65 for the questions regarding illness and retirement, we find an average discount rate of 5.43\%.

In a regression with individual fixed effects, we explain this elicited discount rate with the variable reflecting the clarity of the image of the future situation in the specific domain and domain specific dummies. Table 2.12 shows that in domains in which people have a clearer image, they have lower discount rates. This implies that they were more willing to invest in the life-domain they could imagine better. Also, the table indicates that relative to investing in a fund for their children, people are more willing to invest in funds for housing, retirement or a disease.

\subsubsection{Imagination and length of stay in education}

The second question we will answer is whether better imagination is related with a shorter stay in education. We use the number of months people indicate to have spent in education as a measure for the length of stay in education.

In the 2003 college graduate sample we do not have a measure of imagination, but we can 
include as a proxy the doubt people had when they chose their education or the regret about the choice of educational discipline they experienced afterwards. Table 2.13 shows that people who doubted their choice of education less, stay shorter in college. This is in line with our theory that people with better imagination stay shorter in college. Repeating our analysis with regret as a proxy for imagination produces very similar results.

The second regression in the table shows the results when we analyze the relation between imagination and the length of stay for the college graduates in the 2005 supplement. The results are again that those with better imagination stay shorter in education. The last column shows moreover that including other attributes does not affect the relation between imagination and the length of stay.

One could argue that people with higher imagination stay shorter in education because they have more cognitive skills and therefore pass exams more easily. On the other hand, people with more cognitive skills may be expected to be more willing to invest in education. If so, a positive correlation between cognition and years in education may be expected. Cognitive skills are indeed positively related to imagination (see table 2.11). However, table 2.13 shows that conform standard theory, more cognitive skills are related with a longer stay in education. Higher grades on the other hand are associated with a shorter stay. This is consistent with papers showing that achievement depends not only on cognition but also on noncognitive factors such as conscientiousness.

Theoretically the discount rate is a function of traditional time preference and of imagination. The former is expected to have a negative relation with length of stay, while the latter has a positive relation with length of stay. The resulting correlation of the discount rate and length of stay is an empirical question. Figure 2.1 shows the result of the relation between the discount rate and the length of stay in education in the 2003 college graduate survey. The correlation is clearly positive, and regression analysis shows that it is significant $(t=4.523)$. Analyzing the relation in our 2005 supplement sample, we find for the discount rate measure based on the vacation question also a positive relation with length of stay in education. This relation remains significantly positive when we include the other individual attributes. However, we find no relation between the discount rate based on monetary questions and length of education. This shows that the relation is not robust, but depends on the measure we use for the discount rate. The relation between imagination and the length of stay in education remains robust when we include the measures for the discount rate in the regression shown in table 2.13 .

Interestingly, Chesson and Viscusi (2000) confirm the finding that a higher discount rate is related to further studying. Because of the inconsistency with the standard discount rate 
Table 2.13: Imagination and the length of the stay in education

\begin{tabular}{|c|c|c|}
\hline & 2003 college graduate survey & Supplement to 2004 graduate survey \\
\hline Constant & $\begin{array}{l}55.923^{* * * *} \\
(0.641)\end{array}$ & $\begin{array}{l}53.465^{* * * *} \\
(1.450)\end{array}$ \\
\hline Doubt & $\begin{array}{l}0.894 * * * \\
(0.099)\end{array}$ & \\
\hline Imagination & & $\begin{array}{c}-0.570 * * \\
(0.224)\end{array}$ \\
\hline Male & $\begin{array}{l}2.520 * * * \\
(0.208)\end{array}$ & $\begin{array}{l}3.716^{* * *} \\
(0.463)\end{array}$ \\
\hline Age & $\begin{array}{c}-0.307 * * * \\
(0.019)\end{array}$ & $\begin{array}{c}-0.189^{* * * *} \\
(0.042)\end{array}$ \\
\hline Educational level father & $\begin{array}{l}0.195^{* * * *} \\
(0.053)\end{array}$ & $\begin{array}{c}0.218^{*} \\
(0.124)\end{array}$ \\
\hline Educational level mother & $\begin{array}{c}0.100 \\
(0.061)\end{array}$ & $\begin{array}{l}0.419^{* * * *} \\
(0.122)\end{array}$ \\
\hline Immigrant & $\begin{array}{l}0.984 * * * \\
(0.327)\end{array}$ & $\begin{array}{l}1.627^{* *} \\
(0.682)\end{array}$ \\
\hline Level high school & $\begin{array}{l}0.936 * * * \\
(0.241)\end{array}$ & $\begin{array}{l}2.946^{* * * *} \\
(0.535)\end{array}$ \\
\hline Average grade & $\begin{array}{c}-1.384 * * * \\
(0.088)\end{array}$ & $\begin{array}{c}-1.344 * * * * \\
(0.181)\end{array}$ \\
\hline Dummy university & & $\begin{array}{l}12.259 * * * \\
(0.580)\end{array}$ \\
\hline Anxiety & & $\begin{array}{c}-0.242 \\
(0.248)\end{array}$ \\
\hline Self-image & & $\begin{array}{c}-0.388 \\
(0.292)\end{array}$ \\
\hline Self-confidence & & $\begin{array}{c}-0.297 \\
(0.295)\end{array}$ \\
\hline Cognitive skills & & $\begin{array}{l}1.158^{* * * *} \\
(0.238)\end{array}$ \\
\hline Risk preference & & $\begin{array}{c}-0.440 * * \\
(0.207)\end{array}$ \\
\hline Enjoying education & & $\begin{array}{c}0.027 \\
(0.232)\end{array}$ \\
\hline
\end{tabular}

Note: $* \mathrm{p}<0.10, * * \mathrm{p}<0.05, * * * \mathrm{p}<0.01$.

All regressions are OLS. We included dummies for 9 groups of educational disciplines at the professional college level: Agriculture, Education, Technics, Economics, Health, Behavior and society, Language and culture, Law and public order, and Science. We show the standardized coefficients and standard errors. The dependent variable is the number of months stayed in education. 
Figure 2.1: Duration of education and the discount rate

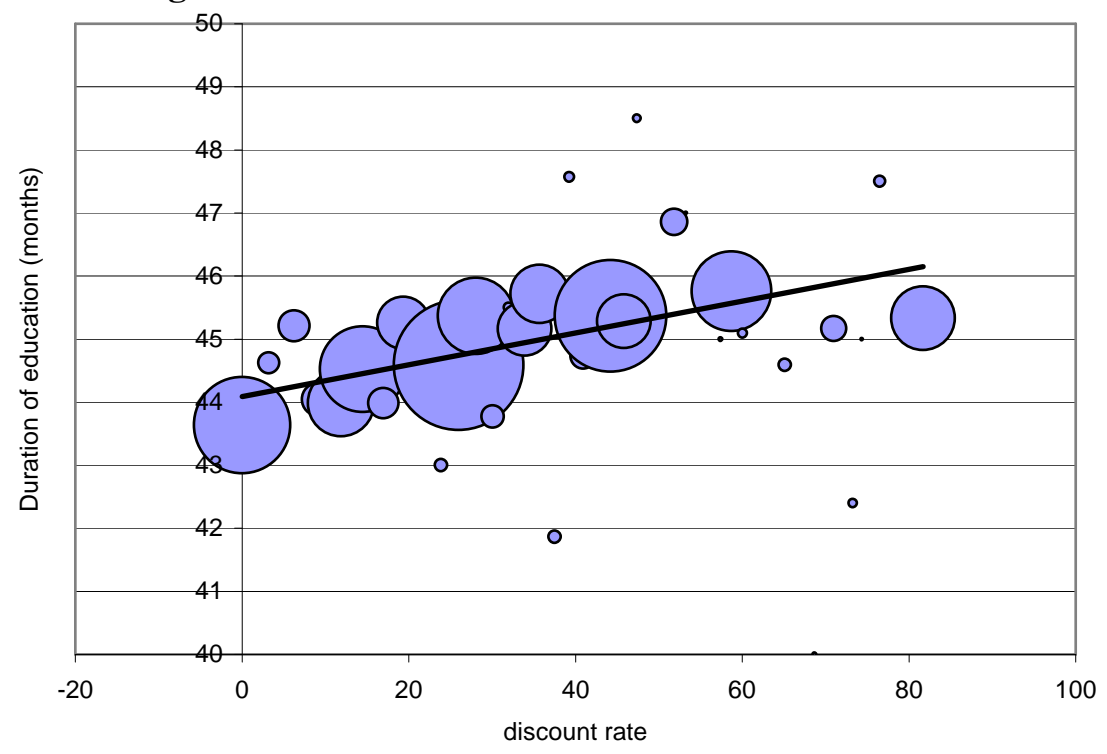

Source: Research Centre for Education and the Labour Market Graduate Survey 2003. The size of the balls is determined by the amount of respondents.

argument they explain their findings in terms of measurement problems in their tests, related to the lack of cognitive capabilities of many survey subjects. Fersterer and Winter-Ebmer (2003) find for Austrian data that smoking at age 16 reduces educational attainment with 0.43 years. Their sample includes a substantial group of students who left education at 16, and therefore the choice analyzed in their paper is essentially a participation decision while our results reflect years of education conditional on participation in further education.

A different piece of evidence relating imagination with length of stay could be provided by analyzing whether specific information about future consequences of choices could support students when they have to make crucial choices, also when they have less abilities to imagine the future in general.

One potential candidate is to analyze the behavior of natives relative to that of immigrants. It can be argued that immigrants have less information about the Dutch labor market than natives. Throughout the chapter, we find indeed consistently that immigrants report similar outcomes as people with lower imagination. They have less imagination, higher discount rates and report more regret of the choice of their educational discipline. Table 2.13 shows that immigrant college students stay longer in education.

Another test could be to use the idea that students who had parents or family working in the field they are interested in, have the advantage that they have a person in their direct surroundings from whom they can receive specific information. Observing your parents working 
Table 2.14: Regret, duration of the stay in education for students who formed an image about their field due to family working in this field and those who did not gain from such information

\begin{tabular}{lcc}
\hline \hline & $\begin{array}{c}\text { Regret }^{a} \\
\%\end{array}$ & $\begin{array}{c}\text { Duration of stay } \\
\text { in education (months) }\end{array}$ \\
\hline No specific information from family member & \\
Specific information from family member & 22.3 & 54.2 \\
& $18.5^{* *}$ & $53.3^{*}$ \\
\hline \hline Note $* * \mathrm{p}<0.10, * * \mathrm{p}<0.05, * * * \mathrm{p}<0.01$ &
\end{tabular}

Note: $* \mathrm{p}<0.10, * * \mathrm{p}<0.05, * * * \mathrm{p}<0.01$

\begin{abstract}
${ }^{a}$ Regret is a dummy variable with the value 1 for graduates who answered no to the question 'In retrospect, would you choose the professional college education you followed again?' and 0 for those who answered yes. In this table we multiply this by 100 and hence define the regret rate in percentages.

${ }^{b}$ Indicate in which way you formed an image of the education you followed or the profession you can practice with the education. Answer categories were: 1 . by the job or education of my father, 2. by the job or education of my mother, 3. by the job or education of other relatives, 4. by the job or education of friends, 5. by the media, 6. apprenticeship, 7. courses at school, 8. study counselor. The variable specific information from family members is a combination of the first three answer categories.
\end{abstract}

in a certain field, and talking to them about their experiences will improve the understanding of the work life in that job. In table 2.14 we show that students with relatives working in the field of their educational choice, indicate to regret their choice less (18.3\%, relative to $22.3 \%$ ) and to stay about 0.9 less months in their education.

\title{
2.4.3 Regret of length of stay in education
}

The third research question is whether imagination is related with regret of the length of stay in education. To answer this question, we included - as explained in the data section - in the DNB Household survey, two questions with which we are able to measure regret of the length of stay in education.

In table 2.15 we analyze with which characteristics regret of the timing of graduation is related. The first column in the table shows that people with more imagination regret the length of stay significantly less than those with lower imagination.

We included several other attributes in the regression. However, the second column shows that when we include these other attributes, our finding remains robust. Note also, that none of the other attributes shows to have any relation with regret. 
Table 2.15: Regret of length of stay in education

\begin{tabular}{|c|c|c|}
\hline & Regret of Stay & Regret of Stay \\
\hline Constant & $\begin{array}{c}-1.048 \\
(1.070)\end{array}$ & $\begin{array}{c}-1.318 \\
(1.149)\end{array}$ \\
\hline Male & $\begin{array}{c}-0.124 \\
(0.148)\end{array}$ & $\begin{array}{c}-0.088 \\
(0.170)\end{array}$ \\
\hline Age & $\begin{array}{c}0.037 \\
(0.027)\end{array}$ & $\begin{array}{c}0.043 \\
(0.030)\end{array}$ \\
\hline VMBO & $\begin{array}{c}0.358 \\
(0.695)\end{array}$ & $\begin{array}{c}0.409 \\
(0.733)\end{array}$ \\
\hline HAVO/VWO & $\begin{array}{c}0.146 \\
(0.731)\end{array}$ & $\begin{array}{c}0.166 \\
(0.767)\end{array}$ \\
\hline MBO & $\begin{array}{l}0.128 \\
(0.678)\end{array}$ & $\begin{array}{c}0.174 \\
(0.710)\end{array}$ \\
\hline $\mathrm{HBO}$ & $\begin{array}{c}0.624 \\
(0.676)\end{array}$ & $\begin{array}{c}0.722 \\
(0.713)\end{array}$ \\
\hline WO & $\begin{array}{c}0.845 \\
(0.680)\end{array}$ & $\begin{array}{c}0.886 \\
(0.716)\end{array}$ \\
\hline Imagination $^{a}$ & $\begin{array}{c}-0.204 * * * \\
(0.078)\end{array}$ & $\begin{array}{c}-0.211^{* *} \\
(0.087)\end{array}$ \\
\hline Impulsiveness & & $\begin{array}{l}0.039 \\
(0.088)\end{array}$ \\
\hline Risk aversion & & $\begin{array}{c}-0.038 \\
(0.083)\end{array}$ \\
\hline Discount rate & & $\begin{array}{c}0.019 \\
(0.085)\end{array}$ \\
\hline Anxiety & & $\begin{array}{c}0.101 \\
(0.109)\end{array}$ \\
\hline Self-image & & $\begin{array}{c}0.018 \\
(0.120)\end{array}$ \\
\hline Self-confidence & & $\begin{array}{c}-0.016 \\
(0.117)\end{array}$ \\
\hline
\end{tabular}

Note: $* \mathrm{p}<0.10, * * \mathrm{p}<0.05, * * * \mathrm{p}<0.01$.

Source: Supplement to DNB household panel 2004. Regret is defined by the difference between the questions "In which year did you finish your last education?" and "If you could plan the educations you followed in your life again, in which year would you have liked to have finished your education in retrospect?". VMBO, HAVO/VWO, MBO, HBO, WO are dummies being 1 if the respondent had one of these levels of education as highest diploma, and 0 otherwise. We exclude those who wanted in retrospect to have graduated later, and those who wanted to have graduated more than 5 years earlier than their actual age of graduation.

${ }^{a}$ Imagination is measured by the answer to 6 statements: 1 . I think about how things can be in the future and try to influence these in my every day life, 2. I am often occupied with things that will have an effect in several years, 3. I am only occupied with the present, assuming that things will be alright in the future (-), 4. With everything I do, I only think about the immediate consequences of these actions (days or weeks) (-), 5. I think it is important to take warnings about negative consequences of my actions seriously, even if these consequences would appear in the far future, 6 . I think it is more important to be occupied with things which will have important consequences in the future, than with things which have immediate but less important consequences. 


\subsection{Conclusions}

In this chapter, we analyze three implications of the theory that the discount rate is partly determined by the ability to imagine the future: (1) Variation in imagination between people can explain heterogeneity in discount rates, and for a given person, if certain results are imagined more vividly than other results, different discount rates will apply for different goods. (2) Students with less imagination will be less able to imagine working life than college life and will therefore discount the period after graduation more. As a consequence, they will procrastinate entrance to the labor market. (3) When the students enter the labor market, they receive a clear image of what it is like to be working. At this point in time, they can evaluate their choice to stay longer in education from a perspective in which imagination does not play a role. If the students stayed longer because they discounted working life more, those with less imagination will have a higher probability to regret delaying their entrance to the labor market.

To test the empirical relevance of the model, we use three custom-designed surveys. Our main findings are (1) a robust negative correlation between imagination and discount rates between people, and within people for different aspects of their lives. (2) We find evidence that college students with better imagination stay shorter in education. Additional evidence for our model is that graduates who plausibly obtained less information about their future working life because their parents are immigrants or they do not have any family members working in a related field report less satisfaction with their choice of study and stay in education longer. (3) We find that people with more imagination report less regret of the length they stayed in school.

We believe that our conclusions have important consequences for policy making which are different from those in standard time discounting models. If people with high discount rates would be making conscious decisions in favor of the present, there would be no reason to expect them in retrospect to regret their decision more. We argue that present oriented behavior is highly determined by a lack of imagination, and that people with high discount rates therefore regret their choices more.

We limit the discussion to choices about length of stay in education, but it seems obvious that our conclusions can be translated to other areas. For instance, many people who smoke, drink, use drugs and have other harmful habits show signs of regret by indicating that they would like to quit. Since Becker and Murphy (1988), present oriented harmful behavior has been interpreted as the result of people having high discount rates. Although present oriented behavior usually does not seem to be a deliberate choice from an outsiders perspective, it is a rational choice which limits the case for public interference. We argue instead that people care 
about their present more because they have a blurred vision of their future. ${ }^{22}$ This conclusion does encourage policy interventions.

Interventions in educational choices are very important since staying longer in education than necessary is very expensive. We calculated elsewhere that the costs of staying in education longer than the nominal duration amount to on average 5.3\% of GDP across several European countries (Borghans and Golsteyn 2007b).

Our findings raise several questions that could be addressed in future research. A first question is whether also in other investment settings, an effect of the power of imagination can be found. Power of imagination could be an important determinant of choices regarding healthy behavior, or of successful entrepreneurship. Secondly, what are the determinants of power of imagination, explaining why some students are more successful in their choices than others? Related to that one could wonder what measures could improve the power of imagination. Especially the hypothesis raised by Becker and Mulligan (1997) that education itself plays a crucial role in lowering the discount rate by improving the power of imagination, could be investigated to find a clue about the measures to improve the quality of investments.

${ }^{22}$ This is related to Orphanides and Zervos (1995) who argue that people who do not think "it could happen to them" are more addict-prone. 
3 Skill Transferability, Regret and Mobility 


\subsection{Introduction}

Human capital investments are typically made in a context of large uncertainty, since students choose their education before they have any serious experience of working in a related field. Among others, Freeman (1975), Siow (1984) and Zarkin (1985) have analyzed uncertainty with respect to market wages related to educational choices. As noted by Weiss (1971), the individual will face an even larger uncertainty regarding his individual preferences for possible occupations. Consequently, many graduates entering the labor market discover that the occupational field they have chosen does not suit them. The consequences of this uncertainty on further investments in human capital have remained unexplored.

The aim of this chapter is to analyze the effect of uncertainty before choosing the initial education on human capital investment decisions after graduation. ${ }^{1}$ In our model in section 3.3, students improve their insight about their occupational preferences and labor market prospects during the years they spend in education and during the time they enter the labor market. After graduation, they can choose whether and how intensely they will continue studying. At the same time, these graduates evaluate their choice of occupational field. Those who discover that another field better fits their personal preferences, and thus regret their initial choice, have an incentive to switch to this different field.

The key insight of the model is that the probability of graduates regretting their choice, switching from one field of education to another will increase when their education provides them with skills that can easily be transferred to other disciplines. If skill transferability is relatively high, these graduates are expected to be able to switch fields with only modest additional investments in human capital and without large losses in wages due to under-utilization of their human capital. When graduates who can less easily transfer their skills switch, it can be expected that larger investments in additional human capital are needed and that larger wage drops will be experienced.

Section 3.4 describes the data with which we evaluate the empirical support for the model: a sample of 2,675 Dutch graduates from higher education, approached three years after graduation. A graduate is defined as a switcher when the field in which he continued his education differs from his original field and/or if the graduate indicates that his occupation does not match his education. $29.5 \%$ of the graduates switch. To measure regret, we make use of

\footnotetext{
${ }^{1}$ This chapter is based on a joint work with Lex Borghans which is forthcoming in Applied Economics. We thank Arnaud Dupuy, Ben Kriechel, Edwin Leuven, Philip Marey, Derek Neal, Hessel Oosterbeek, Gerard Pfann, Catherine Ris, Wendy Smits, Rolf van der Velden, Maarten Vendrik, Bas ter Weel, seminar participants at the 2003 Human Capital Workshop at Maastricht University, the 2003 EALE conference in Seville and the 2003 Transitions in Youth conference at Madeira, the editor of Applied Economics and an anonymous referee for valuable comments and Christina Lönnblad for editorial assistance.
} 
a survey question covering exactly our theoretical concept of regret. We ask the graduates: "Looking back, if you were free to choose again, would you choose the same study program?" Approximately $17 \%$ of the graduates report that they regret their choice.

In section 3.5, we explain our empirical strategy. We estimate equations for the probability that a student switches after graduation, the loss of income if he switches and the additional training taken by those who switch. We use the fact that graduates who continue to study reveal latent information about the skill transferability of their original education. To measure differences in transferability, we therefore add separate dummies for 18 educational fields to each of the equations, mentioned above. In the second step we test the predictions of our model by comparing the estimates of the transferability parameters from these equations.

Consistent with the model, the empirical analysis in section 3.6 shows that conditional on regret, a high skill transferability increases the probability of switching from one field to another and that if graduates switch, they participate longer in education when transferability is lower. Furthermore, for those who change fields, wage losses are larger when transferability is lower. Hence, the results show that regret inflicts damage on a graduate's human capital and that this damage is reduced if skill transferability is higher. Concerning the magnitude of the damage, the results indicate that if wages are $1 \%$ lower due to lower skill transferability, the probability that a graduate who regrets his choice actually switches decreases by 2.2 percentage points, while those who do switch take on average 0.3 months additional education.

\subsection{Contribution to the literature}

Next to the contribution to the literature about uncertainty in educational choices, our analysis gives new insights into other areas. This chapter is related to the literature about the transition from school to work. Ryan (2001) and Müller and Shavit (1998), among others, analyze the labor market entrance of young workers, characterized by high rates of job turnover, high rates of unemployment and discrepancies between job requirements and skills acquired at school, from the perspective of the gap between college and work these graduates must bridge. In this chapter, we analyze the same transition period from the perspective that a pupil's image of working life differs from reality. From this perspective, educational choice is the crucial step, while only the consequences of earlier "mistakes" are revealed during the transition from school to work.

Furthermore our analysis contributes to the literature about training, since it adds repairing initial educational choices as a cause for training to the well-known arguments such as education-training complementarity (Heckman 2000, Brunello 2004) and depreciation of hu- 
man capital (Ben-Porath 1967, Rosen 1976). This literature on human capital formation is generally concerned with choices of education levels. In our analysis, we instead focus on the choice of a discipline.

The literature on educational mismatch focuses on the returns to schooling of graduates with a higher level of education than the level needed in their jobs. Sloane, Battu, and Seaman (1999) and Dolton and Vignoles (2000), among others, show that although surplus education gives some positive return, overeducated workers earn less than adequately allocated workers with a similar schooling. Groot (1996) shows that overeducated workers earn less and undereducated workers earn more than correctly allocated workers in the same jobs. Controlling for measurement error, Robst (1994) finds there to be no returns to excess schooling. McGuinness (2003) shows that wage gaps would still occur even if workers were perfectly matched to jobs due to disproportionate returns associated with the successful attainment of certain categories of jobs. Büchel and Mertens (2004) find that overeducation leads to lower relative wage growth. Hersch (1991) finds that overqualified workers are more likely to quit, are less satisfied with their jobs and take less training. Defining mismatch as a difference between the field of study required and actual field of study from which the individual has graduated, Heijke, Meng, and Ris (2003) find that graduates with more generic competencies are more likely to be mismatched and involved in training. The characteristic feature of these mismatch models is that workers are randomly assigned to jobs (Jovanovic 1979, Sauer 1998). This random assignment produces a mismatch because some workers lack the appropriate skills. While this is an effective assumption when investigating how workers are affected by a mismatch, this theory does not give any insight into the reasons for the mismatch. In our model, graduates decide whether they leave their initial education. Because our model is more explicit about the nature of the mismatch, it provides an important complement to the mismatch theory.

Our idea is linked with the literature on occupational mobility. However, a large part of the literature on occupational mobility assumes that workers can practically change jobs as often as they want and that they even use this opportunity to discover their career preferences. For instance, Neal (1999) and Miller (1984) find that young workers choose to switch often to find their optimal career path. Topel and Ward (1992) show that adjustments are mainly made by the group of new entrants as a trial-and-error process, while Sicherman and Galor (1990) analyze job changes that are an integral part of workers' careers. This means that a worker does not leave because he is mismatched, but because he intended to leave from the outset. Our analysis focuses on a switch to an entirely different field of occupations instead of a switch between two jobs within a field of occupations. Therefore, in our analysis, the loss of human capital due to switching becomes crucial. In some studies on job mobility, the loss of human 
capital has been studied more specifically. Shaw (1984) investigates mobility between sectors and finds that occupational skills are only partially transferable with occupational change. In standard wage equations, occupational experience therefore far better predicts the wage than overall experience. We find similar results for educational skills, which means that human capital accumulated through education is also field specific and that some skills are lost when switching from one field to another. Furthermore, Neal (1998), Bils (1985) and McLaughlin and Bils (2001) find that more able workers change jobs less often, because they have a higher loss of job-specific skills.

\subsection{The model}

Consider a pupil ${ }^{2}$ who starts to study. In his career, three periods can be distinguished. The first period comprises a constant $s_{1}$ years of full-time education. At the start of period 1, the pupil decides which field of education to attend. The educational decision is based on the maximization of expected utility of the professions he could practice after studying. ${ }^{3}$ This utility is derived from intrinsic (the extent to which he likes his job) and extrinsic (income) factors. At this point in time, the student is still uncertain about both his preferences and the income he can expect. We assume the intrinsic factors $\left(I_{k}\right)$ to depend on occupation ${ }^{4} k$ and to be constant over time, ${ }^{5}$ and annual wage $\left(Y_{t}\right)$ to be derived from human capital. ${ }^{6}$ Wages $Y_{t}=\pi_{k} H_{t}(s)(1-v)$ are a combination of the amount of knowledge gathered by the student $H_{t}(s)=s^{\theta}$ (where $\theta(0 \leq \theta<1)$ reflects the decreasing marginal revenues of education), the occupation-specific return (market value) of this knowledge $\left(\pi_{k}\right)$ and the time spent working $(1-v)$. The fraction $v$ of time not spent working is used for further education or training. We assume the elasticity of substitution between intrinsic and extrinsic factors to be unity. Therefore, people tend to like a profession more if they can earn a higher wage from it, and vice versa. ${ }^{7}$ The only costs of education are foregone earnings and switching between different fields of education is not possible in period 1. For simplicity, we also assume the interest rate to be 0 (future earnings are not discounted) and the wage is independent of work experience. The utility of the student/worker equals:

\footnotetext{
${ }^{2}$ We use the term "pupil" to indicate an individual who is in secondary school, "student" to indicate a person who attends college and "graduate" to indicate that one has successfully finished college.

${ }^{3}$ For simplicity, utility can only be derived from working and not from studying.

${ }^{4}$ In our model we use this subscript also to indicate the field of education.

${ }^{5} \mathrm{We}$ assume that the pupil bases his choice on an estimation of $I_{k}$ and is not yet aware of the true value of his preferences. While his perception of his true preferences might change, his true preferences are constant.

${ }^{6}$ Individual subscripts are excluded from the model.

${ }^{7}$ An additive version of the model $\left(U=\sum_{t} I_{k}+Y_{t}\right)$ gives similar results.
} 


$$
U=\sum_{t} I_{k} Y_{t}
$$

When the individual graduates, he enters period 2. The length of period 2 is $s_{2}$ years. This length is also assumed to be constant. Unlike the pupil at the beginning of the first period who was characterized by uncertainty, due to his study and early labor market experience, the graduate knows his labor market position and whether he likes his discipline at the beginning of period 2. Therefore, the graduate can evaluate his choice of education and decide whether to stay in his original discipline (working and/or studying) or switching to a different one. If the graduate switches, skills from his initial field of education can be transferred to the other field of education. This implies that the amount of knowledge $(H)$ depends on the skill transferability, $\zeta_{k}$, which is specific for each field of study. ${ }^{8}$ If $\zeta_{k}=0$ switching involves a total re-start, if $\zeta_{k}$ increases, skills become more transferable. In period 2 , the graduate can choose the intensity of studying $(v)$. After period 2, no more studying is possible and the individual will work for $n$ years in the profession linked to the last education taken. A person retires at $T=t_{0}+s_{1}+s_{2}+n$, where $t_{0}$ is the age at which a person starts his education. The effect of human capital acquired at school is assumed to only become effective for the wage at the end of each period (when a diploma is obtained). Figure 1 and 2 show the behavior of graduates in time frames when they remain in their own discipline and switch to another, respectively.

Figure 1

Career path of the graduates who do not switch field of education

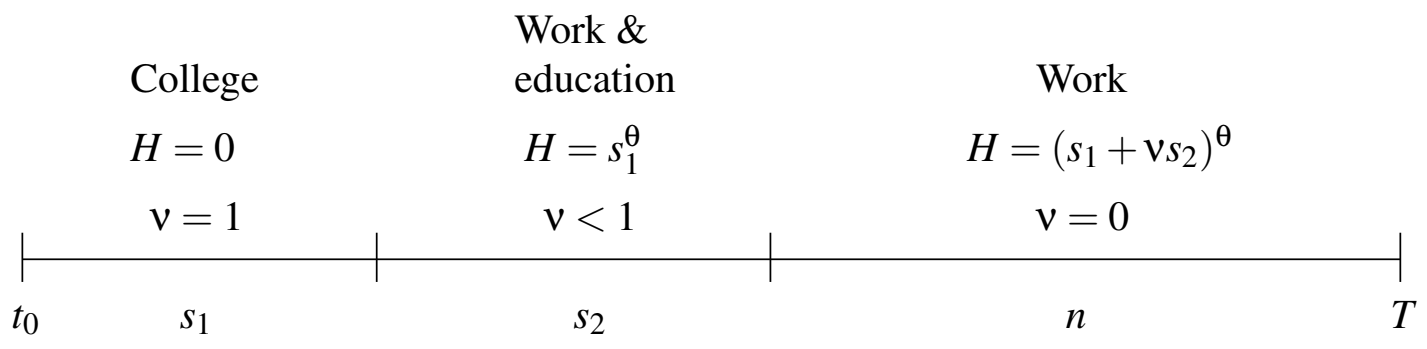

\footnotetext{
${ }^{8}$ We assume a general skill transferability between educations and leave non-symmetric skill transferabilities between educations for future research.
} 
Figure 2

Career path of the graduates who switch field of education

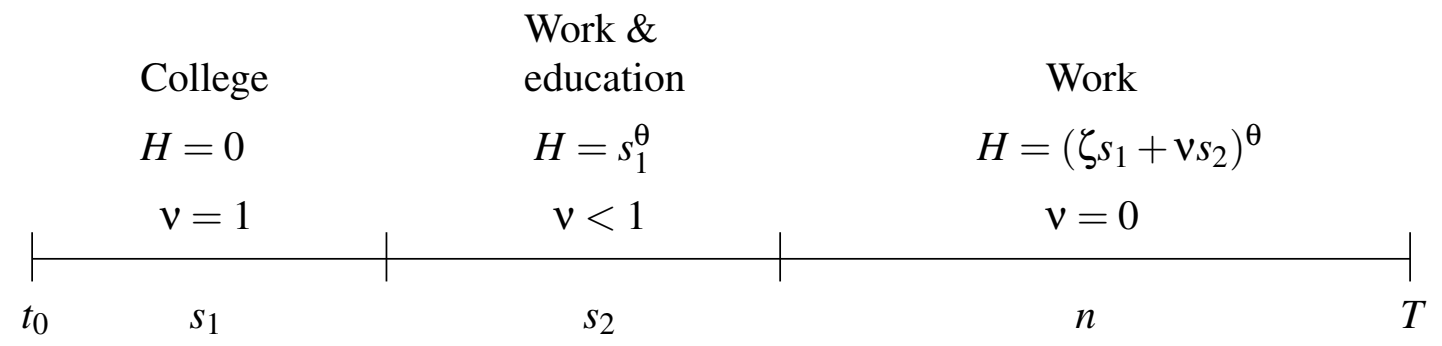

The individual's utility in a specific period can be described by:

$$
U_{t}=\left(1-v_{t}\right) I_{k} \pi_{k} H\left(s_{t}\right)
$$

with $v_{t}=1$ in period $1, v_{t}=v$ in period 2, and $v_{t}=0$ in period 3. Let us first consider what the graduate's utility will be if he stays in his educational field $k$. In this case, skills are perfectly transferable $\left(\zeta_{k}=1\right)$, since the individual has no human capital in period $1\left(H\left(s_{0}\right)=\right.$ 0 ) and since $v=1$ in period 1 and $v=0$ in period 3 , and utility thus becomes:

$$
\begin{aligned}
U_{k} & =\sum_{t=0}^{s_{1}} 0 * I_{k} \pi_{k} H\left(s_{0}\right)+\sum_{t=s_{1}}^{s_{1}+s_{2}}(1-v) I_{k} \pi_{k} H\left(s_{1}\right)+ \\
& +\sum_{t=s_{1}+s_{2}}^{T} 1 * I_{k} \pi_{k} H\left(s_{1}+v s_{2}\right) \\
& =s_{2}(1-v) I_{k} \pi_{k} s_{1}^{\theta}+n I_{k} \pi_{k}\left(s_{1}+v s_{2}\right)^{\theta} .
\end{aligned}
$$

The first part of function 3.3 defines the utility that can be gained in period 2, in which the individual can earn an income $s_{1}^{\theta}$ by working $(1-v) s_{2}$ and the second part is the income he gets in period 3 as a result of his study efforts in periods 1 and 2. 
The optimum amount the individual can study in his original discipline in period 2 can then be derived from the first-order condition for maximizing utility with respect to $\mathrm{v}$ :

$$
s_{2} \mathrm{v}_{k}=\left(\frac{n \theta}{s_{1}^{\theta}}\right)^{\left(\frac{1}{1-\theta}\right)}-s_{1}
$$

This function shows that the study time in period 2 increases if the (expected) working life is longer. As opposed to this, if the income to be gained from period 1 education $\left(s_{1}^{\theta}\right)$ increases, study efforts in period 2 decrease.

Utility from the option to switch to another discipline $j$, can be derived analogously to the above. The difference is that $\zeta_{k}$ does not have to be equal to one:

$$
U_{j}=(1-v) s_{2} I_{k} \pi_{k} s_{1}^{\theta}+n I_{j} \pi_{j}\left(\zeta_{k} s_{1}+v s_{2}\right)^{\theta}
$$

Equation 3.5 takes into account that the amount of human capital decreases if the transferability decreases. Moreover, utility during working time in the third period is now dependent on the intrinsic valuation of the second education. ${ }^{9}$ Maximizing this function with respect to $\checkmark$ gives:

$$
s_{2} v_{j}=\left(\left(\frac{I_{j}}{I_{k}}\right)\left(\frac{\pi_{j}}{\pi_{k}}\right)\left(\frac{n \theta}{s_{1}^{\theta}}\right)\right)^{\frac{1}{1-\theta}}-\zeta_{k} s_{1}
$$

Function 3.6 shows that if the skill transferability from education $k$ in the first period to education $j$ in the second period increases, study efforts in the second period decrease. If the intrinsic value of $j$ is relatively large as compared to the intrinsic value of $k$, the study efforts in $j$ will increase. The reason for this is that the intrinsic utility from working in $k$ is lower, which reduces the opportunity costs for additional education. This is a consequence of the specification of the utility function where intrinsic value and money are not fully substitutable. With an additive utility function, this effect disappears.

By substituting the optimal duration of education in $U_{k}$ and $U_{j}$, the choice to switch or not can be derived. Utility in $j$ will be larger than or equal to utility in $k$ if:

\footnotetext{
${ }^{9}$ This is due to our assumption that graduates start working in the latest chosen profession.
} 


$$
\left(\frac{I_{j}}{I_{k}}\right)\left(\frac{\pi_{j}}{\pi_{k}}\right) \geq\left(1+\frac{\theta}{1-\theta}\left(1-\zeta_{k}\right) s_{1}\left(\frac{s_{1}^{\theta}}{n \theta}\right)^{\frac{1}{1-\theta}}\right)^{1-\theta}
$$

In 3.7, the combination of the ratios on the left-hand side gives information about the individual's difference in ex ante and ex post perception regarding the disciplines. If the left-hand side is smaller than unity, ex post information points in the same direction as ex ante information, namely that education $k$ is the best education for the individual. If the combination of the ratios exceeds unity, however, the information after graduation points out that in retrospect, $j$ instead of $k$ would have been the better educational choice. The graduate then regrets his initial choice. The difference between ex ante and ex post utility can either stem from an overestimation of the labor market perspectives of education $k$ relative to $j$, or because the graduate simply underestimated how much he liked $j$ relative to $k$.

Second, the right-hand side of the equation exceeds unity if $\zeta$ is smaller than unity. If $\zeta$ is greater than unity, the right-hand side is smaller than unity. Hence, if the left-hand side is larger than unity and also larger than the right-hand side, a graduate who regrets his choice will switch from $k$ to $j$. A graduate who does not regret his initial education will switch if $\zeta_{k}>1 .{ }^{10}$ Hence, conditional on the amount of regret of a graduate, the skill transferability of education $k$ determines whether a graduate will switch.

Before the start of period 1, students must choose an educational field. At that point in time, they have no perfect information about their own preferences. Denoting the expected preferences by $\hat{I}_{j}$ implies that if $\zeta_{k}$ were equal for all $k$, they would choose $k$ if $\hat{I}_{k} \pi_{k}>\hat{I}_{j} \pi_{j}$. However, if $\zeta_{k}$ 's differ between fields of study and students realize that they face uncertainty regarding their professional preferences, students close to the break-even point will tend to choose the field of study with a higher $\zeta_{k}$. Fields of study with a higher skill transferability will therefore attract more uncertain students and the frequency of regret will be higher in these fields.

\footnotetext{
${ }^{10}$ This may occur if a profession demands skills from different educations. Changing education then becomes a prerequisite for working in such a profession, not a correction of the original choice. Next to this, switching can also be explained by a consumption effect when some studies provide much direct utility but do not offer interesting job opportunities. For simplicity, we assume in our model that utility can merely be derived from an education while working. Extensions including consumption motives from education do not affect the empirical results.
} 


\subsection{Data description and definitions}

The data used in the analysis are taken from the Dutch 1998 CHEERS survey. In this survey, graduates from higher vocational education and university are approached three years after their graduation in 1995. ${ }^{11}$ Since we want to focus our analysis on regular students, we selected those aged below $35 .{ }^{12}$ 2,675 graduates remain. Their average age is 28.7 years, $56 \%$ are female, $80.5 \%$ are working with an average wage of 11.1 euros/hour.

The survey is unique for our purposes because it contains information on the (initial) chosen discipline, the discipline(s) studied in the three years after the initial education, the relation between the graduate's job and his education, the duration of the time spent studying after the original discipline and the level of regret of the original field of study.

In table 3.1, the shares of respondents are reported by original educational field of study. The initial field of study is defined by the education finished in 1994/1995. The disciplines are classified by two-digit ISCED codes. As can be seen in the table, only $0.5 \%$ had followed a Life Science education, $0.1 \%$ Manufacturing and Processing and $0.4 \%$ a Veterinary education. These groups are excluded from the analysis. In the analyses, we use Teaching as the reference group.

After graduation, respondents are able to continue their studies in the same or another field of study in the regular educational system or attend courses. In the survey, they are asked "Have you followed a course/training with the intention of substantially increasing or broadening your professional qualifications?" Therefore, courses and training for (hobby or other) non-work related purposes are not taken into account in the analysis. Both the disciplines of the regular education and the courses/training are classified with two-digit ISCED codes. A comparison of the discipline chosen after graduation with the initial field of study, determines whether the graduate switches from one field to another. Here, the implicit assumption is that a switch will be observed when there is a change in the contents of the education. Since each educational field is a combination of a number of detailed educational titles, it is possible that some individuals move between relatively different educations in the same field with no change observed, while others move between relatively similar educations that fall into different fields and a switch will be observed. We assume that, on average, graduates who move across categories experience a larger change of the contents of their education than those moving across educations within a field. $18.7 \%$ of the graduates continued their education in a different field. Besides a move from one education to another, it is possible that a graduate switches without additional education. He might start working in a job not related to his ed-

\footnotetext{
${ }^{11}$ Therefore, the duration of further education is not only truncated at zero but also at three years.

${ }^{12}$ The results do not change qualitatively when all graduates are included.
} 
Table 3.1: Distribution of respondents over disciplines in original education

\begin{tabular}{l|c}
\hline \hline Disciplines & Percentage \\
\hline & \\
Teacher education and education science & 10.8 \\
Arts & 3.9 \\
Humanities & 4.6 \\
Social and behavioral science & 6.5 \\
Journalism and information & 2.6 \\
Business and administration & 21.0 \\
Law & 5.0 \\
Life science & 0.5 \\
Physical science & 1.9 \\
Mathematics and statistics & 0.8 \\
Computing & 3.4 \\
Engineering and engineering trades & 9.0 \\
Manufacturing and processing & 0.1 \\
Architecture and building & 3.4 \\
Agriculture and forestry & 3.0 \\
Veterinary & 0.4 \\
Health & 10.8 \\
Social services & 7.3 \\
Personal services & 3.5 \\
Transport services & 0.7 \\
Environmental protection & 0.8 \\
& \\
\hline Total & 675 \\
Number of graduates & \\
\hline Source: CHEERS, 1999 & \\
\hline
\end{tabular}

ucation and acquire the necessary skills on the job. Therefore, we extended the definition of switching by taking into account those graduates indicating that their job does not require the skills learned in college. The question asked is to what extent working people make use of the knowledge and skills acquired in the education finished in 1994/1995. The answer categories vary from "not at all" (1) to "to a very high extent" (5). If graduates were not at all (1) or to a small extent (2) making use of their skills, we added them to our population of switchers. ${ }^{13}$ It can be seen from table 3.2 that $14.7 \%$ of the working graduates are not working in a related field. In total, the number of switchers therefore equals $29.5 \%$. Background information concerning switching can be found in table A1.

In table A2, information is given about the origin and direction of the switchers. In our analysis, we use dummies for the education from which the graduate originates to estimate the transferability parameters. We do not take into account towards which field the graduate switches. The average distance is measured by skill transferability.

The survey asks the length for each training expressed in months. When respondents participate in regular education, the exact beginning and ending dates are asked. ${ }^{14}$ One year of

\footnotetext{
${ }^{13}$ In the robustness analysis, we investigate the effect on the results when switching is defined differently.

${ }^{14}$ There is no information available about the intensity of training or education in hours per week.
} 
Table 3.2: Usage of skills acquired by the initial education in current profession

\begin{tabular}{l|c}
\hline \hline Usage of skills in profession & Number of graduates \\
\hline & 133 \\
Not working & 34 \\
Not at all & 340 \\
Very little & 846 \\
Sometimes & 997 \\
Often & 325 \\
All the time & \\
\hline Total & 2,675 \\
\hline
\end{tabular}

Table 3.3: Number of respondents continuing education in same or different field and mean duration of further education

\begin{tabular}{l|rcc}
\hline \hline & Response & $\begin{array}{c}\text { Length of stay in further education } \\
\text { Initial field } \\
\text { (months) }\end{array}$ & $\begin{array}{c}\text { Other field } \\
\text { (months) }\end{array}$ \\
& & & \\
\hline No further education & 1,783 & 0.0 & 0.0 \\
Same field & 391 & 19.8 & 0.0 \\
Other field & 454 & 0.0 & 12.7 \\
Same and other field & 47 & 13.5 & 14.2 \\
& & & \\
\hline \hline
\end{tabular}

education is recoded into 12 months. Since people in general consider their formal education as more important than their training and training is often combined with work, we valued the intensity of training as half the intensity of regular education by multiplying the duration by .5 . Table 3.3 reports the number of respondents which continued to study and the average number of months that they on average spent in their continued education. The first column shows that $30 \%$ of the respondents continued to study after their initial education. About half the graduates chose to study a different topic than the original discipline. Moreover, a very small amount of graduates continued to study both in their original discipline and in another discipline. In our analysis, we included these with the graduates who switched. Those who stayed in the same field studied on average 19.8 months after graduation, while those who continued in a different field stayed on average 12.7 months after graduation.

Furthermore, in a section with questions on the field of education from which the person graduated in 1994/95, the respondents are asked: "Looking back, if you were free to choose again, would you choose the same study program?" The answers are scaled from "very probable" (1) to "not likely at all" (5). This variable is interpreted as the regret one has of studying 
Table 3.4: Regret of initial education and switching behavior

\begin{tabular}{l|cccc}
\hline \hline & & & \\
Level of regret & Response & Percentage & \% switch & \% no switch \\
\hline & & & \\
No regret & 732 & 27.4 & 21.7 & 78.3 \\
Little regret & 1,029 & 38.5 & 26.6 & 73.4 \\
Neutral & 452 & 16.9 & 32.5 & 67.5 \\
Regret & 314 & 11.7 & 37.9 & 62.1 \\
Strong regret & 148 & 5.5 & 60.8 & 39.2 \\
& \multicolumn{5}{l}{} \\
\hline Total & 2,675 & 100.0 & 70.5 \\
\hline
\end{tabular}

in the original discipline. ${ }^{15}$ Table 3.4 shows the level of regret from the original education. Most respondents are happy with their choice, but about $17 \%$ are dissatisfied. Other surveys provided similar percentages of regret. It can be noted that the number of respondents changing disciplines increases with an increase in the level of regret. More information on the regret variable is given in the appendix. Table A3 shows that graduates with an Environmental protection or education in Journalism regret their choice most.

\subsection{Empirical strategy}

The model shows skill transferability to be related to (1) the probability of switching (positively), (2) the duration of education if one switches (negatively) and (3) the value of acquired human capital in another field of education (positively). Since skill transferability cannot be directly observed, we will identify the model by assuming the transferability of human capital to vary between fields of study. The empirical strategy is to estimate each of the three relationships mentioned above, using dummies for fields of study. This means that we apply a random coefficient approach where the transfer parameter in each equation depends on educational dummies plus an error term. Since the estimated parameters of these dummies reflect the same theoretical concept "transferability", this allows us to test the model by comparing the estimates of the three equations.

\footnotetext{
${ }^{15}$ The concept of regret as defined in regret theory (introduced into economic theory by Loomes and Sugden (1982), Bell (1982) and Fishburn (1982)) fits closely to our definition. While utility directly depends on the level of regret in regret theory, utility here only depends on actual consumption and job satisfaction. In regret theory, people therefore try to avoid a situation of regret, while in our model, people just try to maximize utility.
} 


\subsubsection{Switching between fields of education}

Rewriting 3.7 yields

$$
s^{*}=\left(\left(\frac{I_{j}}{I_{k}}\right)\left(\frac{\pi_{j}}{\pi_{k}}\right)\right)^{\frac{1}{1-\theta}}-1-\frac{\theta}{1-\theta}\left(1-\zeta_{k}\right) s_{1}\left(\frac{s_{1}^{\theta}}{n \theta}\right)^{\frac{1}{1-\theta}}
$$

where the graduate will switch if and only if $s^{*}>0$. Assuming $\theta$ to be relatively small, equation 3.8 can be linearized and a straightforward expression for the decision to switch can be obtained. The constants are collected in $\beta_{0}$. Because the labor market value of education is essentially reflected in a diploma and not in years of education (being a slow student is not a positive asset), we assume that the value of the initial education within the same discipline does not depend on duration. Therefore, $n \theta / s_{1}^{\theta}$ is rewritten as a constant $(\lambda){ }^{16}$ We assume the relative attractiveness of the alternative $j$ to $k$ to be a linear function of regret as measured in our survey: $\left(\frac{I_{j}}{I_{k}}\right)\left(\frac{\pi_{j}}{\pi_{k}}\right)=\tau_{0}+\tau_{1} *$ regret $+\varepsilon .{ }^{17}$ Because of the binary nature of the variable $s^{*}$, we write the function in logit form. Following from 3.8, the $\zeta$-parameters have a positive relation with switching and are conditional on the level of regret. To identify the transferability for each educational discipline, we include dummy variables for the (initial) fields of study $(e d u c): \zeta_{i}=\zeta_{0}+\sum_{k=2}^{k=18} \zeta_{k} * e d u c_{k}+\varepsilon$. $\varepsilon$ is assumed to have a logistic distribution. As explained above, we include interaction terms in the switching equation, separately estimating the educational dummies for graduates with low levels of regret $\left(R_{0}\right.$, regret $=1$ or 2$)$ and graduates with higher levels of regret $\left(R_{1}\right) . X$ denotes the control variables gender, age and age-squared. ${ }^{18}$

$$
\begin{aligned}
s^{*} & =\beta_{0}+\beta_{1} * X+\beta_{2} * \text { regret }+R_{0} * \sum_{k=2}^{k=18} \zeta_{k}^{s_{0}} * e d u c_{k}+ \\
& +R_{1} * \sum_{k=2}^{k=18} \zeta_{k}^{s_{1}} * e d u c_{k}+\varepsilon \\
\text { Switch } & =0, s^{*}<0 \\
\text { Switch } & =1, s^{*}>0
\end{aligned}
$$

\footnotetext{
${ }^{16}$ Note that this also implies that $s_{1}$ is a constant.

${ }^{17}$ For simplicity of notation, $\varepsilon$ is used in the equations in this chapter to indicate the error term. This does not imply that we impose the error terms from different equations to be the same.

${ }^{18}$ The results are similar if the transferability parameters are not conditional on regret.
} 


\subsubsection{Duration of further education}

Using the same assumptions and by linearizing, equations 3.4 and 3.6 reduce to 3.10 and 3.11 respectively, where $D_{n s}$ equals the study duration for those who do not switch and $D_{s}$ the duration for those who switch, i.e.

$$
D_{n s}=\lambda-s_{1}+\varepsilon
$$

and

$$
D_{s}=\gamma_{0}+\gamma_{1} * \text { regret } * \lambda-\zeta_{k} s_{1}+\varepsilon
$$

The duration function for those who do not switch reduces to a constant as shown in equation 3.10. The duration function for switchers also includes the amount of regret and the transfer parameter $\zeta_{k}$.

To identify the transferability of human capital, we include dummy variables for the educations. The constants $\lambda$ and $\zeta_{0}$ can be integrated with $\gamma_{0}$ leading to a new constant $c$. The duration function for those who switch then reduces to a linear function of a constant, the regret variable, dummies for the disciplines and an error term.

Naturally, there might be other factors influencing the duration of additional education that differ between fields of study. To correct the differences in the transferability parameters for this for the non-switchers, we take the deviations of the transferability parameters in the switchers' duration function relative to the parameters in the non-switchers' duration function. This is done by estimating a system where the $\eta$ parameters, being the correction for the true $\zeta$ parameters, appear in both duration functions. We also include the regret variable in the duration function for those who do not switch to test if, as in the mathematical model, the duration for non-switchers is not affected by this variable. As in our theoretical model, we truncated the duration functions at zero. This yields

$$
\overline{D_{s}}=c+\gamma_{0} * X+\gamma_{1} * \text { regret }+\sum_{k=2}^{k=18} \eta_{k}^{d} * e d u c_{k}-\sum_{k=2}^{k=18} \zeta_{k}^{d} * e d u c_{k}+\varepsilon
$$

and 


$$
\bar{D}_{n s}=c+\eta_{0} * X+\eta_{1} * \text { regret }+\sum_{k=2}^{k=18} \eta_{k} * e d u c_{k}+\varepsilon
$$

where

$$
\begin{gathered}
D_{(n) s}>0 \rightarrow D_{(n) s}=\bar{D}_{(n) s} \\
D_{(n) s}<0 \rightarrow D_{(n) s}=0 .
\end{gathered}
$$

\subsubsection{Wage}

Switching from one field to another will lead to a loss of human capital. The more transferable skills acquired during the first period of education are, the less the individual will suffer from this loss of human capital. Therefore, we estimate a wage equation that includes dummies for each field of study and an interaction term for each field that equals 1 only when the graduate has switched. The corresponding parameters reflect the relationship between transferability and wage, conditional on switching fields of study. In addition to the usual control variables, we include tenure. Furthermore, we included the regret variable to check whether it has an impact on the wage. We separated this variable for those who do not switch, $S_{0}$, and those who switch, $S_{1}$ (dummy variables). The wage function can then be written as:

$$
\begin{aligned}
\log (\text { wage }) & =\kappa_{0}+\kappa_{1} * X+\kappa_{2} * \text { tenure }+\kappa_{3} * S_{0} * \text { regret }+\kappa_{4} * S_{1} * \text { regret }+ \\
& +\sum_{k=2}^{k=18} \kappa_{k} * e d u c_{k}+\sum_{k=1}^{k=18} \zeta_{k}^{w} *\left(e d u c_{k} * \text { switch }\right)+\varepsilon .
\end{aligned}
$$

In our model, the wage consists of the product of human capital $(H)$ and the value of human capital $(\pi)$. Limited transferability of skills will diminish the amount of human capital. However, we measure the wage rather than the amount of human capital. Regret can be related to discrepancies between perception and reality of both the intrinsic valuation and the market value of human capital in a certain field. As far as people switch field because of changes in market value, transfer losses of changing occupations will be underestimated when using a wage equation. Only when intrinsic motives are the main determinant of occupational 
mobility immediately after graduation, these wage effects will be an adequate measure of transferability. Since the data of the survey reveal that mobility is to a large extent driven by intrinsic aspects, we expect the wage effects to reveal the transferability of skills.

\subsubsection{The second step: Identifying transferability}

We expect to find that the transferability-parameters of the switch equation 3.9, the duration equation 3.12 and the wage equation 3.14 are all determined by the same underlying skill transferability. Allowing for scale differences and some measurement error, this means that $\zeta_{k}^{d}=\alpha_{0}^{d}+\alpha_{1}^{d} \zeta_{k}+\varepsilon^{d}, \zeta_{k}^{s_{0}}=\alpha_{0}^{s_{0}}+\alpha_{1}^{s_{0}} \zeta_{k}+\varepsilon^{s_{0}}, \zeta_{k}^{s_{1}}=\alpha_{0}^{s_{1}}+\alpha_{1}^{s_{1}} \zeta_{k}+\varepsilon^{s_{1}}$ and $\zeta_{k}^{w}=\alpha_{0}^{w}+\alpha_{1}^{w} \zeta_{k}+\varepsilon^{w}$. As a consequence, all four estimated transferability dummies must be positively related. This implies that transferability has a negative coefficient in the duration equation and a positive one in the switch equation and that our assumption holds that the loss of human capital increases, conditional on a switch, when transferability is low. To test this, we first compute the separate equations. From each equation, we find 17 transferability parameters (one for each field of study except the reference category). The relation between these parameters is tested by weighted least squares. We weigh by the number of graduates per educational discipline to take into account the heteroscedasticity of these estimates. Hence,

$$
\begin{gathered}
\zeta^{s_{0}}=v_{0}+v_{1} * \zeta^{d}+\varepsilon, \\
\zeta^{s_{1}}=\psi_{1}+\psi_{1} * \zeta^{d}+\varepsilon, \\
\zeta^{d}=\mu_{0}+\mu_{1} * \zeta^{w}+\varepsilon, \\
\zeta^{s_{0}}=\omega_{0}+\omega_{1} * \zeta^{w}+\varepsilon, \\
\zeta^{s_{1}}=\phi_{0}+\phi_{1} * \zeta^{w}+\varepsilon, \\
\zeta^{s_{0}}=\rho_{0}+\rho_{1} * \zeta^{s_{1}}+\varepsilon .
\end{gathered}
$$

To be consistent with the theoretical model, $v_{1}, \psi_{1}, \mu_{1}, \omega_{1}, \phi_{1}$ and $\rho_{1}$ must be positive. Since the estimates of the transfer parameter all contain measurement error this test of the consistency of the model does not provide any unbiased estimates of the relationship between the probability to switch (for those who regret their choice and those who do not regret their choice), the duration of additional education and wage losses. All four estimates provide a measure of transferability without any a priori scale. Since it is interesting to get an indication 
about the size of these effects, we also estimate the equations, each linking two measures of transferability, using a third measure as an instrument. Assuming the measurement errors to be uncorrelated, this provides unbiased estimates of the parameters.

\subsection{Results}

The estimation results are shown in table A4. The first column reports the estimation results from the switching equation. These results reveal a significant relationship between regret and the decision to switch to another field after graduation. Compared to Teachers, there are fields of study for which the probability to switch is significantly lower conditional on regret, but there are also fields of study with a significantly higher probability to switch. Since we measure the relative impact of transferability on the probability to switch, this measure can only be ordinally interpreted, so that 0 and 1 have no specific meaning.

In the second and third column, the parameter estimates of the time graduates spent on further education are presented. Here, regret has no significant effect on the duration of education. In the model, this relationship resulted from the complementarity between the intrinsic and the extrinsic value of a job. As a result for graduates who like a certain job less, the utility loss of forgone income in this job is also lower. The estimation results indicate that such interaction does not exist or is at least not strong enough to be significant. In the fourth column, we report the estimates of the wage function. Tenure and age have the usual impact on wage and men earn more than women.

From the perspective of our model, it is not only crucial that regret induces switching, but also that skill transferability determines whether graduates regretting their choice actually change fields and, when they switch, how much human capital they lose and how much education they take to compensate for this loss. Since we use educational dummies as proxies for skill transferability, this implies that the relative size of these dummies has to be consistent between the different equations. In a second step, we test the relationship between these dummies by weighted (by the number of graduates per educational discipline) least squares regressions to take the heteroscedasticity of the estimations into account. Table 3.5 shows that the relation between the transferability parameters in the equations can be confirmed. Therefore, the data are consistent with the assumption that people lose human capital when they switch and that skill transferability has both a positive effect on switching and a negative effect on the investment in education for those who switch.

In theory, the coefficients in table 3.5 also provide information about the relative size of the effect distinguished in the model. The coefficients are biased, however, due to the fact that both 
Table 3.5: Correlation between transferability parameters (St. Error in parenthesis)

\begin{tabular}{|c|c|c|}
\hline & Coefficient & $\mathrm{R}$-squared \\
\hline $\begin{array}{l}\text { Model } 1 \text { (dependent=Switch without regret) } \\
\text { Intercept } \\
D_{s}\end{array}$ & $\begin{array}{l}0.184 * * * \\
(.010) \\
0.073 * * * \\
(0.001)\end{array}$ & 0.525 \\
\hline $\begin{array}{l}\text { Model } 2 \text { (dependent=Switch with regret) } \\
\text { Intercept } \\
D_{s}\end{array}$ & $\begin{array}{l}0.029^{* *} \\
(0.011) \\
0.056^{* * *} \\
(0.002)\end{array}$ & 0.325 \\
\hline $\begin{array}{l}\text { Model } 3 \text { (dependent=Wage) } \\
\text { Intercept } \\
\text { Duration of } \text { training }\end{array}$ & $\begin{array}{l}-0.265 * * * \\
(0.004) \\
0.019 * * * \\
(0.001) \\
\end{array}$ & 0.301 \\
\hline $\begin{array}{l}\text { Model } 4 \text { (dependent=Wage) } \\
\text { Intercept } \\
\text { Switch without regret }\end{array}$ & $\begin{array}{l}-0.332 * * * \\
(0.003) \\
0.174 * * * \\
(0.006) \\
\end{array}$ & 0.260 \\
\hline $\begin{array}{l}\text { Model } 5 \text { (dependent=Wage) } \\
\text { Intercept } \\
\text { Switch with regret }\end{array}$ & $\begin{array}{l}-0.319 * * * \\
(0.003) \\
0.183 * * * \\
(0.006)\end{array}$ & 0.272 \\
\hline $\begin{array}{l}\text { Model } 6 \text { (dependent=Switch without regret) } \\
\text { Intercept } \\
\text { Switch with regret }\end{array}$ & $\begin{array}{l}0.038 * * * \\
(0.005) \\
0.922^{* * *} \\
(0.009)\end{array}$ & 0.803 \\
\hline
\end{tabular}

\footnotetext{
Source: CHEERS, 1999

The estimates in this table show the relations between the transferability parameters. All relations are regressed separately by weighted least squares.
}

$* \mathrm{p}<0.10, * * \mathrm{p}<0.05, * * * \mathrm{p}<0.01$ 
the explanatory and the dependent variable contain measurement error. To correct for this, we use IV-estimators (not shows in table 3.5). Assuming the error terms in each set of dummies to be independent from other sets, for each equation we use the other sets to instrument for this measurement error. Taking a linear approximation of the logistic switching function at the average of .25 for those who do not regret their choice and .39 for those who regret, we find that when graduates who switch take one additional month of training due to lower skill transferability, the probability of switching is $1.8 \%$ lower for those who do not regret their choice and $2.2 \%$ lower for those who regret. When wages are $1 \%$ lower after switching, graduates take on average .3 months additional training. Finally, we find some indication that students who are uncertain about their educational choice tend to more frequently choose fields of study that provide skills that can more easily be transferred to other fields.

Our model also has implications for the initial study choices. A person who is unsure about his initial choice will take the estimated skill transferability into account and strategically decide to choose a more general field of education. If the discipline was not what he expected, he will be able to switch to a different discipline without sizable costs. If uncertain persons are more likely to regret their education afterwards, those who choose a broader discipline should, on average, have a higher level of regret. We tested the relation between the transferability parameters and the mean level of regret, which indeed is significant and positive. Therefore, it can be predicted that the average amount of regret would even be higher if there were no general fields of study.

A second implication of the model is that people who do not regret their initial education, are more likely to switch if the transferability increases. We find a positive relation between the average level of switching and the transferability parameters for those who do not regret their initial choice.

\subsubsection{Robustness and extensions}

\section{Switching differently defined}

In our analysis, we measure a switch by monitoring the field of one's education or further education and, at the same time, the relation between the original education and the present job. We add the latter group because people can switch without additional education by starting to work in a job not related to their education and acquiring the skills on the job. In this definition, graduates who work outside their educational domain do so voluntarily. An important point is that graduates may instead also be unable to find a job related to their education. They are then involuntarily "mismatched." Our finding that switchers earn lower wages may 
therefore confound two effects: one due to the loss of human capital, one due to a mismatch penalty.

If we define switching as a continuation in a different field of education only, we find that if wages are $1 \%$ lower due to lower skill transferability, the probability of a graduate regretting his choice actually switching decreases by 5.8 percentage points, while those who switch take on average 0.4 months additional education. Comparing these estimates with the original ones, we see that the differences are small. This implies that either there are few graduates who involuntarily have a job which does not relate to their education or that these graduates react similarly to stimuli as graduates who switch education.

\section{Do low-ability graduates switch more often?}

To some it may appear that there are other reasons for switching than a high level of regret or high transferability. What if, for instance, graduates who regret their choice are typically less intelligent than those who do not regret their choice? If so, not regret but intelligence would predict switching behavior. Assuming that intelligence can be measured by wages, we checked (see table A4) if those who regret their choice receive a lower wage than graduates who do not regret their choice, both for switchers and non-switchers. We find that there is only a (significantly negative) effect for non-switchers (coefficient $=-0.063, p=0.003$ ). In other words, graduates who do not switch but regret their choice of education receive lower wages than those who do not regret their choice. If intelligence were to be of importance instead of regret, we would have to find the same relationship also for switchers. The negative relation that we find for non-switchers is probably due to our strict definition of a switch, being a change from one field of study to another. It is, however, possible that a graduate switches from one discipline to another within a field of study. Then, we do not measure a switch but the graduate loses human capital because he switches.

\subsection{Conclusion}

The choice of discipline has an enormous impact on the satisfaction of later careers. However, students who choose their education have very limited information about what they will like when they get older and what the labor market perspectives of the chosen profession will be. Therefore, it is likely that some of them will regret their choice of education. To analyze the impact of regret on switching to another profession, we developed a choice model where the individual must decide after the initial education (i) whether or not to change occupations after graduation and (ii) how much to invest in education, either in his original discipline 
or in an alternative discipline. The individual maximizes his utility which depends both on wages and intrinsic motivation. From the model, it can be concluded that besides regret, skill transferability is the key determinant for his choices. If occupational mobility leads to a large loss of human capital, so transferability is low, the probability that the graduate will switch is low. However, when graduates with a low skill transferability nevertheless decide to change occupations, they will invest more in education. Using data about Dutch graduates from the CHEERS survey, we have tested our model. Consistent with our model we find that, conditional on the level of regret, higher skill transferability induces switching and reduces the wage loss and the duration of the training followed after the initial education. 


\subsection{Appendix}

Table A1

Distribution of switching over gender and disciplines in original education.

\begin{tabular}{|c|c|c|}
\hline Disciplines & $\%$ No switch & $\%$ Switch \\
\hline Male & 69.1 & 30.9 \\
\hline Female & 71.7 & 28.3 \\
\hline Teachers & 70.6 & 29.4 \\
\hline Arts & 73.1 & 26.9 \\
\hline Humanities & 61.3 & 38.7 \\
\hline Social sc. & 61.8 & 38.2 \\
\hline Journalism & 68.6 & 31.4 \\
\hline Business & 77.0 & 23.0 \\
\hline Law & 69.6 & 30.4 \\
\hline Life sc. & 53.8 & 46.2 \\
\hline Physical sc. & 54.0 & 46.0 \\
\hline Mathematics & 66.7 & 33.3 \\
\hline Computing & 76.7 & 23.3 \\
\hline Engineering & 58.3 & 41.7 \\
\hline Manufacturing & 50.0 & 50.0 \\
\hline Architecture & 68.1 & 31.9 \\
\hline Agriculture & 65.4 & 34.6 \\
\hline Veterinary & 81.8 & 18.2 \\
\hline Health & 84.0 & 16.0 \\
\hline Social & 72.8 & 27.2 \\
\hline Personal & 61.7 & 38.3 \\
\hline Transport & 55.0 & 45.0 \\
\hline Environmental & 59.1 & 40.9 \\
\hline
\end{tabular}

Source: CHEERS, 1999 
Table A2

Distribution of switchers over disciplines from which they come and to which they switch

\begin{tabular}{l|cc}
\hline Disciplines & $\begin{array}{c}\text { Percentage } \\
\text { from }\end{array}$ & $\begin{array}{c}\text { Percentage } \\
\text { towards }\end{array}$ \\
\hline Teacher education and education science & 10.2 & 0.0 \\
Arts & 3.2 & 2.5 \\
Humanities & 5.2 & 7.7 \\
Social and behavioral science & 8.6 & 11.7 \\
Journalism and information & 3.4 & 1.9 \\
Business and administration & 13.4 & 38.1 \\
Law & 6.4 & 5.2 \\
Life science & 0.4 & 1.1 \\
Physical science & 4.0 & 2.7 \\
Mathematics and statistics & 0.8 & 1.0 \\
Computing & 3.4 & 9.2 \\
Engineering and engineering trades & 12.2 & 5.0 \\
Manufacturing and processing & 0.0 & 0.0 \\
Architecture and building & 3.6 & 2.1 \\
Agriculture and forestry & 3.6 & 0.8 \\
Veterinary & 0.2 & 0.0 \\
Health & 4.8 & 5.7 \\
Social services & 8.4 & 2.3 \\
Personal services & 5.4 & 0.2 \\
Transport services & 1.4 & 1.5 \\
Environmental protection & 1.6 & 1.0 \\
& & \\
\hline Total & 100.0 & 100.0 \\
Number of switchers & 501 & 522 \\
& & \\
\hline \hline
\end{tabular}

Source: CHEERS, 1999

Some people switch more than once. All fields to which they switch are reported. Therefore, the amount of switchers in their original discipline is lower than the amount of switchers in the fields to which they switch. 
Table A3

Distribution of regret over gender and disciplines in original education.

\begin{tabular}{|c|c|c|c|c|c|}
\hline Disciplines & $\begin{array}{c}\text { No } \\
\text { regret }\end{array}$ & $\begin{array}{l}\text { Little } \\
\text { regret }\end{array}$ & Neutral & Regret & $\begin{array}{r}\text { Strong } \\
\text { regret }\end{array}$ \\
\hline Male & 27.2 & 39.3 & 16.6 & 12.6 & 4.3 \\
\hline Female & 27.5 & 37.8 & 17.1 & 11.1 & 6.5 \\
\hline Teachers & 27.0 & 37.4 & 18.3 & 10.0 & 7.3 \\
\hline Arts & 33.7 & 40.4 & 6.7 & 13.5 & 5.8 \\
\hline Humanities & 21.0 & 35.5 & 21.0 & 12.9 & 9.7 \\
\hline Social sc. & 24.9 & 38.2 & 17.3 & 13.3 & 6.4 \\
\hline Journalism & 18.6 & 37.1 & 18.6 & 18.6 & 7.1 \\
\hline Business & 27.0 & 44.1 & 14.1 & 11.0 & 3.7 \\
\hline Law & 32.6 & 37.8 & 16.3 & 10.4 & 3.0 \\
\hline Life sc. & 38.5 & 30.8 & 15.4 & 7.7 & 7.7 \\
\hline Physical sc. & 26.0 & 36.0 & 26.0 & 8.0 & 4.0 \\
\hline Mathematics & 23.8 & 33.3 & 23.8 & 4.8 & 14.3 \\
\hline Computing & 38.9 & 33.3 & 14.4 & 11.1 & 2.2 \\
\hline Engineering & 27.5 & 37.5 & 18.3 & 12.9 & 3.8 \\
\hline Manufacturing & 100.0 & & & & \\
\hline Architecture & 24.2 & 42.9 & 17.6 & 12.1 & 3.3 \\
\hline Agriculture & 30.9 & 33.3 & 19.8 & 11.1 & 4.9 \\
\hline Veterinary & 36.4 & 36.4 & 18.2 & 9.1 & \\
\hline Health & 29.9 & 33.7 & 19.1 & 11.5 & 5.9 \\
\hline Social & 26.7 & 39.0 & 16.9 & 11.3 & 6.2 \\
\hline Personal & 20.2 & 41.5 & 14.9 & 12.8 & 10.6 \\
\hline Transport & 25.0 & 25.0 & 25.0 & 20.0 & 5.0 \\
\hline Environmental & 9.1 & 36.4 & 18.2 & 18.2 & 18.2 \\
\hline
\end{tabular}

Source: CHEERS, 1999 
Table A4

Results of Wage, Switch and Duration equations (St. Error in parenthesis).

\begin{tabular}{|c|c|c|c|c|}
\hline Variables & Switch & $D_{s}$ & $D_{n s}$ & Wage \\
\hline Intercept & $\begin{array}{c}-6.243 \\
(8.595)\end{array}$ & $\begin{array}{c}77.529 \\
(117.426)\end{array}$ & $\begin{array}{l}-22.269 \\
(172.321)\end{array}$ & $\begin{array}{c}-5.833^{*} \\
(3.279)\end{array}$ \\
\hline Regret & $\begin{array}{l}0.393^{* * * *} \\
(0.064)\end{array}$ & $\begin{array}{c}0.533 \\
(0.611)\end{array}$ & $\begin{array}{c}0.093 \\
(0.875)\end{array}$ & \\
\hline Regret*switch & & & & $\begin{array}{c}0.028 \\
(0.027)\end{array}$ \\
\hline Regret*no switch & & & & $\begin{array}{l}-0.063 * * * \\
(0.021)\end{array}$ \\
\hline Male & $\begin{array}{c}0.127 \\
(0.105)\end{array}$ & $\begin{array}{c}0.356 \\
(1.596)\end{array}$ & $\begin{array}{c}0.196 \\
(1.965)\end{array}$ & $\begin{array}{c}0.075 * \\
(0.045)\end{array}$ \\
\hline Tenure & & & & $\begin{array}{l}0.002 * * \\
(0.001)\end{array}$ \\
\hline Age & $\begin{array}{c}0.379 \\
(0.591)\end{array}$ & $\begin{array}{c}-3.751 \\
(7.949)\end{array}$ & $\begin{array}{c}3.809 \\
(12.024)\end{array}$ & $\begin{array}{l}0.518 * * \\
(0.225)\end{array}$ \\
\hline Agesq & $\begin{array}{r}-0.008 \\
(0.010)\end{array}$ & $\begin{array}{c}0.063 \\
(0.134)\end{array}$ & $\begin{array}{c}-0.062 \\
(0.207)\end{array}$ & $\begin{array}{c}-0.009 * * \\
(0.004)\end{array}$ \\
\hline Teachers & Ref. & Ref. $(\zeta)$ & Ref. $(\eta)$ & Ref. \\
\hline Arts & & $\begin{array}{r}-7.737 \\
(6.245)\end{array}$ & $\begin{array}{c}-8.760 * \\
(5.324)\end{array}$ & $\begin{array}{c}-0.312 * * * \\
(0.115)\end{array}$ \\
\hline Humanities & & $\begin{array}{c}6.340 \\
(6.813)\end{array}$ & $\begin{array}{c}1.809 \\
(6.012)\end{array}$ & $\begin{array}{c}-0.069 \\
(0.123)\end{array}$ \\
\hline Social sc. & & $\begin{array}{c}-1.742 \\
(6.846)\end{array}$ & $\begin{array}{c}-2.856 \\
(6.200)\end{array}$ & $\begin{array}{l}0.245^{* *} \\
(0.112)\end{array}$ \\
\hline Journalism & & $\begin{array}{c}-0.087 \\
(9.514)\end{array}$ & $\begin{array}{c}-6.161 \\
(8.074)\end{array}$ & $\begin{array}{c}0.174 \\
(0.155)\end{array}$ \\
\hline Business & & $\begin{array}{c}-8.614 \\
(5.639)\end{array}$ & $\begin{array}{c}-11.862 * * \\
(4.863)\end{array}$ & $\begin{array}{l}0.255^{* * * *} \\
(0.081)\end{array}$ \\
\hline Law & & $\begin{array}{c}-0.046 \\
(6.433)\end{array}$ & $\begin{array}{c}-6.539 \\
(5.369)\end{array}$ & $\begin{array}{l}0.362 * * * \\
(0.123)\end{array}$ \\
\hline Physical sc. & & $\begin{array}{c}-2.374 \\
(8.203)\end{array}$ & $\begin{array}{r}-1.597 \\
(6.691)\end{array}$ & $\begin{array}{c}0.221 \\
(0.243)\end{array}$ \\
\hline Mathematics & & $\begin{array}{c}-13.909 \\
(17.733)\end{array}$ & $\begin{array}{l}-9.376 \\
(15.285)\end{array}$ & $\begin{array}{c}0.638 \\
(0.392)\end{array}$ \\
\hline Computing & & $\begin{array}{c}0.174 \\
(9.559)\end{array}$ & $\begin{array}{c}-7.178 \\
(7.192)\end{array}$ & $\begin{array}{l}0.448 * * * \\
(0.160)\end{array}$ \\
\hline Engineering & & $\begin{array}{c}-0.439 \\
(6.732)\end{array}$ & $\begin{array}{r}-7.922 \\
(5.693)\end{array}$ & $\begin{array}{l}0.264 * * \\
(0.113)\end{array}$ \\
\hline Architecture & & $\begin{array}{c}-7.243 \\
(8.363)\end{array}$ & $\begin{array}{r}-12.208^{*} \\
(6.838)\end{array}$ & $\begin{array}{c}0.127 \\
(0.139)\end{array}$ \\
\hline
\end{tabular}


Table A4 (continued)

\begin{tabular}{|c|c|c|c|c|}
\hline Variables & Switch & $D_{s}$ & $D_{n s}$ & Wage \\
\hline Agriculture & & $\begin{array}{c}-0.584 \\
(10.001)\end{array}$ & $\begin{array}{r}-9.637 \\
(8.050)\end{array}$ & $\begin{array}{c}0.037 \\
(0.140)\end{array}$ \\
\hline Health & & $\begin{array}{c}-5.653 \\
(6.348)\end{array}$ & $\begin{array}{c}-10.311^{* * *} \\
(4.963)\end{array}$ & $\begin{array}{l}0.281 \text { *** } \\
(0.087)\end{array}$ \\
\hline Social & & $\begin{array}{c}-2.042 \\
(6.917)\end{array}$ & $\begin{array}{c}-8.568 \\
(5.882)\end{array}$ & $\begin{array}{c}0.076 \\
(0.101)\end{array}$ \\
\hline Personal & & $\begin{array}{c}5.095 \\
(9.793)\end{array}$ & $\begin{array}{c}-4.435 \\
(8.853)\end{array}$ & $\begin{array}{c}0.220 \\
(0.162)\end{array}$ \\
\hline Transport & & $\begin{array}{l}-5.418 \\
(23.023)\end{array}$ & $\begin{array}{l}-8.568 \\
(21.320)\end{array}$ & $\begin{array}{c}0.018 \\
(0.405)\end{array}$ \\
\hline Environment & & $\begin{array}{l}-1.539 \\
(47.211)\end{array}$ & $\begin{array}{c}0.561 \\
(47.395)\end{array}$ & $\begin{array}{l}0.478 \\
(0.405)\end{array}$ \\
\hline Switch*Teachers & & & & $\begin{array}{c}-0.297^{* *} \\
(0.140)\end{array}$ \\
\hline Switch*Arts & & & & $\begin{array}{c}0.218 \\
(0.288)\end{array}$ \\
\hline Switch*Humanities & & & & $\begin{array}{r}-0.210 \\
(0.189)\end{array}$ \\
\hline Switch*Social sc. & & & & $\begin{array}{r}-0.320^{*} \\
(0.167)\end{array}$ \\
\hline Switch*Journalism & & & & $\begin{array}{c}-0.384 \\
(0.254)\end{array}$ \\
\hline Switch*Business & & & & $\begin{array}{c}-0.457 * * * \\
(0.125)\end{array}$ \\
\hline Switch*Law & & & & $\begin{array}{c}-0.115 \\
(0.208)\end{array}$ \\
\hline Switch*Physical sc. & & & & $\begin{array}{c}-0.024 \\
(0.320)\end{array}$ \\
\hline Switch*Mathematics & & & & $\begin{array}{c}-0.661 \\
(0.515)\end{array}$ \\
\hline Switch*Computing & & & & $\begin{array}{c}-0.206 \\
(0.275)\end{array}$ \\
\hline Switch*Engineering & & & & $\begin{array}{r}-0.292^{*} \\
(0.149)\end{array}$ \\
\hline Switch*Architecture & & & & $\begin{array}{c}-0.143 \\
(0.251)\end{array}$ \\
\hline Switch*Agriculture & & & & $\begin{array}{c}-0.239 \\
(0.227)\end{array}$ \\
\hline Switch*Health & & & & $\begin{array}{c}-0.425^{* *} \\
(0.181)\end{array}$ \\
\hline Switch*Social & & & & $\begin{array}{c}-0.148 \\
(0.183)\end{array}$ \\
\hline
\end{tabular}


Table A4 (continued)

\begin{tabular}{|c|c|c|c|c|}
\hline Variables & Switch & $D_{s}$ & $D_{n s}$ & Wage \\
\hline Switch*Personal & & & & $\begin{array}{r}-0.453^{*} \\
(0.236)\end{array}$ \\
\hline Switch*Transport & & & & $\begin{array}{c}0.058 \\
(0.658)\end{array}$ \\
\hline Switch*Environment & & & & $\begin{array}{r}-1.156^{*} \\
(0.512)\end{array}$ \\
\hline$R_{0} *$ Arts & $\begin{array}{c}-0.153 \\
(0.328)\end{array}$ & & & \\
\hline$R_{0} *$ Humanities & $\begin{array}{c}0.288 \\
(0.307)\end{array}$ & & & \\
\hline$R_{0} *$ Social sc. & $\begin{array}{l}0.584 * * \\
(0.247)\end{array}$ & & & \\
\hline$R_{0} *$ Journalism & $\begin{array}{c}0.441 \\
(0.387)\end{array}$ & & & \\
\hline$R_{0} *$ Business & $\begin{array}{c}-0.405^{* *} \\
(0.195)\end{array}$ & & & \\
\hline$R_{0} *$ Law & $\begin{array}{c}0.151 \\
(0.278)\end{array}$ & & & \\
\hline$R_{0} *$ Physical sc. & $\begin{array}{c}0.774 * \\
(0.409)\end{array}$ & & & \\
\hline$R_{0} *$ Mathematics & $\begin{array}{c}0.045 \\
(0.803)\end{array}$ & & & \\
\hline$R_{0} *$ Computing & $\begin{array}{c}-0.253 \\
(0.357)\end{array}$ & & & \\
\hline$R_{0} *$ Engineering & $\begin{array}{l}0.474 * * \\
(0.229)\end{array}$ & & & \\
\hline$R_{0} *$ Architecture & $\begin{array}{c}0.056 \\
(0.323)\end{array}$ & & & \\
\hline$R_{0} *$ Agriculture & $\begin{array}{c}0.214 \\
(0.348)\end{array}$ & & & \\
\hline$R_{0} *$ Health & $\begin{array}{c}-0.762 * * * \\
(0.264)\end{array}$ & & & \\
\hline$R_{0} *$ Social & $\begin{array}{c}-0.062 \\
(0.258)\end{array}$ & & & \\
\hline$R_{0} *$ Personal & $\begin{array}{c}0.368 \\
(0.314)\end{array}$ & & & \\
\hline$R_{0} *$ Transport & $\begin{array}{c}1.071 \\
(0.781)\end{array}$ & & & \\
\hline$R_{0} *$ Environment & $\begin{array}{l}1.039 \\
(0.691)\end{array}$ & & & \\
\hline$R_{1} *$ Arts & $\begin{array}{c}0.206 \\
(0.440)\end{array}$ & & & \\
\hline
\end{tabular}


Table A4 (continued)

\begin{tabular}{|c|c|c|c|c|}
\hline Variables & Switch & $D_{s}$ & $D_{n s}$ & Wage \\
\hline$R_{1} *$ Humanities & $\begin{array}{c}0.486 \\
(0.322)\end{array}$ & & & \\
\hline$R_{1}{ }^{*}$ Social sc. & $\begin{array}{c}0.129 \\
(0.299)\end{array}$ & & & \\
\hline$R_{1} *$ Journalism & $\begin{array}{c}-0.586 \\
(0.457)\end{array}$ & & & \\
\hline$R_{1} *$ Business & $\begin{array}{c}-0.375 \\
(0.231)\end{array}$ & & & \\
\hline$R_{1}$ *Law & $\begin{array}{c}0.187 \\
(0.364)\end{array}$ & & & \\
\hline$R_{1} *$ Physical sc. & $\begin{array}{c}0.535 \\
(0.524)\end{array}$ & & & \\
\hline$R_{1} *$ Mathematics & $\begin{array}{c}0.080 \\
(0.790)\end{array}$ & & & \\
\hline$R_{1} *$ Computing & $\begin{array}{c}-0.457 \\
(0.466)\end{array}$ & & & \\
\hline$R_{1} *$ Engineering & $\begin{array}{c}0.427 \\
(0.276)\end{array}$ & & & \\
\hline$R_{1} *$ Architecture & $\begin{array}{c}0.086 \\
(0.414)\end{array}$ & & & \\
\hline$R_{1} *$ Agriculture & $\begin{array}{c}0.134 \\
(0.413)\end{array}$ & & & \\
\hline$R_{1}$ *Health & $\begin{array}{c}-0.947 * * * \\
(0.301)\end{array}$ & & & \\
\hline$R_{1} *$ Social & $\begin{array}{c}-0.338 \\
(0.304)\end{array}$ & & & \\
\hline$R_{1} *$ Personal & $\begin{array}{l}0.085 \\
(0.363)\end{array}$ & & & \\
\hline$R_{1} *$ Transport & $\begin{array}{c}-0.189 \\
(0.884)\end{array}$ & & & \\
\hline$R_{1} *$ Environment & $\begin{array}{c}-0.563 \\
(0.766)\end{array}$ & & & \\
\hline \multicolumn{5}{|c|}{$\begin{array}{l}\text { Source: CHEERS, } 1999 \\
* \mathrm{p}<0.10, * * \mathrm{p}<0.05, * * * \mathrm{p}<0.01 \\
D_{s} \text { is the duration of education (in months) when a graduate switches, } D_{n s} \text { is the duration } \\
\text { of education when a graduate remains in his own field, wages are logarithms of the wage, } \\
R_{0} \text { is no regret }(1,2) \text { and } R_{1} \text { is regret }(3,4,5) .\end{array}$} \\
\hline
\end{tabular}


3 Skill Transferability, Regret and Mobility 
4 Imagination and Investments in Skill-Deficiencies 


\subsection{Introduction}

Human capital investments are typically made in a context of large uncertainty. When people make their investment decision, they will have to anticipate the consequences of that decision in the future. In a context of choosing a field of education, we reported in the second and third chapter of this thesis that approximately $20 \%$ of college graduates would have chosen a different discipline and that many would try to graduate earlier if they would be able to choose again. We found that the ability to make investment decisions with which one is satisfied in retrospect is systematically related to personal attributes, where the power to imagine the future stands out as the most important determinant of being able to choose the right field of study.

This chapter attempts to answer how people make investment decisions in a later stage of their careers. ${ }^{1}$ How do workers act in situations where they are offered courses to reduce on-the-job skill-deficiencies? In particular, do people choose courses to reduce work-related skill-deficiencies, and do they choose courses deliberately? Which personal characteristics determine the outcome of these choices? The aim of this research is to analyze these questions using an experimental approach in which we ask workers to choose courses from a fixed set of options. The main advantage of the experiment is that we avoid the usual endogeneity problems concerning the decision to participate in training.

We ask 1,631 young workers to consider a situation in which they are offered by their firm a package of three training courses. Throughout the paper, we refer to the courses in this package as the courses offered by default. The workers can choose to accept these courses or to exchange them for courses from a menu of three alternatives. The default courses and the alternatives are randomly selected for each participant from a set of six courses. This set is the same for all participants and contains courses in a foreign language (English), Management, Stress management, Team work, Computer skills and Efficient working. From an earlier survey we have collected information about the perceived skill-deficiencies of the subjects in fields related to the courses offered.

The idea is that people consider the default option as an implicit advise about what is a reasonable choice. The combination of randomized default packages and survey information about perceived deficiencies, allows us to identify how the actual choices are related to this implicit advise and to perceptions about the usefulness of the courses in the mind of the respondent. First, we find that workers on average have a strong propensity to choose the default

\footnotetext{
${ }^{1}$ This is a joint work with Lex Borghans. We thank Tim Barmby, Arnaud Dupuy, Rachel Griffith, Hans Heijke, David Huffman, Moshe Hazan, Huub Meijers, Markus Mobius, Bas ter Weel and seminar participants at Maastricht University, the 2005 NAKE day, IZA and the 2006 SOLE conference for valuable comments.
} 
courses. Hence, many workers do not seem to make a deliberate choice. Second, we find that the probability to accept the default is related to the skill-deficiency of the respondent in the field of the training that is offered. A default offer therefore seems to reinforce the individual perception of skill-needs. Third, we find however that when workers choose their own courses from the menu, they do not choose courses with which they can reduce skill-shortages. Relating choice behavior to personal characteristics, we find, fourthly, evidence that workers who have a more developed capacity to imagine the future invest more in their skill-deficiencies. Better imagination also increases the probability of making a deliberate choice. We find that lower anxiety, lower risk aversion, and more cognitive skills also increase the probability of a deliberate choice, but these attributes are not related with investments in the skill-needs of the respondent.

The analysis of the effect of training on the reduction of on-the-job skill-deficiencies is related to the effects of training on productivity and wages as discussed by among many others Conti (2005) and Parent (1999). Frazis and Loewenstein (2005) show that the returns to training are very heterogeneous. We argue that differences in the effective choice of courses - related to both personal characteristics and environmental circumstances - can contribute to this heterogeneity. We argue that individuals differ in their interest and ability to choose courses and that individual attributes determine the return on the investment in training. Therefore, this essay contributes also to the literature on the effect of non-cognitive skills on labor market outcomes (Mueser 1979, Bowles, Gintis, and Osborne 2001, Heckman, Stixrud, and Urzua 2006).

Other authors have investigated the discriminatory factors that determine whether or not people participate in courses. Shields (1998) shows that participation in training differs substantially between workers. Colquitt, LePine, and Noe (2000) show that psychological factors such as anxiety influence to a large extent whether people invest in human capital and Eraut (2000) shows that self-confidence is an important factor that stimulates course participation at work. E.g. Field (2000) and Sargant and Aldridge (2002) have pointed out that course participation crucially depends on whether people face impediments or stimuli to participate. Such impediments may be of practical or financial nature. This chapter adds to this literature that stimulating training participation does not necessarily imply that people will choose the most profitable courses.

The analysis is also related to literature about choosing when faced with defaults options. In recent literature the idea that defaults may influence decisions is used in analyses related to organ donation decisions (Johnson and Goldstein 2003, Abadie and Gay 2006), car insurances (Johnson, Hershey, Meszaros, and Kunreuther 1993), car purchases (Park, Yun, and MacInnis 
2000), consent with e-mail marketing (Johnson, Bellman, and Lohnse 2002) and pensions with 401(k) saving (Choi, Laibson, Madrian, and Metrick 2005), ${ }^{2}$ yet no attempt has thus far been made to introduce this notion in the human capital literature.

Section 4.2 is concerned with a description of the data and the set-up of the experiment. Section 4.3 discusses the estimation method. Section 4.4 reports the results. Section 4.5 shows additional tests and section 4.6 concludes.

\subsection{Data and the experiment}

We use two Dutch data sets. The first is the Fall 2004 Research Centre for Education and the Labour Market Schoolleaver Survey. We measured the skill-deficiency of the respondents in this survey. In the second survey which was held in the spring of 2005 we approached the same respondents again and asked them to participate in an experiment.

\subsubsection{Skill-deficiency}

In the 2004 survey, workers are interviewed 1.5 years after they graduated from professional college ("Hoger Beroepsonderwijs (HBO)") or university. Some of the graduates followed their education at a later age. We selected young workers in the age below 35 years of age.

The respondents are asked to indicate the level of their skills with respect to a comprehensive set of aspects. In addition they are asked which level of skills is required in their jobs with respect to these aspects. We use the difference between the skills a person indicates to be required for the job and the skills he indicates to posses as a measure for the skill-deficiency. Table 4.1 gives the exact wording of the question and indicates the 6 skills we will use to analyze our hypotheses: working well under pressure; applying ICT; communicating in foreign languages; drawing on other people's capabilities; working productively with other people; and working in accordance with a budget.

We are interested in the propensity of respondents to choose courses related to their skilldeficiency. If the measure is negative or zero, a person has no skill-deficiency. We recoded negative values of the measure to zero. ${ }^{3}$ We find that $55.3 \%$ of the respondents have skilldeficiencies regarding at least one of the selected skills.

\footnotetext{
${ }^{2} \mathrm{~A} 401(\mathrm{k})$ plan is a type of employer-sponsored retirement plan in the U.S. which allows an employee to save for retirement by deferring income taxes on the saved money and earnings until withdrawal.

${ }^{3}$ In the robustness analysis, we show that if we would not recode the negative values, the results remain similar.
} 
Table 4.1: Skill-deficiency question

\begin{tabular}{|c|c|c|}
\hline $\begin{array}{l}\text { Below are aspects that could be of importance in your job. } \\
\text { Rate for each of these aspects: }\end{array}$ & $\begin{array}{c}\text { The required level } \\
\text { in your job } \\
\text { Average }<->\text { Excellent }\end{array}$ & $\begin{array}{c}\text { Your own level } \\
\text { Average }<->\text { Excellent }\end{array}$ \\
\hline $\begin{array}{l}\text { Working well under pressure } \\
\text { Applying ICT } \\
\text { Communicating in foreign languages } \\
\text { Drawing on other people's capabilities } \\
\text { Working productively with other people } \\
\text { Working in accordance with budget, planning or guidelines }\end{array}$ & $\begin{array}{lllll}1 & 2 & 3 & 4 & 5 \\
1 & 2 & 3 & 4 & 5 \\
1 & 2 & 3 & 4 & 5 \\
1 & 2 & 3 & 4 & 5 \\
1 & 2 & 3 & 4 & 5 \\
1 & 2 & 3 & 4 & 5\end{array}$ & 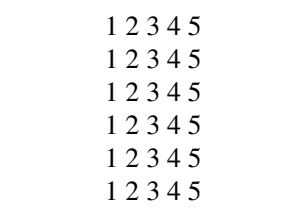 \\
\hline
\end{tabular}

Source: Research Centre for Education and the Labour Market 2004 Graduate Survey.

\subsubsection{The experiment}

To avoid the risk of respondents checking their choices with the level of the skill-deficiency for internal consistency, we approached the respondents of the 2004 survey again in the spring of 2005. Respondents were approached by e-mail to fill out a questionnaire on the internet called "Dealing with difficult choices." In the mail, we explained that the aim of the research is to increase understanding of how young people deal with difficult decisions, especially those related to educational choices. We explained that knowledge about these processes is of great societal and scientific importance since e.g. $20 \%$ of all graduates indicate that they regret their educational choice. To stimulate participation and deliberate answers, we offered the respondents upon completion of the questionnaire a profile about their personal style to deal with choices.

In the survey, we made a hypothetical offer of courses with an experimental set-up to 1,631 workers with a high probability to stay in their current jobs. ${ }^{4}$ We employ this experiment to avoid endogeneity in opportunities to participate in training and to randomize the offer of courses. The hypothetical nature of the experiment is chosen because knowledge about behavioral aspects of participation in education and training is still limited. Therefore we want to explore the mechanisms before doing field experiments.

In the experiment we offered courses related to the 2004 list of aspects. The skills asked

\footnotetext{
${ }^{4}$ The choice for investing in skill-shortages might be affected by the preference for leaving the current job for another job which requires a different skill mix. To have a homogenous group of respondents, we consider only those who have a high probability to stay in their current jobs. We selected workers based on the question: "How well is your job related to your education?" The answers range from 1. poor, 2. insufficient, 3. sufficient, 4. good. We select the respondents who have a sufficient or good relation between education and their job. $73.7 \%$ of the workers have a job which is sufficient or well related to their education 1.5 years after graduation.
} 
Table 4.2: The specific courses offered related to the skills

\begin{tabular}{l|r}
\hline \hline Skill $^{a}$ & Course $^{b}$ \\
\hline Working well under pressure & Stress Management \\
Applying ICT & Computer \\
Communicating in foreign languages & English \\
Draw on other people's capabilities & Management \\
Working productively with other people & Team Work \\
Working in acc. with budget, planning or directions & Efficient working \\
\hline \hline Source: Research Centre for Education and the Labour Market 2004 Graduate Survey and \\
2005 supplement.
\end{tabular}

${ }^{a}$ Question asked in the 2004 survey to analyze the required and own level of skills.

${ }^{b}$ Translation of the skill into the specific course offered in the 2005 supplement.

in the 2004 survey often were too general in nature to offer as a course to the graduates. We therefore translated the general skills into more specific courses. Table 4.2 shows which course we propose for each skill. Obviously, even more specific courses could be offered. We chose however to leave it to the respondents to imagine which specific course they would take within the courses offered because of the potentially great diversity in the levels of the respondents with respect to the skills and the specific needs.

The hypothetical offer reads as follows:

Suppose your work has a new settlement in which everyone can participate during working hours in the following courses, the expenses of which are fully covered by the employer: English, Computer skills, Stress Management. However, it is also possible to exchange one or more courses. The alternatives are Management skills, Team work, Efficient working. Do you choose the suggested set of courses or do you want to exchange?

Note that we phrased this question in a way that there are no financial or time-related restrictions to the employee. And the question is constructed such that the courses which are offered in the "default" package, are the courses which the employer suggests to the employees. Thereby, implicitly, an advise or a statement about the most appropriate choice is generated.

To identify the effect of the default, we randomized the offered courses. We offered a first group of respondents courses in English, Stress management and Efficient working, with the alternative choices Computer use, Team working and Management. A second group was offered English, Computer use and Stress management, with the alternatives Efficient working, 
Team working and Management. And a third group was offered Efficient working, Team working and Management, with the alternatives English, Computer use and Stress management.

The respondents first had to indicate whether they want to choose the offered package or whether they want to exchange courses. If they want to exchange, they had to indicate which courses to leave out and which to add.

We find that $33.0 \%$ of the respondents takes the default package (i.e. all the courses offered), while the remaining respondents exchange at least one course for another course. Choosing the default saves the respondent some time. One potential critique therefore is that respondents might choose the default to faster complete the survey. We checked whether the default was chosen more often by respondents who took less time to complete the survey. We find however the opposite: respondents who choose the default take on average more time to complete the survey. This might indicate that those who take a lot of time in each question are more hesitant when it comes to choosing. We find this relationship between choosing the default and responding slower in the survey for all 8 parts in the survey. The possibility that people who need more time to answer questions become more easily impatient further on in the survey and might therefore rush through the survey is therefore not supported by the evidence.

Table 4.3 shows that some courses are more popular than others. English, Computer courses and Team work are selected least often. This is in line with what we expected: respondents have had ample opportunities at school and in college to invest in these skills, so their deficiencies are lowest. The table shows furthermore that most people indicate that they need more skills related to Stress management, Management and Efficient working.

\subsubsection{Individual attributes}

We relate choice behavior to personal characteristics of the individuals. We analyze the relations of the choices with the following psychological characteristics: time discounting, capacity to imagine the future, anxiety and risk aversion. Besides this we will look at the relation with cognitive skills. A comprehensive list of the questions measuring these personal characteristics is shown in table 4.4 .

People with high discount rates (i.e. who value the future less) may weigh the consumption aspect of the course more highly. We expect them therefore to have a lower propensity to choose courses to reduce their skill-deficiencies. The discount rate is measured by the question:

“Suppose you win a 10-day holiday trip worth 2000 euros to an interesting desti- 
Table 4.3: The choice of courses, average skill-deficiency per course and the percentage of respondents skill deficient in a course

\begin{tabular}{l|cccc}
\hline \hline & Chooses course (\%) & Average skill-deficiency $^{a}$ & St.Dev. & Deficiency $^{b}(\%)$ \\
\hline & 38.5 & 0.14 & 0.43 & 11.0 \\
English & 72.3 & 0.29 & 0.55 & 23.1 \\
Efficient work & 47.4 & 0.13 & 0.36 & 11.4 \\
Team work & 70.8 & 0.28 & 0.52 & 23.1 \\
Management & 17.7 & 0.13 & 0.40 & 10.8 \\
Computer & 53.3 & 0.28 & 0.53 & 22.9 \\
Stress Management & & & \\
& & & & \\
\hline \hline
\end{tabular}

Source: Research Centre for Education and the Labour Market 2004 Graduate Survey and 2005 supplement. Note: The experiment to measure the choice for courses reads as follows: Suppose your work has a new settlement in which everyone can participate during working hours in the following courses, the expenses of which are fully covered by the employer: English, Computer skills, Stress Management. However, it is also possible to exchange one or more courses. The alternatives are Management skills, Team work, Efficient working. Do you choose the suggested set of courses or do you want to exchange? We randomized the offered courses and alternatives. We report in this table which courses are chosen most often.

${ }^{a}$ A skill-deficiency is defined as the difference between the self-assessed required level of skills on the job and the self-assessed own level of skills. We regarded 6 skills: Working well under pressure, Applying ICT, Communicating in foreign languages, Drawing on other people's capabilities, Working productively with other people, Working in accordance with budget, planning or guide lines. A negative skill-deficiency is recoded to zero.

${ }^{b}$ Percentage of the respondents who are skill deficient.

nation. To spread participation, you are asked if you can delay your trip with three years in exchange for a longer vacation. How many days should you be offered in addition to accept the offer in 3 years?"

We find that $97.6 \%$ of the respondents filled out an answer between 0 and 30 days. On average people answered 11.6 days (st.dev. 9.0). This corresponds to a discount rate of $27.0 \% .^{5}$ Compared with an interest rate at a bank this average discount rate is therefore very high. In the literature (Frederick, Loewenstein, and O'Donoghue 2002) it is known that the measure of time discounting is strongly influenced by anchoring effects but that some people consistently score higher or lower on these measures. We validated the measure for the discount rate with a measure which is used often in psychology (Rachlin, Raineri, and Cross 1991). The measure uses trade-offs between amounts of money now and amounts of future money to elicit time discounting and is significantly correlated with our time discounting measure (correlation: 0.156, t-value: 6.741).

When choosing between courses, it will be important to understand the significance of the investment for the accumulation of human capital. We expect therefore that having a high

\footnotetext{
${ }^{5}$ In the tables, we divide this discount rate by 100.
} 
capacity to imagine the future will be related with investing more in skill-deficiencies. The capacity to imagine the future is measured by 9 statements about the image one has about the future (e.g. "I can imagine well what my next job will look like") and the experiences one has had about the past ("My life is now like I thought it would be 3 years ago"). Cronbach's Alpha equals 0.68 .

Colquitt, LePine, and Noe (2000) show that anxiety and risk aversion are important for choosing to participate in training. We will analyze whether these factors are also important for the quality of the choice for courses. Anxiety indicates to what extent people are afraid of things they do not have experience with. We expect those with higher anxiety to choose the default more often. It is measured by 3 statements such as "I often think back about unpleasant experiences." Cronbach's Alpha equals 0.48.

Risk averse people can also be expected to have a higher propensity to choose the default. Risk aversion is measured by offering the respondents one amount of money they can get for sure or a higher amount of money with a chance of getting it and a chance of not getting it. We asked 6 questions in which we varied the amounts of money and the chance of getting the money. To deduce information most efficiently, we used follow-up questions. An example is the question: "What would you choose: 800 Euros, or 50\% chance on nothing, 50\% chance on 2000 Euros?" If the respondent chose 800 Euros, he would get the question: What would you choose: "800 Euros, or 50\% chance on nothing, 50\% chance on 2400 Euros?" A respondent who chose 2000 Euros in the first question would get the question: "What would you choose: 800 Euros, or $50 \%$ chance on nothing, $50 \%$ chance on 1600 Euros?"

We expect that people with more cognitive skills will better understand the significance of the investment, and that they will be more able to choose deliberately. Cognitive skills are measured by 8 questions taken from Frederick (2005). An example of these questions is

"Together, a ball and a cap cost 1.10 Euros. The ball costs 1.00 Euros more than the cap. How much does the cap cost?"

Crohnbach's Alpha equals 0.75 for these questions. Frederick (2005) shows that scores on this Cognitive Reflection Test are correlated with SAT-scores and scores on several other IQ tests and with the ability to make choices. We find significant correlations between the average number of correctly answered questions and high school grades for nearly all subjects taught in high school and with the average college grade. This indicates that the measure for cognitive skills plausibly reflects some general type of cognitive skills. 


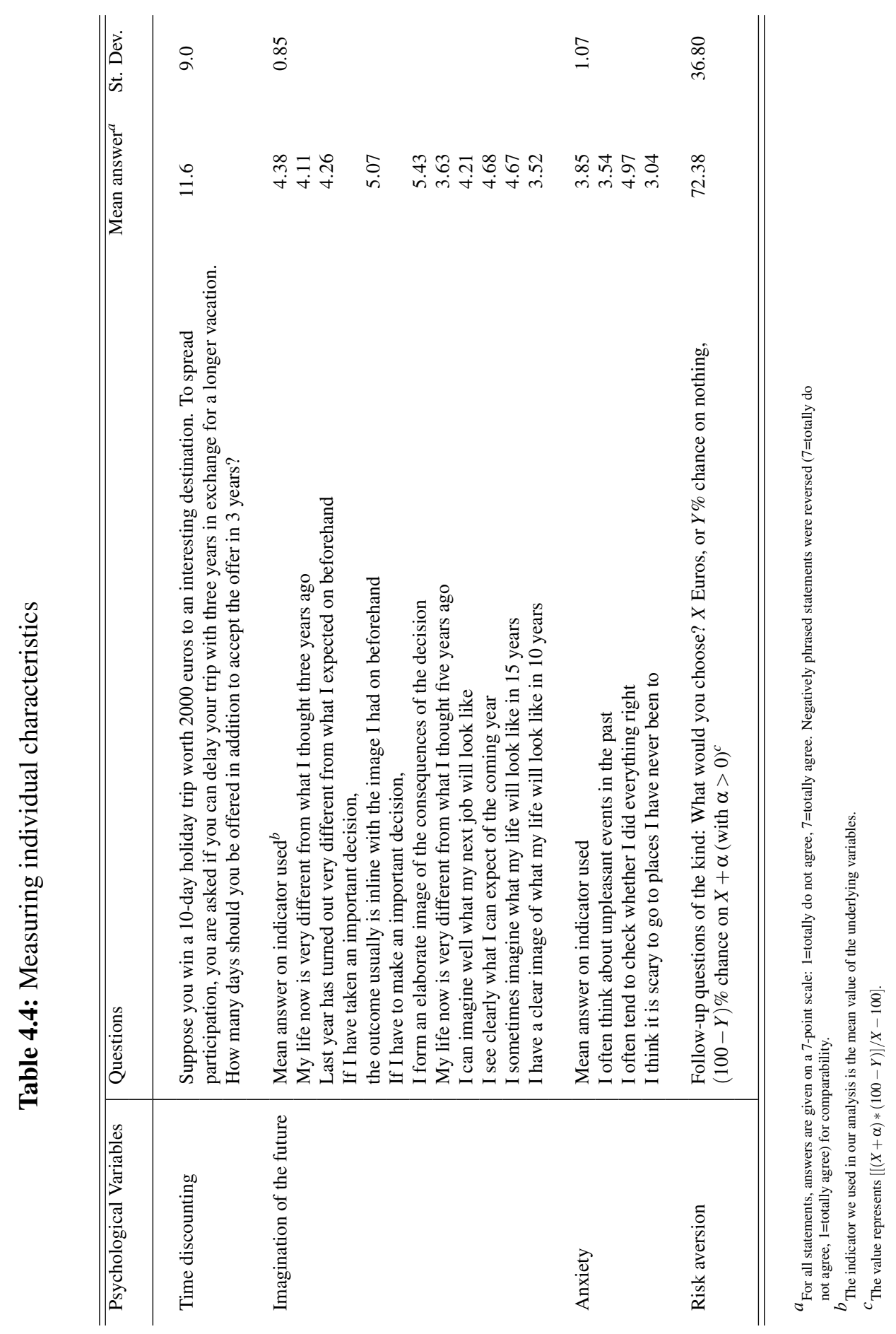




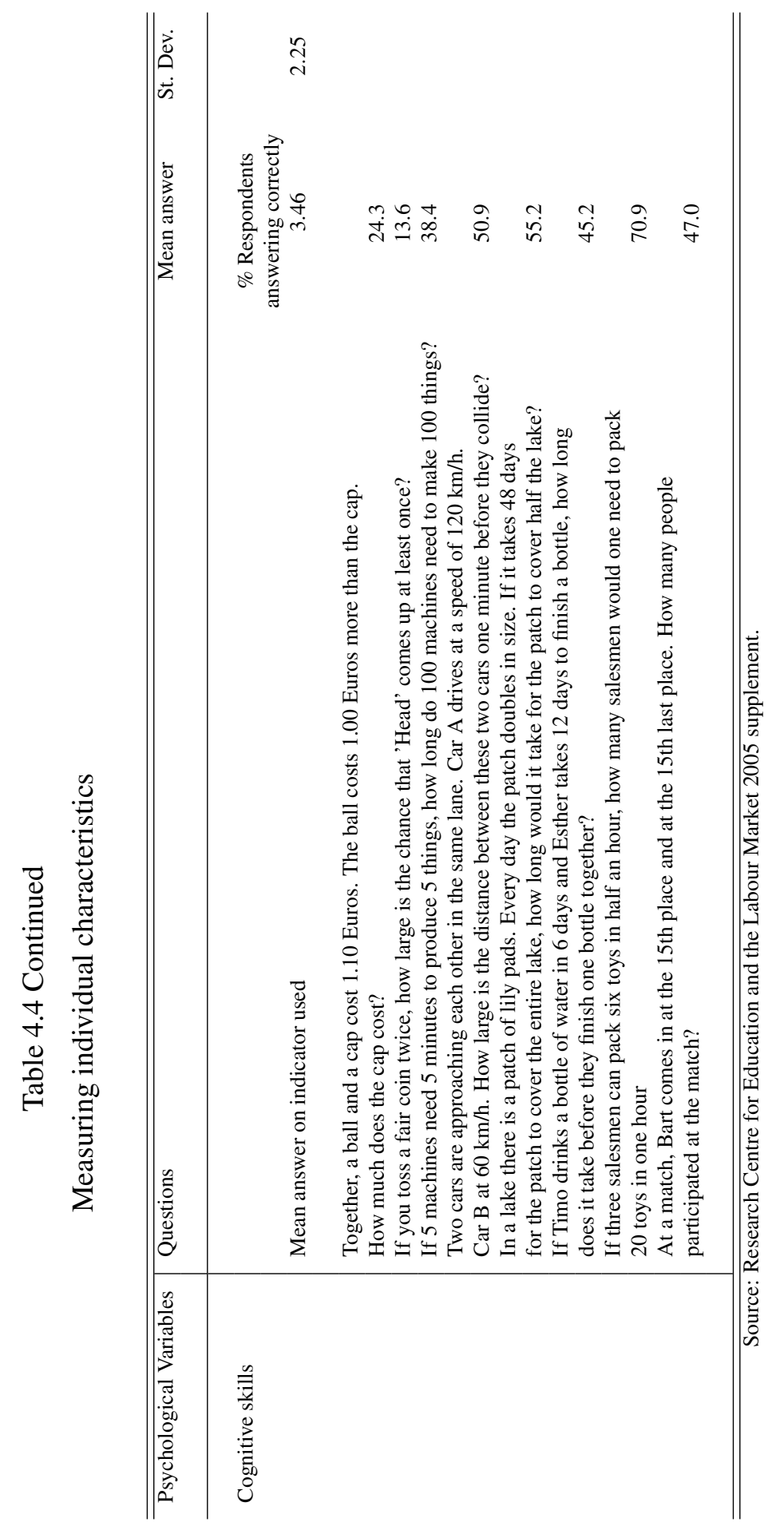


Table 4.5: Correlations between measures of personal characteristics

\begin{tabular}{l|ccccc}
\hline \hline & Time discounting & Cognitive skills & Anxiety & Imagination & Risk aversion \\
Time discounting & 1.000 & -0.036 & -0.015 & $-0.081^{* * *}$ & $-0.052^{* *}$ \\
Cognitive skills & & 1.000 & $-0.094^{* * * *}$ & 0.030 & $-0.095^{* * *}$ \\
Anxiety & & & 1.000 & $-0.066^{* * *}$ & $0.089^{* * *}$ \\
Imagination & & & & 1.000 & 0.021 \\
Risk aversion & & & & & 1.000 \\
& & & & \\
\hline \hline
\end{tabular}

Source: Research Centre for Education and the Labour Market 2005 graduate survey supplement. $* \mathrm{p}<0.10, * * \mathrm{p}<0.05, * * * \mathrm{p}<0.01$.

Table 4.5 shows the correlation between the measures. The table indicates that the discount rate is related negatively with imagination and risk aversion. Cognitive skills are related negatively with anxiety and risk aversion. More anxiety is related with less imagination and more risk aversion.

\subsection{Method}

We use a ranked-order logit regression. ${ }^{6}$ This is a system of the following simultaneously estimated equations:

$$
\begin{aligned}
Y_{E} & =\alpha_{1} * E+\alpha_{2} * D_{i E}+\alpha_{3} * S D_{i E}+\alpha_{4} *(S D * D)_{i E}+\varepsilon_{i E} \\
Y_{E W} & =\beta_{1} * E W+\alpha_{2} * D_{i E W}+\alpha_{3} * S D_{i E W}+\alpha_{4} *(S D * D)_{i E W}+\varepsilon_{i E W} \\
Y_{T W} & =\gamma_{1} * T W+\alpha_{2} * D_{i T W}+\alpha_{3} * S D_{i T W}+\alpha_{4} *(S D * D)_{i T W}+\varepsilon_{i T W} \\
Y_{M T} & =\delta_{1} * M t+\alpha_{2} * D_{i M T}+\alpha_{3} * S D_{i M T}+\alpha_{4} *(S D * D)_{i M T}+\varepsilon_{i M T} \\
Y_{C} & =\zeta_{1} * C+\alpha_{2} * D_{i C}+\alpha_{3} * S D_{i C}+\alpha_{4} *(S D * D)_{i C}+\varepsilon_{i C} \\
Y_{S M} & =\eta_{1} * S M+\alpha_{2} * D_{i S M}+\alpha_{3} * S D_{i S M}+\alpha_{4} *(S D * D)_{i S M}+\varepsilon_{i S M}
\end{aligned}
$$

in which $Y$ is a latent variable describing the preference for a course (estimated by a dummy variable with the value 1 if the course is chosen and 0 if it is not chosen), $E$ stands for English, $E W$ for Efficient working, $T W$ for Team work, $M T$ for Management, $C$ for Computer skills,

\footnotetext{
${ }^{6}$ See for a comprehensive overview of this method Allison and Christakis (1994).
} 
and $S M$ for Stress management. $D_{i E}$ is a dummy for whether English is the default for individual $i, S D_{i E}$ is the skill-deficiency of person $i$ in English. To estimate whether courses related to topics in which the respondent has a skill-deficiency are chosen more often if offered in the default package we include for each course a cross effect of the skill-deficiency and the default: $(S D * D)$.

The three courses with the highest $Y$ are chosen. Note first that by having the same parameters per variable for the different courses, we assume that the effect of the variables on the preference for the course will be the same across courses. ${ }^{7}$ Secondly, because we are measuring within person differences, we do not include separate individual characteristics. In an extension of the model, we do include however interactions of these characteristics with the variables of interest. $D, S D$, and $S * S D$ are then replaced respectively by:

$$
\begin{aligned}
D_{i c} & =\pi_{0}+\sum_{1}^{k} \pi_{k} * D_{i c} * \psi_{i k}+\varepsilon_{1 i c} \\
S D_{i c} & =\rho_{0}+\sum_{1}^{k} \rho_{k} * S D_{i c} * \psi_{i k}+\varepsilon_{2 i c} \\
(S D * D)_{i c} & =\sigma_{0}+\sum_{1}^{k} \sigma_{k} *(S D * D)_{i c} * \psi_{i k}+\varepsilon_{3 i c}
\end{aligned}
$$

in which $c$ is a vector of courses, and $\psi$ are individual characteristics.

\subsection{Results}

Table 4.6 shows the main results of our analysis. First, we only include the default and the skill-deficiency variable in a regression. We find that people choose to reduce their skilldeficiencies and that their choice is largely driven by the default option. Concerning the size of the coefficients, we find that if a course is included in the default package, the probability that the course is chosen increases by $25.7 \%$ relative to another otherwise equally attractive course. ${ }^{8}$ A 1-point increase in the skill-deficiency increases the chance of choosing the course by $6.3 \%$.

\footnotetext{
${ }^{7}$ In the robustness analysis, we drop this assumption.

${ }^{8}$ This result is obtained by multiplying the coefficient with $0.5(1-0.5)$.
} 
Table 4.6: Default, skill-deficiency and the choice for courses

\begin{tabular}{|c|c|c|c|c|}
\hline Default $^{a}$ & $\begin{array}{l}\text { Model 1 } \\
1.029 * * * \\
(0.040)\end{array}$ & $\begin{array}{c}\text { Model } 2 \\
0.971 * * * \\
(0.044)\end{array}$ & $\begin{array}{c}\text { Model } 3 \\
1.029 * * * \\
(0.040)\end{array}$ & $\begin{array}{c}\text { Model } 4 \\
1.637 * * * \\
(0.180)\end{array}$ \\
\hline Skill-deficiency & $\begin{array}{l}0.250 * * * \\
(0.042)\end{array}$ & $\begin{array}{c}0.099 \\
(0.061)\end{array}$ & & \\
\hline Default*Skill-deficiency & & $\begin{array}{l}0.266^{* * * *} \\
(0.077)\end{array}$ & & \\
\hline Own level & & & $\begin{array}{c}-0.217 \text { *** } \\
(0.030)\end{array}$ & $\begin{array}{c}-0.044 \\
(0.046)\end{array}$ \\
\hline Required level & & & $\begin{array}{l}0.117 \text { *** } \\
(0.024)\end{array}$ & $\begin{array}{c}0.046 \\
(0.036)\end{array}$ \\
\hline Default*Own level & & & & $\begin{array}{c}-0.274 * * * \\
(0.054)\end{array}$ \\
\hline Default*Required level & & & & $\begin{array}{l}0.113 * * * \\
(0.043)\end{array}$ \\
\hline Dummies per course & Incl. & Incl. & Incl. & Incl. \\
\hline
\end{tabular}

Source: Research Centre for Education and the Labour Market 2005 graduate survey supplement. $* \mathrm{p}<0.10, * * \mathrm{p}<0.05, * * * \mathrm{p}<0.01$

${ }^{a}$ The experiment to measure the choice for courses reads as follows: Suppose your work has a new settlement in which everyone can participate during working hours in the following courses, the expenses of which are fully covered by the employer: English, Computer skills, Stress Management. However, it is also possible to exchange one or more courses. The alternatives are Management skills, Team work, Efficient working. Do you choose the suggested set of courses or do you want to exchange? We randomized the offered courses and alternatives. We analyze the effect of having a specific course offered to a person by default on the choice for this course.

When we include the interaction of the skill-deficiency with the default in the regression to analyze whether topics in which the respondent has a skill-deficiency are chosen more often if offered in the default package, we find that the effect of the skill-deficiency is completely taken over by the interaction variable. Therefore, workers generally do not have the propensity to choose courses with which they can reduce job related skill-shortages. However, workers choose courses which reduce their skill-deficiency more often if these courses are in the default package.

To analyze which component of the skill-deficiency drives the result, we separate this variable in the skills possessed and the skills required. We find that people invest less in the skills they already have and more in skills they still need at their jobs. Interestingly, the coefficient of the own skills is about double the size of the coefficient of the required skills. This might indicate that people are investing more in general skills than in job-specific skills. Adding the interaction with the default, we find similarly that the interaction term with the default is significant for both own skills and required skills, while the separate variables own skills and required skills are not significant. 


\subsubsection{Individual attributes}

An interesting question is which people react more to a course being in the default set, and which people invest more in their skill-deficiency. Table 4.7 shows the interactions of personal characteristics with the default and the skill-deficiency variables.

We find that workers who have a more developed capacity to imagine the future invest more in their skill-deficiencies. Imagination is the only personal attribute which is related with the skill-deficiency.

Better imagination also increases the probability of making a deliberate choice. We find that lower anxiety, lower risk aversion, and more cognitive skills also increase the probability of a deliberate choice, but these attributes are not related with investments in the skill-needs of the respondent.

The relations between these characteristics and the choice for the default or the skilldeficiency reduction are plausible. At the minimum, this may serve as a validation of the methodology we followed to measure the investment decisions. Next to this, we may conclude from these findings that especially the power to imagine the future is an important characteristic related to investing in courses that reduce skill-deficiencies.

\subsection{Robustness}

\subsubsection{Linearity assumption of skill-deficiency variable}

In the analysis, a negative skill-deficiency is recoded to zero skill-deficiency and we assume a linear relation between the skill-deficiency and the choice for the course. To investigate whether the results differ if we did not recode negative values and if we dropped the assumption of linearity of the skill deficiency variable, we do not recode to zero and break up the skill-deficiency variable into separate dummies for each of its levels, i.e. we regress the likelihood of choosing a course on whether the course is in the default set, dummies for the level of the skill gap and interactions of the default and these dummies. Skill deficiency level -4 is left out as a reference category. Graph 4.1 shows the coefficients of the dummies for the skill deficiencies. Few people indicate to have a skill-deficiency level 3. If we exclude this level, we can see that there is no significant difference in the size of the coefficients. Graph 4.2 shows that for the interaction between the default and the dummies for the skill deficiencies, we find an approximate linear upward trend. These two results validate the assumption of linearity in the skill deficiency variable in the analysis and show that including negative values of the 
Table 4.7: Psychological attributes and the choice for the default and skill deficiency

\begin{tabular}{|c|c|}
\hline \multicolumn{2}{|l|}{ Default model } \\
\hline Constant & $\begin{array}{l}1.104 * * * \\
(0.279)\end{array}$ \\
\hline Anxiety & $\begin{array}{l}0.097 * * * * \\
(0.036)\end{array}$ \\
\hline Cognitive skills & $\begin{array}{c}-0.049 * * * \\
(0.017)\end{array}$ \\
\hline Time discounting & $\begin{array}{c}0.254 \\
(0.231)\end{array}$ \\
\hline Imagination & $\begin{array}{c}-0.136^{* * *} \\
(0.044)\end{array}$ \\
\hline Risk Aversion & $\begin{array}{l}0.003 * * * \\
(0.001)\end{array}$ \\
\hline Skill-deficiency model & \\
\hline Constant & $\begin{array}{c}-0.578 \\
(0.449)\end{array}$ \\
\hline Anxiety & $\begin{array}{c}0.006 \\
(0.054)\end{array}$ \\
\hline Cognitive skills & $\begin{array}{c}-0.003 \\
(0.027)\end{array}$ \\
\hline Time discounting & $\begin{array}{c}0.420 \\
(0.365)\end{array}$ \\
\hline Imagination & $\begin{array}{l}0.155^{* * *} \\
(0.077)\end{array}$ \\
\hline Risk Aversion & $\begin{array}{c}-0.002 \\
(0.002)\end{array}$ \\
\hline Default*Skill-deficiency model & \\
\hline Constant & $\begin{array}{c}0.367 \\
(0.578)\end{array}$ \\
\hline Anxiety & $\begin{array}{c}0.079 \\
(0.071)\end{array}$ \\
\hline Cognitive skills & $\begin{array}{c}-0.007 \\
(0.035)\end{array}$ \\
\hline Time discounting & $\begin{array}{c}-0.582 \\
(0.468)\end{array}$ \\
\hline Imagination & $\begin{array}{c}-0.036 \\
(0.097)\end{array}$ \\
\hline Risk Aversion & $\begin{array}{c}-0.001 \\
(0.002)\end{array}$ \\
\hline Dummies per course & Incl. \\
\hline
\end{tabular}


Figure 4.1: Regression coefficients of dummies per skill-deficiency level

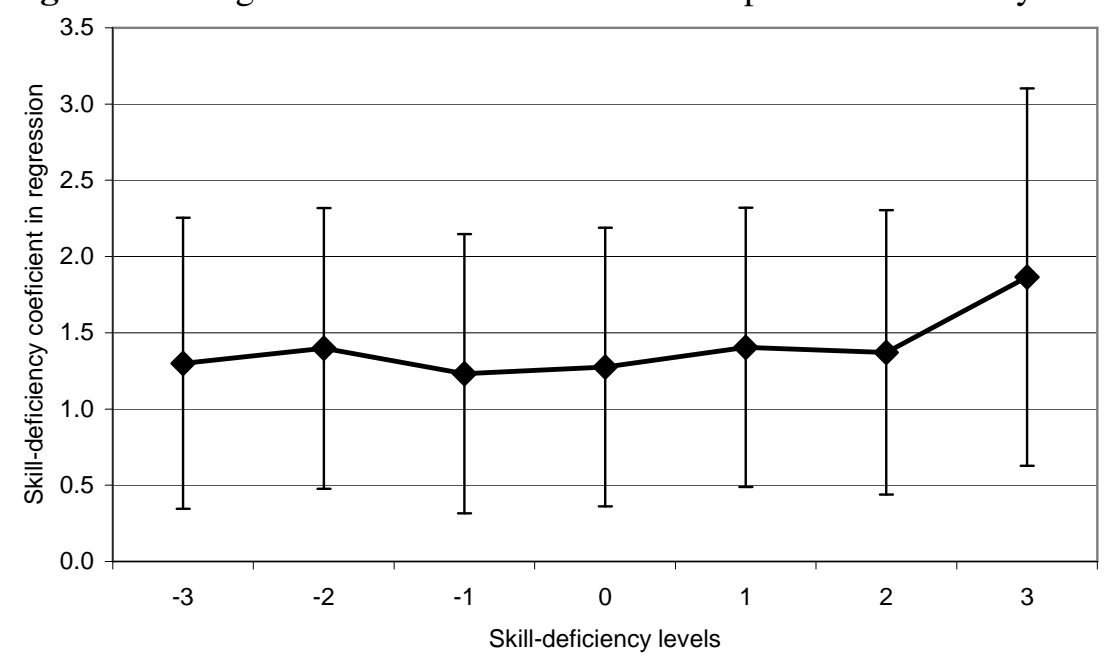

Source: Research Centre for Education and the Labour Market 2005 graduate survey supplement.

skill-deficiency variable would not lead to qualitatively different results. ${ }^{9}$

\subsubsection{Selection bias}

Another concern could be that selection bias drives the results. People who are less ambitious may self-select into jobs which require less skills. They therefore may have less skilldeficiencies and are less required to invest in their skill-needs. In our survey, there are two variables which may serve as proxies for ambition. The first is the question "With respect to your job, indicate to which extent challenge is important to you," and the second is the question "With respect to your job, indicate to which extent career perspectives are important to you." The answer categories to both questions are on a 1-5 scale, 1 being "irrelevant," and 5 being "very important." Table 4.8 shows the answers to this question. The table shows that almost all respondents value challenge and career perspectives highly. Challenge is valued by nearly all respondents as high (4) or very high (5), while career perspective is valued on average less highly than challenge.

We separate the group that has lower ambition from those that have higher ambition based on these two variables. Low ambition is defined as scoring 4 or less on the challenge question. In the second analysis, low ambition is defined as 3 or less on the career perspective question.

\footnotetext{
${ }^{9}$ If we do not recode the negative values of the skill-deficiency to zero, we find that the interaction of the default and the skill-deficiency variable remains positive and significant at the 5\% level (coef: .115, st.err. 0.054). The skill-deficiency variable is still not significantly different from zero, and the default variable remains significantly larger than zero (coef: 1.002, st.err. 0.055). If we interact the default and the dummies for the skill-deficiency with individual attributes, we find similar results as in the main analysis.
} 
Figure 4.2: Regression coefficients of the interaction of the default with dummies per skill-deficiency

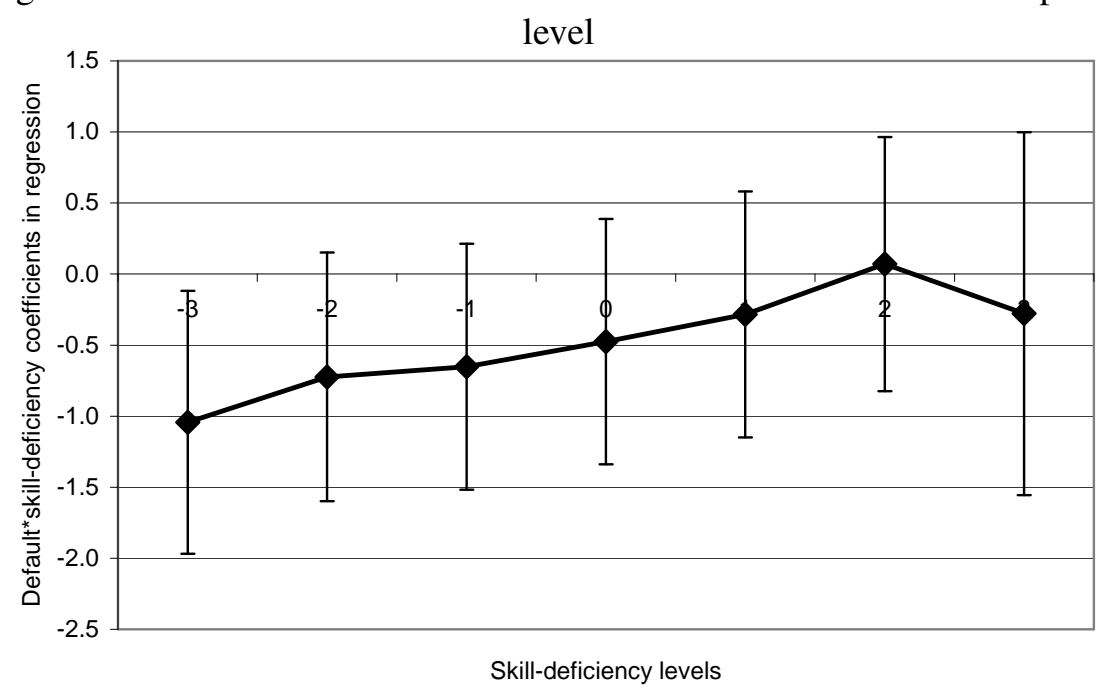

Source: Research Centre for Education and the Labour Market 2005 graduate survey supplement.

Table 4.8: Attitudes related to work

\begin{tabular}{l|rrrrcccc}
\hline \hline Work Attitudes & Irrelevant & & & & Very important & Total & Mean $^{a}$ & St.Dev. \\
Challenge & & & & & & & & \\
Career perspective & 0.1 & 0.3 & 3.6 & 40.4 & 55.6 & 100 & 4.51 & 0.59 \\
& 1.0 & 4.8 & 21.0 & 45.1 & 28.2 & 100 & 3.95 & 0.88 \\
\hline \hline
\end{tabular}

Source: Research Centre for Education and the Labour Market 2005 supplement.

${ }^{a}$ This is the mean score on the questions the answer categories of which range from 1 to 5 . 
Table 4.9: Default, skill-deficiency and the choice for courses for different values attached to challenge in job

\begin{tabular}{l|cccc}
\hline \hline & \multicolumn{3}{|c}{ Highly values challenge in job } & \multicolumn{2}{c}{ Values challenge in job less } \\
& \multicolumn{3}{c}{} & \multicolumn{2}{c}{} \\
& Model 1 & Model 2 & Model 1 & Model 2 \\
Default & $0.977^{* * *}$ & $0.927 * * *$ & $1.077^{* * *}$ & $1.008^{* * * *}$ \\
& $(0.053)$ & $(0.057)$ & $(0.059)$ & $(0.063)$ \\
Skill-deficiency & $0.228^{* * *}$ & 0.101 & $0.254^{* * *}$ & 0.060 \\
& $(0.054)$ & $(0.078)$ & $(0.061)$ & $(0.093)$ \\
Default*Skill-deficiency & & $0.227 * *$ & & $0.337 * * *$ \\
& & $(0.097)$ & & $(0.117)$ \\
Dummies per course & Incl. & Incl. & Incl. & Incl. \\
& & & & \\
\hline \hline
\end{tabular}

Source: Research Centre for Education and the Labour Market 2005 graduate survey supplement. $* \mathrm{p}<0.10, * * \mathrm{p}<0.05, * * * \mathrm{p}<0.01$

Table 4.10: Default, skill-deficiency and the choice for courses for different values attached to career perspectives

\begin{tabular}{l|cccc}
\hline \hline & \multicolumn{3}{|c}{ Highly values career perspectives } & \multicolumn{2}{c}{ Values career perspectives less } \\
& \multicolumn{3}{c}{} \\
& Model 1 & Model 2 & Model 1 & Model 2 \\
Default & $1.004^{* * *}$ & $0.954^{* * *}$ & $1.085^{* * *}$ & $1.016^{* * *}$ \\
& $(0.046)$ & $(0.050)$ & $(0.075)$ & $(0.081)$ \\
Skill-deficiency & $0.266^{* * *}$ & $0.130^{*}$ & $0.229^{* * *}$ & 0.061 \\
& $(0.049)$ & $(0.072)$ & $(0.073)$ & $(0.111)$ \\
Default*Skill-deficiency & & $0.243^{* * *}$ & & $0.280^{* *}$ \\
& & $(0.091)$ & & $(0.134)$ \\
Dummies per course & Incl. & Incl. & Incl. \\
& & & & \\
\hline \hline
\end{tabular}

Source: Research Centre for Education and the Labour Market 2005 graduate survey supplement. $* \mathrm{p}<0.10, * * \mathrm{p}<0.05, * * * \mathrm{p}<0.01$

Table 4.9 and 4.10 show that in the two analyses, the results are similar for both people with high and low ambition. Both groups invest significantly in their deficiencies if a related course is offered to them by default. In both groups, the choices are substantially driven by the default option. Interestingly, we find with both ambition proxies that the interaction of the default and the skill-deficiency has a slightly higher coefficient for the group with lower ambition. This suggests that people in lower level jobs are not lazy or uninterested in their future career, but are willing to invest in their skill-deficiencies. 


\subsubsection{Incentives to invest per course}

For the average skill, people invest in their deficiencies if a course related to the skill is offered to them by default. An interesting question is whether this effect is similar across the six courses.

Table 4.11 reports the findings for the separate skills. We find for all skills that if a course related to the skill is offered in the default, it is chosen more often.

With respect to the skill-deficiency variable, we find that a higher skill-deficiency in a course does not induce people to invest in the course in a similar way. English, Stress management and Computer skills are chosen if the deficiency in these skills is larger, while people choose courses to reduce their skill-deficiency in Computer skills, Team work and Management if these courses are offered to them by default. A higher skill-deficiency in Efficient working is not related to a higher choice for this course.

These results may indicate that people are more able to see the benefits of investing in English and Stress management skills themselves, while the benefits of investing in Team work and Management skills become apparent to them only when their attention is drawn to these skills by their manager. A reason for this may be that English and Stress Management are skills which relate more to personal needs, while Team work and Management relate more to interpersonal skills.

\subsection{Conclusions}

We analyze which people choose courses to reduce work-related skill-deficiencies, and who chooses courses deliberately. To control for differences with respect to opportunities to participate in courses, we use an experiment in which graduates hypothetically have to choose courses. They either accept a randomly designed (default) package of courses or exchange courses from the package with other randomly assigned courses. We relate their choices to an earlier survey in which they were asked to rate their skill-level and the required skilllevel at their jobs with respect to the aspects. Moreover, we measure several individual attributes. We find that in general, people do not seem to choose courses to reduce their skilldeficiencies. However, workers choose courses which reduce their skill-deficiency more often if these courses are in the default package. Our estimates therefore suggest that managers and training specialists can have an important role in an efficient development of workers' human capital. Relating choice behavior to personal characteristics, we find evidence that people with a better developed imagination invest more in their skill-deficiencies and make more independent choices. 
Table 4.11: Analysis per course

\begin{tabular}{l|c}
\hline \hline Default*English & $1.551^{* * * *}$ \\
Default*Stress management & $(0.179)$ \\
& $1.586^{* * *}$ \\
Default*Computer skills & $(0.166)$ \\
& $0.608^{* * *}$ \\
Default*Team work & $(0.141)$ \\
& $1.194 * * *$ \\
Default*Efficient working & $(0.132)$ \\
& $0.562^{* * *}$ \\
Default*Management & $(0.104)$ \\
& $0.594^{* * *}$ \\
Skill-deficiency*English & $(0.139)$ \\
& $0.749^{* * *}$ \\
Skill-deficiency*Stress management & $(0.247)$ \\
& $0.491^{* *}$ \\
Skill-deficiency*Computer skills & $(0.201)$ \\
Skill-deficiency*Team work & $0.345^{*}$ \\
& $(0.176)$ \\
Skill-deficiency*Efficient working & 0.037 \\
Skill-deficiency*Management & $(0.154)$ \\
& 0.127 \\
Default*Skill-deficiency*English & $(0.130)$ \\
& -0.142 \\
Default*Skill-deficiency*Stress management & $(0.091)$ \\
& -0.346 \\
Default*Skill-deficiency*Computer skills & $(0.269)$ \\
& -0.009 \\
Default*Skill-deficiency*Team work & $(0.221)$ \\
& $0.718^{* *}$ \\
Default*Skill-deficiency*Efficient working & $(0.290)$ \\
Default*Skill-deficiency*Management & $0.585 *$ \\
& $(0.321)$ \\
Dummies per course & -0.030 \\
& $(0.159)$ \\
& $0.589 * *$ \\
& $(0.241)$ \\
& Incl. \\
\hline
\end{tabular}

Source: Research Centre for Education and the Labour Market 2005 graduate survey supplement.

$* \mathrm{p}<0.10, * * \mathrm{p}<0.05, * * * \mathrm{p}<0.01$ 
4 Imagination and Investments in Skill-Deficiencies

106 
5 Imagination and Investments in Health: the Body Mass Index 


\subsection{Introduction}

In recent years, many Western countries have experienced a substantial increase in the average body mass of their population. This steady increase has serious consequences for life expectancy and health in general. It therefore raises the question why people take in more calories than recommended at the expense of future health, and why this behavior has changed so much in the past decade.

Comparable to many other forms of risky behavior, it is plausible to assume a link between overweight and a high preference for current relative to future utility. The utility one receives in a future period is weighted today by a discount factor that equals $1 /(1+\delta)$, where $\delta$ represents the discount rate. The higher the discount rate, the lower the discount factor and the less importance one assigns today to utility in that future period. Because of this, when the discount rate rises, the importance assigned to utility in the future period falls, and one is more likely to accept long-run decreases in health and appearance in exchange for the immediate gratification of eating. Among others, decreases in personal savings, rises in consumption (Parker 1999) and rises in credit card debt (Blaylock, Smallwood, Kassel, Variyam, and Aldrich 1999) suggest that average time discounting has increased over time. Along this argument, Komlos, Smith, and Bogin (2004) propose that an increase in the average discount rate, could therefore help explain the recent increase in the average Body Mass Index (BMI).

In this chapter, we analyze this claim from the perspective that time discounting is an aggregate of several psychological attributes. ${ }^{1}$ Many obese people are trying to lose weight, suggesting that they regret having gained weight previously. For this reason, we expect a lack of imagination to be an important predictor for overweight. Other attributes we investigate are impulsiveness, risk aversion, sacrificing for the future, and managing expenditures. We expect that BMI and these psychological attributes can be related but at the same time we think it is very unlikely that psychological attributes underlying time discounting, such as imagination, can have changed rapidly over the course of a few years.

The approach in this chapter consists of four steps. We investigate (1) whether time discounting is related to BMI, (2) which noncognitive skills are related to time discounting, (3) whether these skills can explain differences in BMI between people at a certain point in time, and (4) whether a trend in the skills can account for the increase of BMI over time.

To analyze these questions we use data of the DNB household survey, a survey among a

\footnotetext{
${ }^{1} \mathrm{~A}$ previous version of this chapter is published as Time Discounting and the Body Mass Index, Evidence from the Netherlands, Economics and Human Biology 4(1), Jan. 2006, pp. 39-61. It is a joint work with Lex Borghans. The authors thank Barry Bogin, associate editor John Cawley, Erik de Regt, Inge Sieben, Patricia Smith, Wendy Smits, Bas ter Weel and four anonymous referees for useful comments, John Komlos for his encouragement to write this study and CenterData for providing the data of the DNB household survey.
} 
sample of the Dutch population, for the period 1995-2004. This data set contains information about weight and height, and a set of proxies to measure noncognitive skills of the respondents. We included in this set the willingness to sacrifice present happiness for the future and (budget) managing skills since these traits seem highly related to time discounting. We included impulsiveness since this attribute is typically related to BMI and eating disorders. ${ }^{2}$ We included risk aversion because it may be hypothesized that a high BMI is related with an increased risk of earlier decease. So we expect risk averse people to have a lower BMI. Finally, we included imagination. Judging from the earlier chapters in this thesis, imagination has an important impact on investments in human capital. In this chapter, we analyze whether this also holds for investments in health. We expect a lack of imagination to be an important predictor for overweight because overweight is an investment outcome many people regret. In 2004 we added a supplementary questionnaire to this survey with questions for measuring time discounting which are standard in psychological literature. On the basis of the 2004 data we are able to directly investigate the link between time discounting and BMI, and to investigate the correlation between time discounting and noncognitive skills. We then investigate the development of the noncognitive skills and their link with BMI over time.

We find surprisingly little evidence for a positive correlation between the standard measure of time discounting and BMI. The explanation we pursue for this finding is that time discounting is related to a variety of noncognitive skills. These noncognitive skills may have different correlations with BMI. We find that there is significant correlation between certain noncognitive skills and time discounting and between these noncognitive skills and differences in BMI between people. Significant correlations are found with proxies for impulsiveness, imagination, and budget management skills, although the relationship depends strongly on the choice of the proxy. We find no evidence for correlation between risk aversion or willingness to sacrifice for the future and BMI.

Giving the hypothesis that changes in noncognitive skills have caused changes in BMI the best chance, we analyze the development of proxies for the noncognitive skills that are most strongly related to BMI. We find no evidence for a change of these skills over time. Our main conclusion therefore is that overweight might be related to impulsiveness, imagination and management skills, but the increase in BMI has to be explained by shifts in other parameters that determine the intertemporal decisions regarding the trade-off of current and future health and satisfaction.

${ }^{2}$ For instance, Nederkoorn, Braet, Eijs, Tanghe, and Jansen (2006) show that obesity is related to impulsiveness and give an overview of the psychological literature describing this correlation. Their review shows among others also that obese binge eaters are more impulsive than obese women that do not binge eat, and that bulimia nervosa patients are more impulsive. 
The remainder of this paper is organized as follows. Section 5.2 gives the contribution of this research to the literature. Section 5.3 introduces a model on the relation between time discounting and BMI. Section 5.4 is concerned with the description of the data. Section 5.5 investigates the cross-sectional relationship between time discounting and BMI, between noncognitive skills and time discounting and between noncognitive skills and BMI. Section 5.6 analyzes the relationship between noncognitive skills and BMI over time. Section 5.7 discusses the findings.

\subsection{Contribution to the literature}

The idea that differences in time discounting result from heterogeneity in a variety of noncognitive skills contributes to the literature which describes empirical inconsistencies in correlations between time discounting and investments in human capital. On the basis of the human capital theory, which regards healthy behavior as an investment, as introduced by Becker (1964) and further developed by Grossman (1972), variations in health outcomes are often explained by differences in discount rates. Empirically, these relationships are not very robust however. Among others, Fuchs (1982) and Chapman and Coups (1999) find only minor relations between discount rates and healthy behavior, where the relations are not found for all measures of time discounting or for all behaviors. Chapman and Elstein (1995) and Chapman, Nelson, and Hier (1999) find only weak correlations between time discounting for money and for health. On the other hand, Bickel, Odum, and Madden (1999), Kirby, Petry, and Bickel (1999), Madden, Petry, Badger, and Bickel (1997) and Vuchinich and Simpson (1998) find consistent relations between time discounting and addictive behaviors. More in general, time discounting is expected to play a crucial role in educational participation, and behavior in the labor market. However, empirical evidence is scarce and shows paradoxical results. Fersterer and Winter-Ebmer (2003) show that young people who stay in school longer tend to have lower discount rates. DellaVigna and Paserman (2005) investigate job search behavior focusing on two opposing effects of time discounting. They find that more impatient workers search less intensively for a job, set a lower reservation wage and exit unemployment later, as predicted by a hyperbolic discounting model. Munasinghe and Sicherman (2006) find that workers with higher measured impatience select jobs with flatter wage profiles. Several other authors point at alleged contradictions with respect to time discounting. Komlos, Smith, and Bogin (2004) put forward that while BMI increased, investments in fitness equipment also increased. Ruhm (2000) shows that in economic booms, health outcomes deteriorate, while health improves during recessions. Despite these ambiguous findings, many papers use risky 
behavior, e.g. smoking, as a proxy for time discounting (Sykes, Evans, and McCrum 1990, Evans and Montgomery 1994, Chevalier and Walker 2001, Munasinghe and Sicherman 2006, Fersterer and Winter-Ebmer 2003). Frederick, Loewenstein, and O'Donoghue (2002) give a more extensive overview of these findings.

Besides our explanation for a lack of correlation between time discounting and BMI that heterogenous noncognitive skills are underlying time discounting, we hypothesize in our theoretical model that alternative possibilities to invest in human capital and to engage in risky behavior which are substitutes and/or complements to overconsumption of food could provide an explanation for this finding. Keeping in mind the broad character of human capital, these intervening alternatives could be related to health, but also to education and work. Consequently, the recent increase in BMI can also be related to price changes of these complements and substitutes.

This paper is related to the recent literature investigating the causes of the remarkable increase in BMI (Popkin and Doak 1998, Flegal, Carroll, Kuczmarksi, and Johnson 1998, Mokdad, Serdula, Dietz, Bowman, Marks, and Koplan 1999, Philipson 2001, Komlos and Baur 2004, Ogden, Frayer, Carroll, and Flegal 2004). Technological change has been put forward as an explanation for increasing weights because it has simultaneously lowered the relative price of food and reduced the amount of physical activity required at work and in daily activity (Philipson and Posner 1999, Lakdawalla and Philipson 2002, Philipson 2001). Cutler, Glaeser, and Shapiro (2003) argue that the decrease in the price of calories is of the right magnitude to explain the increase in BMI, while the downward trend in physical activity is far too small to account for this development.

The literature on changes in time discounting over time is less extensive. Komlos, Smith, and Bogin (2004) note that some evidence suggests that average time discounting has increased, e.g. the National Gambling Impact Study Commission (1999) reports an increase in legal gambling in the U.S. over the past three decades. Blaylock, Smallwood, Kassel, Variyam, and Aldrich (1999) note that personal savings in America has decreased and that credit card debt has risen. Parker (1999) shows that private savings have declined since 1980, while personal consumption as a percentage of GDP has increased.

Blaylock, Smallwood, Kassel, Variyam, and Aldrich (1999) and Levy (2002) provide theoretical models explaining obesity using individual differences in discount rates. In a recent paper Komlos, Smith, and Bogin (2004) are the first to hypothesize that the trend in obesity could be related to an increase in time discounting. They provide evidence from a crosscountry comparison of average BMI and saving rates, and time series evidence about these variables for the US, consistent with their hypothesis. However, as they acknowledge, these 
aggregate variables are probably poor proxies for time discounting, which ask for more direct data about discount rates at a micro level to investigate this hypothesis. Smith, Bogin, and Bishai (2005) find that in an NLSY cross-section there is a significant relation between BMI and saving behavior, as a proxy for time discounting, for black and Hispanic men and black women. Cutler and Glaeser (2005) investigate the link between time discounting and obesity by comparing BMI with other forms of risky behavior and conclude that time discounting cannot explain obesity. Allowing for substitutability or complementarity between investments and risky behaviors, we show that time discounting might have very different impacts on each form of behavior.

\subsection{Time discounting and BMI}

Theoretically, BMI and time discounting are related because the immediate consequences of calorie-intake differ from the future consequences. At the margin in developed countries, excessive food intake leads to immediate pleasure or reduction of distress, while it reduces future health and physical appearance. This is a similar trade-off as in many other investment decisions regarding health, education, etc. In a two-period setting, assume that the utility of an agent in period 1 equals $U_{1}=\gamma_{A} A^{\rho}$ (with $\gamma_{A}>0$ and $0<\rho<1$ ), and utility in period 2 equals $U_{2}=-A$, in which $A$ represents a certain form of behavior that increases utility in period 1 , but diminishes utility in period 2. The disutility of $A$ in period 2 is used as unit of measurement. $\rho$ and $\gamma_{A}$ are parameters regarding the diminishing marginal utility of $A$ and the pleasure one derives of $A$, respectively. The price of $A$ in period $1-$ e.g. the price of food - equals $P_{A}$. An agent with discount rate $\delta$, who maximizes the discounted utility for both periods, will maximize:

$$
U=U_{1}-P_{A} A+U_{2}=\gamma_{A} A^{\rho}-P_{A} A-\frac{1}{1+\delta} A
$$

The optimal level of A equals:

$$
A=\left(\frac{\rho \gamma_{A}}{P_{A}+\frac{1}{1+\delta}}\right)^{\frac{1}{1-\rho}}
$$


This expression for $A$ provides potential explanations for why people differ in calorie intake and consequently in BMI. Note that our model describes food intake $A$. This food intake will affect BMI, so the change in BMI will be a function of $A$ : $B M I=f(A)$. When food consumption patterns are persistent, BMI and food intake will be highly correlated, the first representing a stock and the second a flow. Assuming the technical parameter $\rho$ to be equal for all individuals, differences can be related to $P_{A}, \delta$, or $\gamma_{A}$. At a certain point in time, all agents will face the same prices, ${ }^{3}$ so cross-sectional variation in this model can only be related to differences in time discounting and differences in $\gamma_{A}$, reflecting differences in the relative importance of calorie intake compared to the future consequences of this behavior. Examples of this variation could be simple differences in the preferences for food, but also differences in the health risk of obesity to different people. The function shows that people will gain more weight if $\gamma_{A}$ increases, if prices decrease, or time discounting increases. The same expression also provides a framework for understanding shifts over time in the average BMI of the population. Since we are looking at averages, the increasing trend in BMI could be explained by an increase of average discount rate, $\delta$, the average relative pleasure of people in food consumption $\gamma_{A}$, and of course changes in the average price of calorie-rich food. Note that when there are individual differences in time discounting, such changes can shift the BMI of all people simultaneously, but can also affect people with high discount rates more than those with low discount rates.

When time discounting is interpreted as a parameter of the utility function, an increase in BMI does not necessarily imply a fall in welfare. In that situation a fall in prices always implies improved welfare, with people apparently preferring to enjoy high levels of food consumption at the cost of future health problems. Cutler, Glaeser, and Shapiro (2003) argue that with hyperbolic discounting it is possible that lower prices lead to behavior associated with a loss of welfare. The more general interpretation of time discounting as a function of imagination, like we propose in this chapter, leads to similar conclusions.

In the setting presented here, the absence of an empirical link between time discounting and BMI is almost equivalent to a rejection of the Discounted-Utility Model (Samuelson 1937, Koopmans 1960, Lancaster 1963, Fishburn 1970). Several authors have put forward arguments against this model. For example, Loewenstein (1992) argues that a utility function with one single parameter to describe intertemporal decisions is too restrictive, and propose specifications with separate "discount rates" for each individual good. This suggestion is close to the approach we take in this chapter. We separately analyze the underlying noncognitive skills

\footnotetext{
${ }^{3}$ In the U.S., there is some evidence that the poor face higher food prices and/or lack physical access to healthier foods. An interesting extension of the model would be to relax the assumption of homogenous prices.
} 
of time discounting and investigate the relation between the skills and BMI in a cross-section and over time.

There is another explanation of the absence of an empirical link. In practice, overconsumption of food is not the only temptation in life. In a more general framework, alternative possibilities to either invest in future benefits or enjoy life have to be considered simultaneously. Suppose, an agent has to decide about two forms of behavior, $A$ and $B$, which both provide utility in period 1 and disutility in period 2 . Generalizing the utility function in period 1 to $U_{1}=\left(\gamma_{A} A^{v}+\gamma_{B} B^{v}\right)^{\frac{\delta}{v}},(v \leq 1)$ and utility in period 2 to $U_{2}=-A-B$, with prices $P_{A}$ and $P_{B}$, leads to the following optimal level of $A$ :

$$
A=\left(\frac{\rho \gamma_{A}^{\rho / \nu}}{P_{A}+\frac{1}{1+\delta}}\right)^{\frac{1}{1-\rho}}\left(\left(1+\frac{\gamma_{A}}{\gamma_{B}}\right)^{\frac{1}{v-1}}\left(\frac{P_{B}+\frac{1}{1+\delta}}{P_{A}+\frac{1}{1+\delta}}\right)^{\frac{\rho}{v-1}}\right)^{\frac{1}{1-\rho}} \cdot 4
$$

The first part of this equation is almost identical to 5.2. The second part, however, reveals an interesting interaction between different forms of intertemporal trade-offs. When $A$ and $B$ are not perfect substitutes ( $s o v \neq 1$ ), differences between people in parameters with respect to aspect $B$, and changes of the price of $B$ and the averages in the distribution, are also going to affect $A$. The impact of these differences depends on the degree of complementarity of $A$ and $B$. The switching point is when $\rho / v=1$. In practice, there are many applications of two aspects that can be substitutable or complementary. For example, when people need distraction to cope with stress, one could imagine smoking and eating to be substitutes. This model can also link health with labor market behavior. Suppose that $A$ represents food intake and $B$ represents leisure at the cost of investing in training or working hard to invest in a career. When leisure and food intake are substitutes, the model can explain that people who work or learn hard for their future benefits might neglect their health and face an increasing BMI. Empirical studies find negative relations between smoking and various outcomes that may be influenced by high discount rates, e.g. health, educational attainment, earnings levels, use of seatbelts, physical exercise, teeth brushing, and teeth flossing (Hersch and Viscusi 1990, Hersch 1996, 2000, Levine, Gustafson, and Velenchik 1997, Viscusi and Hersch 2001). On the other hand, e.g. Gulliver (1995), Burton and Tiffany (1997) and Picone, Sloan, and Trogdon (2004) provide evidence for the complementarity of smoking and drinking, while Cawley, Markowitz, and Tauras (2004) find that girls with higher BMI are on average more likely to start smoking.

\footnotetext{
${ }^{4}$ One could further generalize the model by introducing a CES utility function for the second period. In such a model, the future consequences of one type of behaviour also depend on other forms of behavior.
} 
It is very interesting to note that the impact of the interaction between two aspects $A$ and $B$ can be different for different values of the discount rate. So when the price of $B$ is very high, it will be especially those with low discount rates who will choose low levels of $B$. When these aspects are substitutes, this will increase consumption of $A$, reversing the relationship between time discounting and the form of behavior. An example is again the situation in which people who work hard to make a career, consume more food to keep on going. If the benefits from investing in a career exceed the costs of increased BMI, a low discount rate could in theory be related to high BMI. These extensions show that in a more general setting, the link between time discounting and BMI becomes an empirical question, which we try to answer in this paper. 5

\subsection{Data and empirical strategy}

Our analyses are based on the DNB household Survey, formerly known as the CentER Savings Survey, collected by CentER (Tilburg, the Netherlands). DNB is a household survey, in which all members of the household are requested to fill out the questionnaire. The children are however excluded from most of the survey questions when they are below 16. The data are unique for our purposes, because they contain both questions about body height and weight and questions that are proxies for noncognitive skills related to time discounting for 19952004. In a supplementary survey in 2004, questions are asked that measure time discounting following the tradition in psychological literature.

\subsubsection{The data}

The survey is taken in March. The samples are representative for the Dutch population of 16 and older. From 1995, this annual survey contains a large number of questions about financial behavior and attitudes, with almost no change in the questions that are used. We use the data from 1995 - 2004. In 1995, the sample contained 4,854 people. This decreased to 2,059 respondents in 2004. In 2000, most of the questions that are relevant for our analyses have only been asked to respondents with a job. This was presumably due to an error in the routing of the questionnaire. Since the distribution of characteristics of the working population differs clearly from the characteristics of the population as a whole, we do not use the data for 2000 in the analyses.

\footnotetext{
${ }^{5}$ While the model describes the different possible expectations one could have about the sign of the relation between BMI and time discounting, we do not aim to estimate a structural variant of the model. This could be an interesting topic for future research.
} 
In October 2004, a supplementary survey has been carried out, targeted at the same respondents as the Basic DNB household Survey of 2004, including two questions that measure time discounting, following the tradition in psychology (Rachlin, Raineri, and Cross 1991).

Apart from the anthropometric measures, the questions about financial behavior and attitudes that provide many proxies for noncognitive skills related to time discounting and the two questions taken from the psychological literature, the survey provides information about sex, age, educational attainment, and income.

\subsubsection{BMI}

Using the information on height and weight, we calculated the BMI as weight in kilograms over the square of height in meters. The data on height and weight are self-assessed, and may therefore be subject to some bias. Cawley (2004) shows that the self-reports of weight and height include some degree of reporting error. ${ }^{6}$ This under- and overreporting hence transforms the scale of BMI and therefore self-assessed BMI data should be interpreted slightly different than BMI based on actual measures of height and weight. However, if the under- and overreporting is related to BMI levels only, relations between BMI and other variables will not be affected by this bias. ${ }^{7}$ A more serious problem could arise if the degree of underreporting would be correlated with time discounting. Regarding the extent of overreporting as reported by Cawley (2004) such biases are unlikely to change the results in this paper substantially. In addition, the data contains a small fraction of implausible answers. To reduce the impact of outliers, we leave out 7 cases for those claiming to weigh less than 35 or more than 135 kilograms. The average male respondent in our sample in 1995 is $180.6 \mathrm{~cm}$ tall and weighs 79.7 kilograms. In 2004, these averages increased to $180.8 \mathrm{~cm}$ and $83.4 \mathrm{~kg}$. Consequently, the average male BMI increased from 24.4 in 1995 to 25.5 in 2004. For females, the average height was stable from $168.3 \mathrm{~cm}$ in 1995 to $168.2 \mathrm{~cm}$ in 2004 while average weight increased from $67.2 \mathrm{~kg}$ to $71.9 \mathrm{~kg}$ in 2004. Their BMI increased from 23.7 in 1995 to 25.4 in 2004. According to e.g. the U.S. Department of Health and Human Services, a person with a BMI below 18.5 is considered undernourished, a BMI between 25 and 29.9 is overweight, while a BMI above 30 is obese. Table 5.1 shows that in 1995, 5.4 percent of the population was obese. In 2004, the percentage of obese people increased to 12.2 percent. The percentage of overweight people increased from 30.2 to 37.0 percent.

Figure 5.1 gives the development of BMI in the population between 1995 and 2004. To

\footnotetext{
${ }^{6}$ Cawley (2000) shows the details of his estimation in an appendix. Women, on average, underreport their weight by $1.5 \%$, where underweight women overreport and overweight women underreport.

${ }^{7}$ This is under the assumption of approximately linear relationships between BMI and the variables.
} 
Table 5.1: BMI levels men and women, 2004

\begin{tabular}{ll|rrrrrr}
\hline \hline & & \multicolumn{3}{c}{1995} & & \multicolumn{2}{c}{2004} \\
BMI* & Men & Women & Total & Men & Women & Total \\
$<18.5$ & Undernourished & 2.2 & 4.2 & 3.1 & 1.1 & 3.0 & 2.0 \\
$18.5 \leq \mathrm{BMI}<25$ & Normal & 57.5 & 65.5 & 61.3 & 47.3 & 50.6 & 48.9 \\
$25 \leq \mathrm{BMI}<30$ & Overweight & 36.0 & 23.6 & 30.2 & 42.1 & 31.1 & 37.0 \\
$\mathrm{BMI} \geq 30$ & Obese & 4.3 & 6.7 & 5.4 & 9.4 & 15.3 & 12.2 \\
& Total & 100.0 & 100.0 & 100.0 & 100.0 & 100.0 & 100.0 \\
& & & & & & & \\
\hline \hline
\end{tabular}

Source: DNB household survey

* BMI is defined as weight in $\mathrm{kg}$ divided by height in meters.

Figure 5.1: The development of BMI, 1995-2004

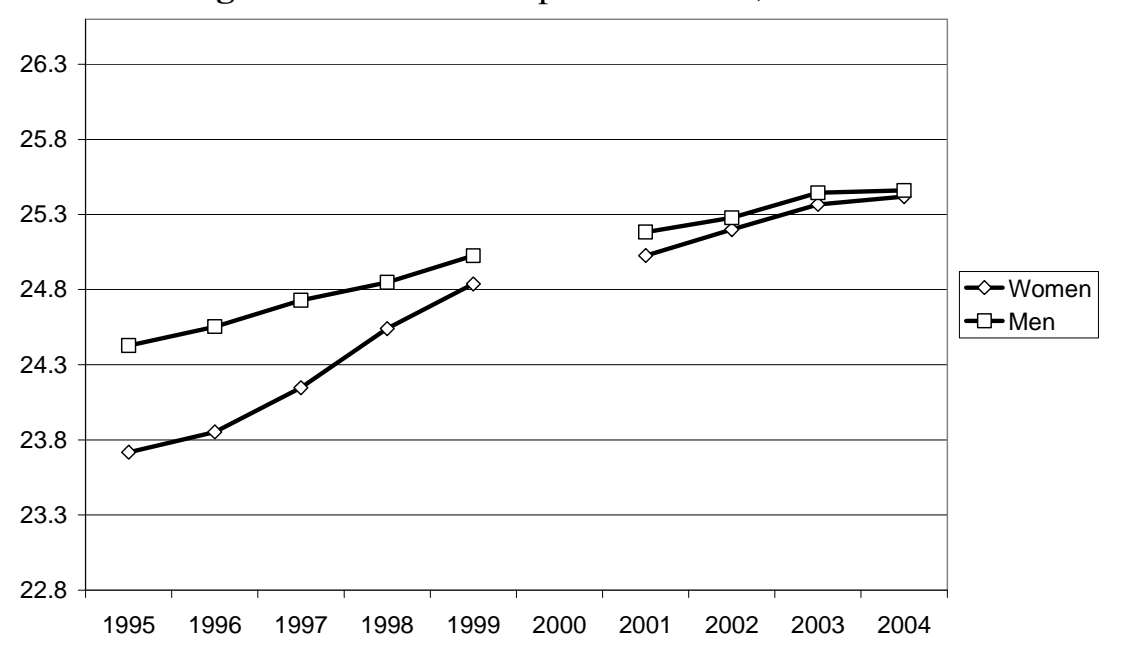

Source: DNB household survey 1995-1999, 2001-2004

Note: The maximum of the scale of the vertical axis is determined by adding 0.5 times the standard deviation to the mean BMI score. Similarly, the minimum of the scale is determined by subtracting 0.5 times the standard deviation of the mean score. The mean and standard deviation are averages of these values over the years for men and women together.

facilitate visual comparison of the size of the developments in the graphs, the vertical axes in all graphs are scaled from the average value in the population in all years minus 0.5 standard deviation in this variable, to the same average plus 0.5 standard deviation. The figure clearly shows the large increase in BMI over this period, and shows that women experience a larger increase than men. Breaking down the development of BMI over time by age and sex, we find that the largest increase in BMI has taken place among women below 40. For women, the gaps in average BMI between age groups $(25-39,40-55,55+)$ diminished considerably, while for men the increase has been similar in the three age groups, keeping the gap between men under 40 and the older two age groups intact.

Interestingly, the standard deviation of BMI increased with the increase in BMI: for men the increase has been 0.303 (3.112 to 3.419) and for women 0.818 (3.875 to 4.694). Figure 5.2 shows the increase in BMI between 1995 and 2004 for men and women across the percentiles 
Figure 5.2: Increase in BMI between 1995 and 2004 for different percentiles of the male and female BMI distribution

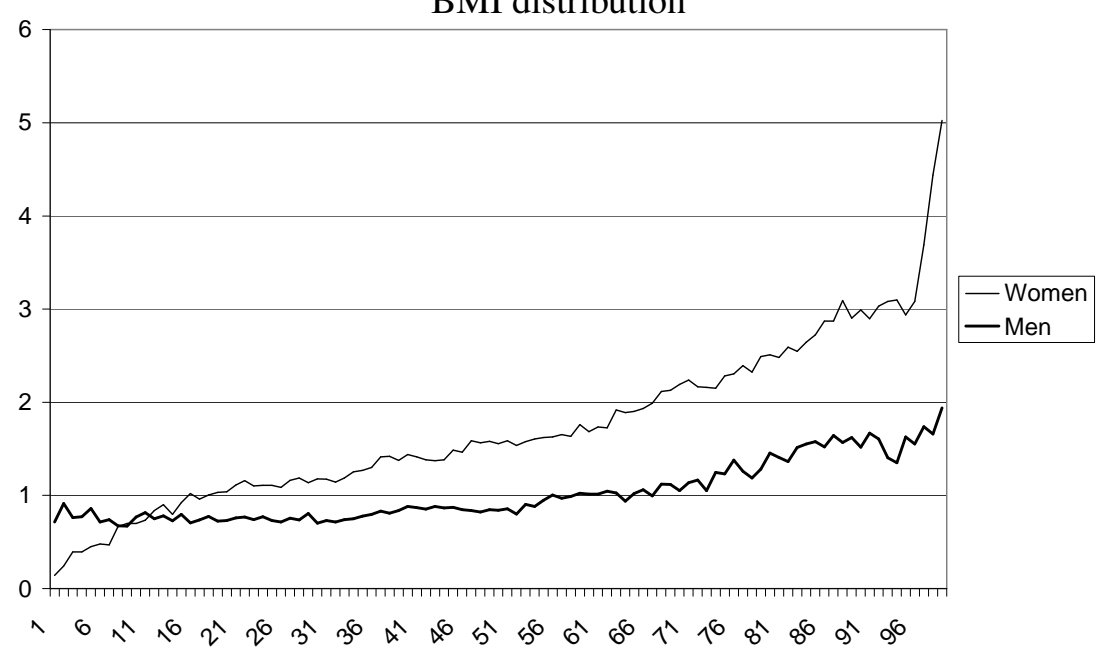

Source: DNB household survey 1995-1999, 2001-2004

Note: The vertical-axis is defined as the difference of the 2004 and the 1995 BMI score, the horizontal-axis is the percentile in the BMIdistribution.

of the BMI distribution. The figure shows that women in a high BMI-percentile became heavier over the years while women that were in a low BMI-percentile remained about equally heavy. For men the development is more equal between the percentiles. Men in all BMIpercentiles became heavier.

\subsubsection{Empirical strategy}

In the supplementary survey of 2004, we were able to include questions that aim at measuring time discounting. Our empirical strategy is, first, to investigate the validity of these measures which are standard in psychological literature. Second, we analyze the correlation between time discounting and a variety of noncognitive skills, which are available in the regular survey. Third, we investigate for 2004 the relationship between these noncognitive skills and BMI. ${ }^{8}$ Fourth, we select the skills that are most successful in explaining BMI, check the robustness of these results and investigate whether this relationship between a skill and BMI can explain the rise in obesity that is observed in the past decade.

\footnotetext{
${ }^{8}$ We do not have measures of the actual eating behavior. The analyses therefore focus on the stock rather than on the flow of food intake.
} 


\subsubsection{Measuring time discounting}

Following the psychological tradition (Rachlin, Raineri, and Cross 1991) we included a battery of six questions, like: "Please indicate, which alternative you would choose: 1. 50 euro now, 2. 70 euro a year from now." Per question, the respondent has to choose one of these two options. Varying the amount of money in alternative 1 and 2, and the timing of the first and second periods, makes it possible to vary an implicit discount rate. ${ }^{9}$ Several papers show that this measure of time discounting is rather sensitive to the wording of the question, and to anchoring effects, i.e. imputed time discounting tends to be biased in the direction of the rate that equates the first pair of options to which the responds are exposed (Green, Jacowitz, Kahneman, and McFadden 1998). We checked the sensitivity of the answers to the level of the awarded money. For a random group of $50 \%$ of the respondents all questions have been asked using amounts that are a factor 10 larger (so "500 euro now" and "700 euro a year from now"). As found in several other papers, see e.g. Thaler (1985), although the implicit discount rate is the same, the level of the results turns out to depend on the exact question. ${ }^{10}$ People who are asked the set with the low money values score a significantly higher discount rate $(t=6.699)$. Verifying the correlation with a large set of other variables, however, we find no significant differences, which suggests that apart from this level effect, different wordings reflect similar differences between people in their trade-off between the present and the future. In all regressions, we include a dummy variable that equals 1 if the low amounts are asked, and 0 if the high amounts are asked, to control for the specific wordings of the question. Table 5.2 provides information about the answers of the respondents on these time discounting questions. For the question mentioned above as an example, which has an implicit break-even discount rate of $40 \%$, approximately $50 \%$ of the respondents prefer the money now, while $50 \%$ prefer to wait. As is usually found, this median discount rate is much higher than typical interest rates at a bank. This may in part be due to the wording of the question and anchoring effects, but also reveals that many people tend to put high weight on immediate gratification compared to their future well-being. We use the number of answers in which a respondent prefers to get the money early as a measure for time discounting.

As an alternative to the standard battery with monetary choices enabling the use of nonmonetary choices as a way to measure time discounting, some authors apply survey questions based on more specific cases (see e.g. Frederick (2005)). To investigate the validity of our monetary measure of the discount rate, we asked the following additional question following

\footnotetext{
${ }^{9}$ The discount rate is represented by the abbreviation "DR" in the tables.

${ }^{10}$ This test is based on linear utility functions. The magnitude effect can in principle be explained also by non-linear utility functions.
} 
Table 5.2: Percentages of the respondents choosing the option that gives them gratification sooner with the high and low monetary questions

\begin{tabular}{lccc}
\hline & \multicolumn{2}{c}{$\begin{array}{c}\text { \% Respondents choosing } \\
\text { gratification sooner }\end{array}$} \\
Questions & $\begin{array}{c}\text { Implicit } \\
\text { time discounting }\end{array}$ & $\begin{array}{c}\text { Low amounts } \\
\text { High amounts }\end{array}$ \\
\hline 50 Euros now or 70 Euros in 1 year & 40 & 60.6 & 47.8 \\
100 Euros in 1 year or 150 Euros in 4 years & 11 & 79.6 & 70.2 \\
100 Euros now or 100 Euros in 1 year & 0 & 95.7 & 96.0 \\
50 Euros in 1 year or 90 Euros in 2 years & 80 & 45.3 & 33.1 \\
50 Euros now or 300 Euros in 4 years & 57 & 25.2 & 19.7 \\
100 Euros in one year or 125 Euros in 2 years & 25 & 80.9 & 73.8 \\
& & & \\
\hline \hline
\end{tabular}

Source: DNB household survey, supplementary survey 2004

Note: A randomly selected group of the respondents were asked questions with the same implicit discount rate but higher amounts, i.c. all monetary values in the questions were multiplied by 10 .

this approach:

"Suppose you win a 10-day holiday trip to an interesting destination. To spread participation, you are asked if you can delay your trip by three years in exchange for a longer vacation. How many days should you be offered in addition to accept the offer in 3 years' time?"

Answers varied from 0 to 365 days, with a mean of 13.8 days and a standard deviation of 33.2. This corresponds to a discount rate of $24.6 \%$. $97.7 \%$ of the observations are in the 0-50 days interval. We truncate our measure at 50 days before calculating the implicit annual discount rate $\left(\frac{\text { days }+10}{10}\right)^{1 / 3}-1$. We find a very significant relationship between this measure and the discount rate based on the monetary questions (t-value: 5.141).

\subsubsection{Noncognitive skills}

The basic questionnaire includes a wide variety of proxies for noncognitive skills that can be important in intertemporal choices. We selected 22 questions which seemed to be most appropriate from a theoretical point of view. We included in this set the willingness to sacrifice present happiness for the future and (budget) managing skills since these traits seem highly related to time discounting. We included impulsiveness since this attribute is typically related to BMI and eating disorders (Nederkoorn, Braet, Eijs, Tanghe, and Jansen 2006). We included risk aversion because it may be hypothesized that a high BMI is related with an increased risk of earlier decease. So we expect risk averse people to have a lower BMI. Finally, we included imagination. Judging from the earlier chapters in this thesis, imagination has an important impact on investments in human capital. Here, we analyze whether this also holds for investments in health. Table 5.3 contains the wordings of all these questions and provides 
some statistics. ${ }^{11}$

The first set of questions relates to the ability or willingness to sacrifice for future happiness. A higher ability to sacrifice is expected to be related to lower time discounting and BMI. Hence, the four statements are all expected to be negatively related to time discounting and BMI.

The second set of questions is related to impulsiveness. Impulsiveness is expected to be related positively with time discounting and BMI. Therefore, all three variables are expected to have a positive expected correlation with time discounting and BMI.

The third set of questions is measuring imagination. A better imagination is expected to be related with lower time discounting and BMI. So FUTURE01 and FUTURE07 are expected to be negatively related, while the other variables are expected to be positively related with time discounting and BMI.

Fourth is a set of questions related to how people are able to manage their expenditures given the budget they have. A low discount rate is expected to be related with less trouble managing the expenditures. There are three statements related to managing and the survey also monitors in great detail accounts, savings, and loans. ASSETS (negative expected correlation with time discounting/BMI) is the total value of the accounts and different kinds of savings, while LIABILITIES (positive expected correlation) reflects the aggregate value of loans and credits, excluding the mortgage on the first house. ${ }^{12}$ We use these two financial summary statistics in euros and as a ratio to yearly net income. The statements and the ASSETS are expected to be negatively related to time discounting and BMI, while the LIABILITIES are expected to be positively related to these variables.

The last group of seven questions concerns statements about saving behavior. RISK asks how risky the investments of the respondent have been. These seven questions seem to be more related to risk aversion than to time discounting, but since risk aversion is known to be related to time discounting (Gafni and Torrance 1984) in the sense that people with high discount rates tend to be less risk averse, we include risk aversion in our set. The expected sign of the correlations with time discounting and BMI are expected to be negative for SAVE1, SAVE2, SAVE3 and SAVE4 and positive for the other variables.

\footnotetext{
${ }^{11}$ Several proxies for time discounting could be combined to reduce measurement error. We prefer the analyses of the separate proxies since for most of them, the correlation with the psychological measure of time discounting is sufficiently large, while furthermore this approach reveals the sensitivity of the results to the specific proxy used. We report the Crohnbach Alpha's in the table.

${ }^{12}$ The mortgage is excluded because it is for most people an investment and therefore incomparable with depths for consumption reasons. Including mortgages would also bias the comparison between people who own or rent a house.
} 


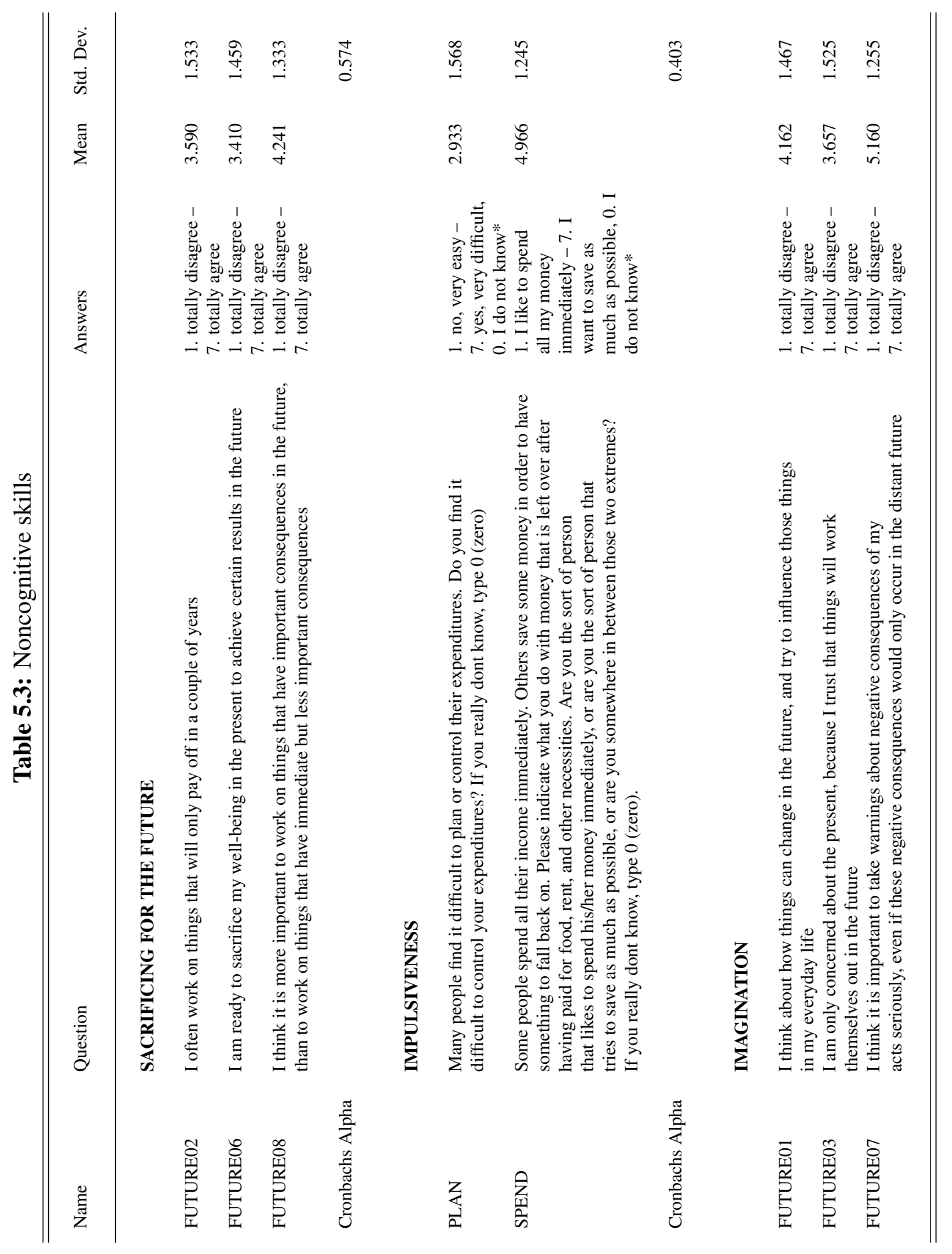




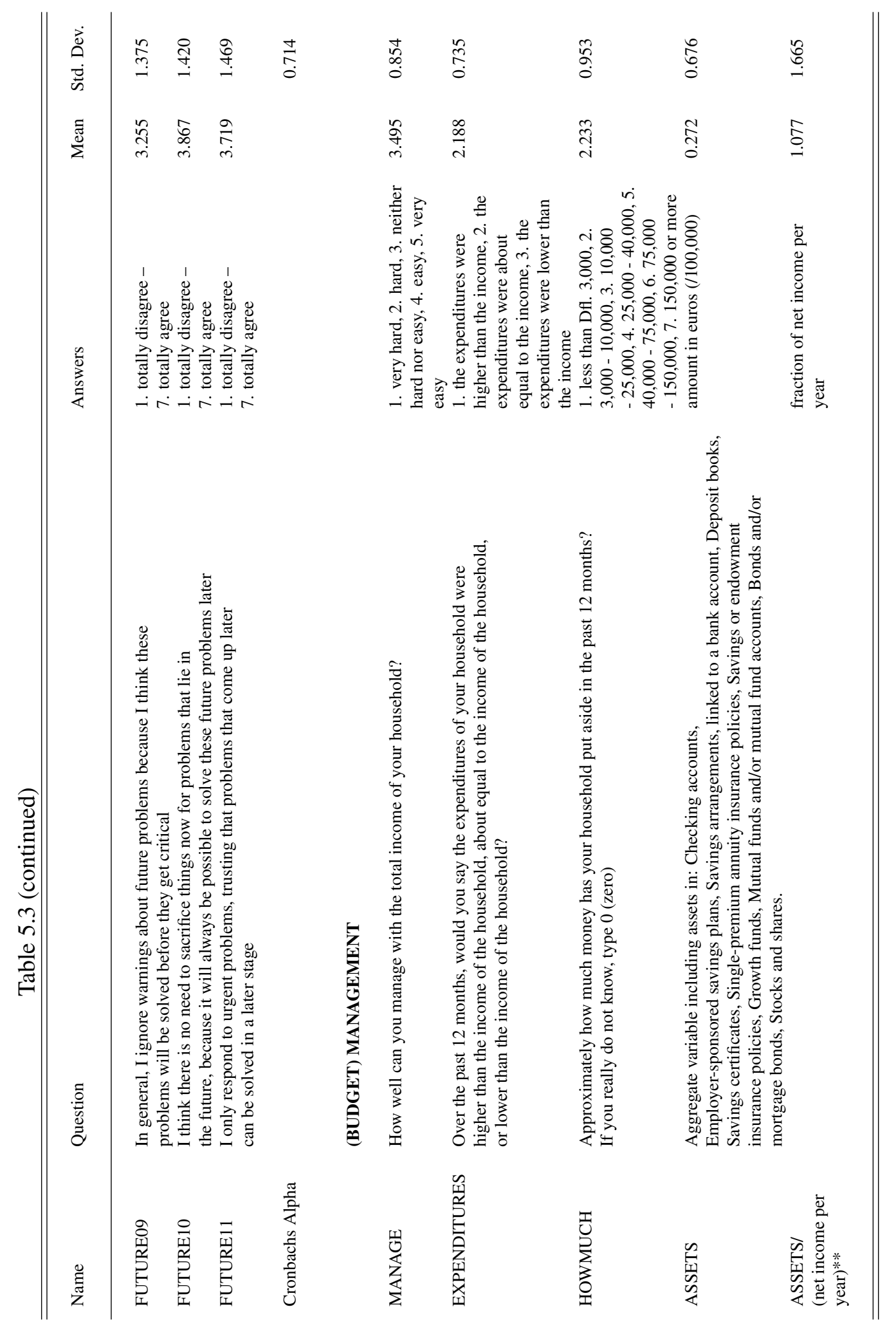




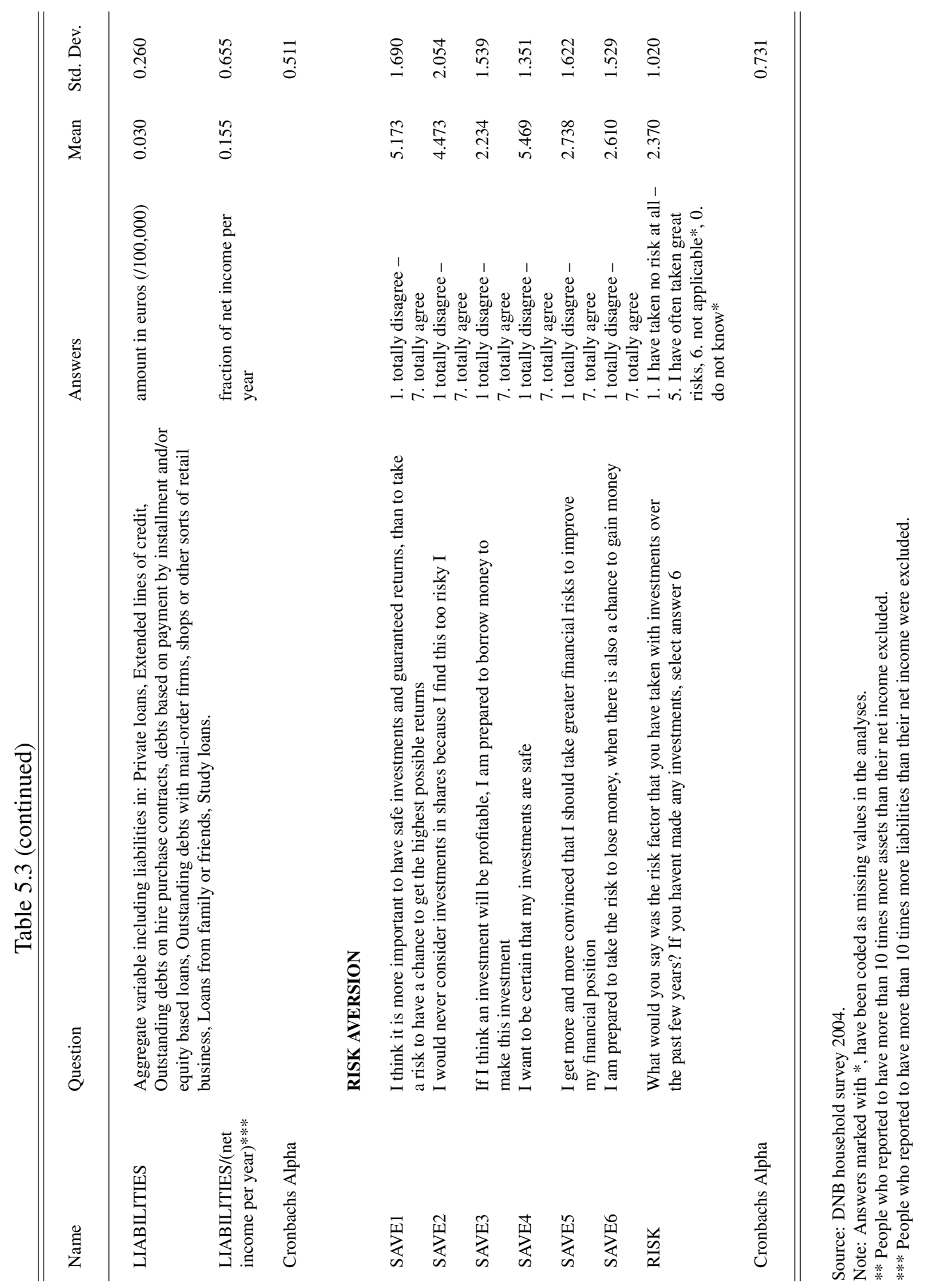




\subsection{Cross-sectional relationship between noncognitive skills and time discounting and BMI}

To investigate the link between the noncognitive skills and time discounting and BMI, we analyze whether the proxies for the skills based on financial information and attitudes are related to the individual discount rate and BMI. Using the data for 2004, we regress time discounting and BMI on each of these proxies, saturating the model for age and sex (i.e. we included a full set of sex-age dummies, to ensure that all age and sex differentials are excluded from the analyses). The first column of Table 5.4 provides the estimates of the parameters for the proxies in relation with our measure of time discounting based on the choices between two amounts of money (DR). With a few exceptions, we find a strong significant relationship between the proxies and the measure of time discounting in the expected direction. SAVE2, SAVE6 and RISK have signs opposite to those expected. Apart from these variables, most proxies however seem to be related to time discounting as expected.

The next step in our analysis is to investigate whether time discounting and the proxies for noncognitive skills are related to BMI. We find surprisingly little correlation between the discount rate and BMI. We also do not find a significant relation between any of the proxies for sacrificing the future and BMI. For the other noncognitive skills, we find that for some proxies there is a significant relationship with BMI, while for others this link is absent. For impulsiveness, the PLAN variable is significantly related with BMI; for imagination, FUTURE03 is related with BMI, although the relation is less significant with the BMI for women; and for managing we find that MANAGE is related for both men and women with BMI. For risk aversion, SAVE2 is related with time discounting and BMI, but its sign is opposite to what we expected. There are no other proxies for risk aversion related with BMI.

It can be concluded therefore that there may be a relationship between noncognitive skills and BMI, but this link is very sensitive to the exact variable that is chosen to proxy the skill. An interesting topic for future research is to analyze the similarities in the proxies that are related to BMI in comparison with those that are not. There is some evidence that time discounting for money and the discount rate for health might not be similar (Cairns 1994, Chapman and Elstein 1995).

PLAN, MANAGE, and FUTURE03 are the variables that have the highest level of significance in the overall relationship with BMI, and remain significant in most regressions for subgroups. To give the hypothesis that the increase in BMI is related to a change in the noncognitive skills over time the best chance, we will use these three proxies for our further analyses. 
Table 5.4: Relationship between time discounting and BMI as dependent variables and noncognitive skills as independent variables

\begin{tabular}{|c|c|c|c|c|}
\hline & \multirow{2}{*}{$\begin{array}{c}\text { TIME DISCOUNTING** } \\
\text { All }\end{array}$} & \multicolumn{3}{|c|}{ BMI } \\
\hline & & All & Women & Men \\
\hline TIME DISCOUNTING & & $\begin{array}{c}0.096 \\
(0.060)\end{array}$ & $\begin{array}{c}0.066 \\
(0.106)\end{array}$ & $\begin{array}{c}0.123^{*} \\
(0.066)\end{array}$ \\
\hline \multicolumn{5}{|l|}{ SACRIFICING } \\
\hline FUTURE02 & $\begin{array}{c}-0.151 * * * \\
(0.027)\end{array}$ & $\begin{array}{c}0.018 \\
(0.067)\end{array}$ & $\begin{array}{c}0.072 \\
(0.117)\end{array}$ & $\begin{array}{c}-0.026 \\
(0.075)\end{array}$ \\
\hline FUTURE06 & $\begin{array}{l}-0.084 * * * \\
(0.029)\end{array}$ & $\begin{array}{c}-0.064 \\
(0.071)\end{array}$ & $\begin{array}{c}-0.173 \\
(0.123)\end{array}$ & $\begin{array}{c}0.032 \\
(0.080)\end{array}$ \\
\hline FUTURE08 & $\begin{array}{c}-0.155^{* * * *} \\
(0.031)\end{array}$ & $\begin{array}{c}-0.148^{*} \\
(0.076)\end{array}$ & $\begin{array}{c}-0.205 \\
(0.134)\end{array}$ & $\begin{array}{c}-0.103 \\
(0.084)\end{array}$ \\
\hline \multicolumn{5}{|l|}{ IMPULSIVE } \\
\hline PLAN & $\begin{array}{l}0.103^{* * *} \\
(0.026)\end{array}$ & $\begin{array}{l}0.489 * * * \\
(0.063)\end{array}$ & $\begin{array}{l}0.628^{* * * *} \\
(0.109)\end{array}$ & $\begin{array}{l}0.378^{* * * *} \\
(0.071)\end{array}$ \\
\hline SPEND & $\begin{array}{c}-0.153 * * * \\
(0.033)\end{array}$ & $\begin{array}{c}-0.116 \\
(0.081)\end{array}$ & $\begin{array}{c}-0.125 \\
(0.141)\end{array}$ & $\begin{array}{c}-0.117 \\
(0.091)\end{array}$ \\
\hline \multicolumn{5}{|l|}{ IMAGINATION } \\
\hline FUTURE01 & $\begin{array}{c}-0.115^{* * * *} \\
(0.028)\end{array}$ & $\begin{array}{c}-0.048 \\
(0.069)\end{array}$ & $\begin{array}{c}-0.106 \\
(0.117)\end{array}$ & $\begin{array}{c}0.006 \\
(0.078)\end{array}$ \\
\hline FUTURE03 & $\begin{array}{l}0.183^{* * * *} \\
(0.026)\end{array}$ & $\begin{array}{l}0.207 * * * \\
(0.065)\end{array}$ & $\begin{array}{c}0.196^{*} \\
(0.116)\end{array}$ & $\begin{array}{l}0.213 \text { *** } \\
(0.072)\end{array}$ \\
\hline FUTURE07 & $\begin{array}{l}-0.124 * * * \\
(0.033)\end{array}$ & $\begin{array}{c}-0.014 \\
(0.080)\end{array}$ & $\begin{array}{c}0.108 \\
(0.138)\end{array}$ & $\begin{array}{r}-0.116 \\
(0.090)\end{array}$ \\
\hline FUTURE09 & $\begin{array}{l}0.089 * * * \\
(0.030)\end{array}$ & $\begin{array}{c}0.088 \\
(0.072)\end{array}$ & $\begin{array}{c}0.008 \\
(0.126)\end{array}$ & $\begin{array}{c}0.153^{*} \\
(0.081)\end{array}$ \\
\hline FUTURE10 & $\begin{array}{l}0.077 * * * \\
(0.029)\end{array}$ & $\begin{array}{c}-0.045 \\
(0.070)\end{array}$ & $\begin{array}{r}-0.130 \\
(0.123)\end{array}$ & $\begin{array}{c}0.021 \\
(0.078)\end{array}$ \\
\hline FUTURE11 & $\begin{array}{l}0.122 * * * \\
(0.027)\end{array}$ & $\begin{array}{c}0.073 \\
(0.068)\end{array}$ & $\begin{array}{c}0.030 \\
(0.120)\end{array}$ & $\begin{array}{c}0.107 \\
(0.075)\end{array}$ \\
\hline MANAGING & & & & \\
\hline MANAGE & $\begin{array}{c}-0.331 * * * \\
(0.047)\end{array}$ & $\begin{array}{c}-0.785 * * * \\
(0.116)\end{array}$ & $\begin{array}{c}-0.953 * * * \\
(0.189)\end{array}$ & $\begin{array}{c}-0.612^{* * * *} \\
(0.137)\end{array}$ \\
\hline EXPENDITURES & $\begin{array}{c}-0.250 * * * \\
(0.055)\end{array}$ & $\begin{array}{c}-0.597 * * * \\
(0.134)\end{array}$ & $\begin{array}{c}-0.957 * * * \\
(0.231)\end{array}$ & $\begin{array}{c}-0.302^{* *} \\
(0.152)\end{array}$ \\
\hline HOWMUCH & $\begin{array}{c}-0.272^{* * * *} \\
(0.053)\end{array}$ & $\begin{array}{c}-0.474 * * * \\
(0.126)\end{array}$ & $\begin{array}{c}-0.798 * * * \\
(0.199)\end{array}$ & $\begin{array}{c}-0.122 \\
(0.155)\end{array}$ \\
\hline ASSETS** & $\begin{array}{c}-0.395^{* * * *} \\
(0.062)\end{array}$ & $\begin{array}{c}-0.280^{*} \\
(0.146)\end{array}$ & $\begin{array}{c}-0.370 \\
(0.333)\end{array}$ & $\begin{array}{c}-0.249 * \\
(0.139)\end{array}$ \\
\hline LIABILITIES** & $\begin{array}{c}-0.137 \\
(0.143)\end{array}$ & $\begin{array}{c}0.358 \\
(0.343)\end{array}$ & $\begin{array}{c}3.143^{*} \\
(1.795)\end{array}$ & $\begin{array}{c}0.211 \\
(0.289)\end{array}$ \\
\hline ASSETS*** & $\begin{array}{c}-0.101^{* * *} \\
(0.030)\end{array}$ & $\begin{array}{c}-0.181 * * * \\
(0.067)\end{array}$ & $\begin{array}{c}-0.125 \\
(0.103)\end{array}$ & $\begin{array}{c}-0.254 * * * \\
(0.086)\end{array}$ \\
\hline LIABILITIES*** & $\begin{array}{c}0.055 \\
(0.075)\end{array}$ & $\begin{array}{c}0.282^{*} \\
(0.157)\end{array}$ & $\begin{array}{c}0.286 \\
(0.227)\end{array}$ & $\begin{array}{c}0.277 \\
(0.221)\end{array}$ \\
\hline
\end{tabular}


Table 5.4 (continued)

\begin{tabular}{lcccc}
\hline \hline & & & & \\
& & & & \\
& & & & \\
& & & & \\
& & & & \\
& & & & \\
& & & & \\
RIME DIISC AVERSION & & & & \\
SAVE1 & $-0.087^{* * *}$ & -0.041 & -0.097 & 0.006 \\
& $(0.025)$ & $(0.061)$ & $(0.106)$ & $(0.068)$ \\
SAVE2 & $0.073^{* * *}$ & $0.159^{* * *}$ & $0.215^{* *}$ & $0.120^{* *}$ \\
& $(0.021)$ & $(0.051)$ & $(0.093)$ & $(0.055)$ \\
SAVE3 & -0.016 & 0.091 & -0.024 & $0.151^{* *}$ \\
& $(0.028)$ & $(0.069)$ & $(0.138)$ & $(0.070)$ \\
SAVE4 & $-0.079^{* *}$ & -0.107 & -0.082 & -0.130 \\
& $(0.032)$ & $(0.076)$ & $(0.130)$ & $(0.088)$ \\
SAVE5 & -0.013 & 0.015 & 0.027 & 0.006 \\
& $(0.026)$ & $(0.063)$ & $(0.117)$ & $(0.068)$ \\
SAVE6 & $-0.055^{*}$ & -0.053 & -0.091 & -0.026 \\
& $(0.028)$ & $(0.069)$ & $(0.131)$ & $(0.074)$ \\
RISK & $-0.108^{*}$ & -0.019 & 0.284 & -0.162 \\
& $(0.059)$ & $(0.135)$ & $(0.299)$ & $(0.136)$ \\
& & & & \\
\hline \hline
\end{tabular}

Source: DNB household survey 2004 and supplementary survey 2004.

Notes: The table contains the estimated coefficients for the noncognitive skills in OLS regressions with DR and BMI as regressand, further including a full set of unreported dummies for all combinations of age and sex. The regressions have been run separately with one proxy at the time. The indicated significance levels are $1 \%(* * *), 5 \%(* *)$ and $10 \%(*)$.

* To control for the level differences in the discount rate, a dummy variable was included in all regressions with DR as dependent or independent variable, being 1 if the respondents answered the questions with low money amounts and 0 if the respondents answered questions in which the money amounts were multiplied by 10 .

** Divided by 100000 .

*** Divided by net income* 1000 .

The human capital theory predicts that the individual discount rate will be negatively related to educational investments and consequently to income. To investigate the robustness of the link between the proxies MANAGE, PLAN and FUTURE03 and BMI, we include dummies for educational achievement and income in these regressions. As in previous regressions, a full set of age and sex dummies is included. For all proxies we find a significant negative parameter for university degree. The effect of the proxies reduces slightly from -.785 to -.655 for MANAGE, from .489 to .468 for PLAN, and .213 to .202 for FUTURE03, but all parameters remain significant at the 1-percent level. Including interaction variables between income/education levels and PLAN, we find that the coefficient of the interaction between PLAN and education level 5 (bachelor degree) (coef: -.376, st.dev.: .221) and the interaction of PLAN and income (coef: -.640, st.dev.: .278) have a significant negative effect on BMI. Adding these interactions increases the effect of the relation between PLAN and BMI (coef: .805, st.dev.: .174). Similarly, the MANAGE-BMI relation remains significant if we include interactions and the coefficient increases (coef: -1.113 , st.dev.: 0.312) with only the incomemanage interaction significant (coef: 1.448, st.dev.: .711). Similar results are also found for FUTURE03. These results indicate that when we control for education, the proxies have a significant impact on mean BMI in the predicted direction while this result seems to be 
somewhat stronger for people with lower incomes.

\subsection{The relationship between noncognitive skills and BMI over time}

An important issue is whether this correlation between noncognitive skills and BMI is able to explain the rise in BMI that the Netherlands has experienced in the past decade. To give this hypothesis the best chance, we will discuss the development of the link between the proxies PLAN, MANAGE and FUTURE03 and BMI.

Figure 5.3 provides the development of the proxies MANAGE and PLAN over time. Again, the range at the vertical axis has been set equal to one standard deviation of the variable concerned, with the average for all years in the center of the graph. Figure 5.4 shows the development for FUTURE03. The figures reveal that the relationship between imagination, impulsiveness, or budget managing skills and BMI cannot explain the marked increase in body mass over the time period investigated. There is no clear downward trend in MANAGE, and no clear upward trend in PLAN and FUTURE03. A linear regression analysis explaining the average value of MANAGE with a time trend gives insignificant coefficients which are insufficient in size to explain the trend in BMI. Similar patterns are found when we investigate the proxies for specific age and sex groups in the data. There might of course be a delay between developments in the average individual discount rate and BMI. It is not very likely, however, that such a lag takes the full length of the 10 years for which we have data available.

This leaves us with the question whether there has been a constant shift in BMI over time for people with different skills, or whether the increase in BMI has been larger among people with high impulsiveness, low management skills or low imagination. We estimate the relationship between the proxies and BMI for all years. Figure 5.5, 5.6 and 5.7 show the development of the estimated parameters for impulsiveness, managing and imagination. These figures reveal that the correlation between these skills and BMI has increased over time: people who are more impulsive or have less management skills or less imagination gained more weight. This was more so for women than for men. This implies that whatever has been the cause of the increase in BMI, the change has not shifted the "optimal" BMI for all people with an equal amount. Potential explanations for the increase in average BMI are thus interacting with the noncognitive skills underlying time discounting. In the specification of the model in Section 2 , changes in the price of calories would not generate such an interaction effect, but shifts in the relative price of substitutes and complements would increase the gap between the BMI of 
Figure 5.3: Development of MANAGE and PLAN as proxies for (budget) management skills and impulsiveness, 1995-2004

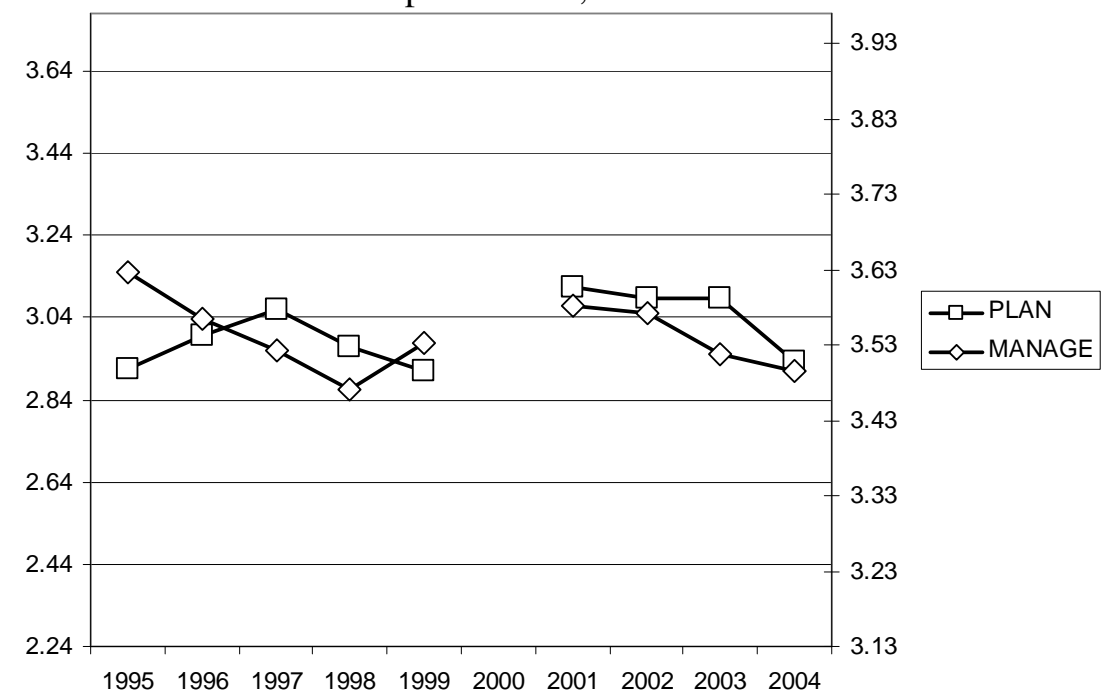

Source: DNB household survey 1995-1999, 2001-2004

Note: The left y-axis is related to the PLAN variable ('Many people find it difficult to plan or control their expenditures. Do you find it difficult to control your expenditures?' with 1 no, very easy, , 7 yes, very difficult), the right y-axis is related to the MANAGE variable ('How well can you manage with the total income of your household?' with 1 very hard 5 very easy). The maximum of the scale of the vertical axis is determined by adding 0.5 times the standard deviation to the mean PLAN/MANAGE score. Similarly, the minimum of the scale is determined by subtracting 0.5 times the standard deviation of the mean score. The mean and standard deviation are averages of these values over the years.

Figure 5.4: Development of the scores on FUTURE03-variable as a proxy for imagination, 1995-2004

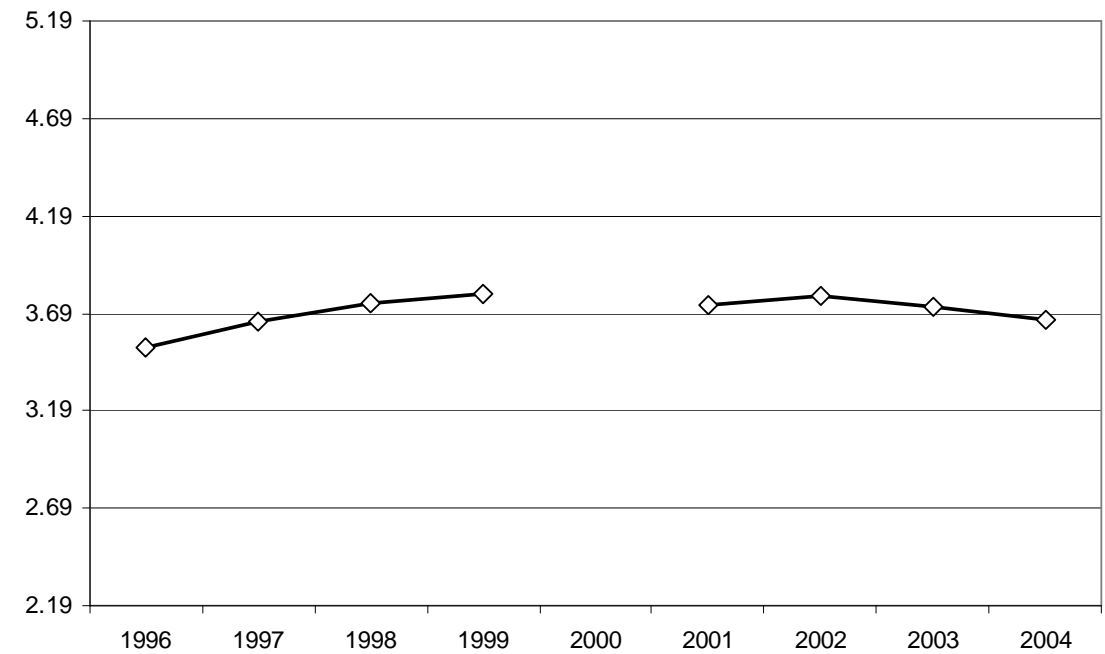

Source: DNB household survey 1995-1999, 2001-2004.

Note: The maximum of the scale of the vertical axis is determined by adding 0.5 times the standard deviation to the mean FUTURE03 score.

Similarly, the minimum of the scale is determined by subtracting 0.5 times the standard deviation of the mean score. The mean and standard deviation are averages of these values over the years. 
Figure 5.5: Development of coefficients for MANAGE in annual regressions explaining BMI, 1995-2004

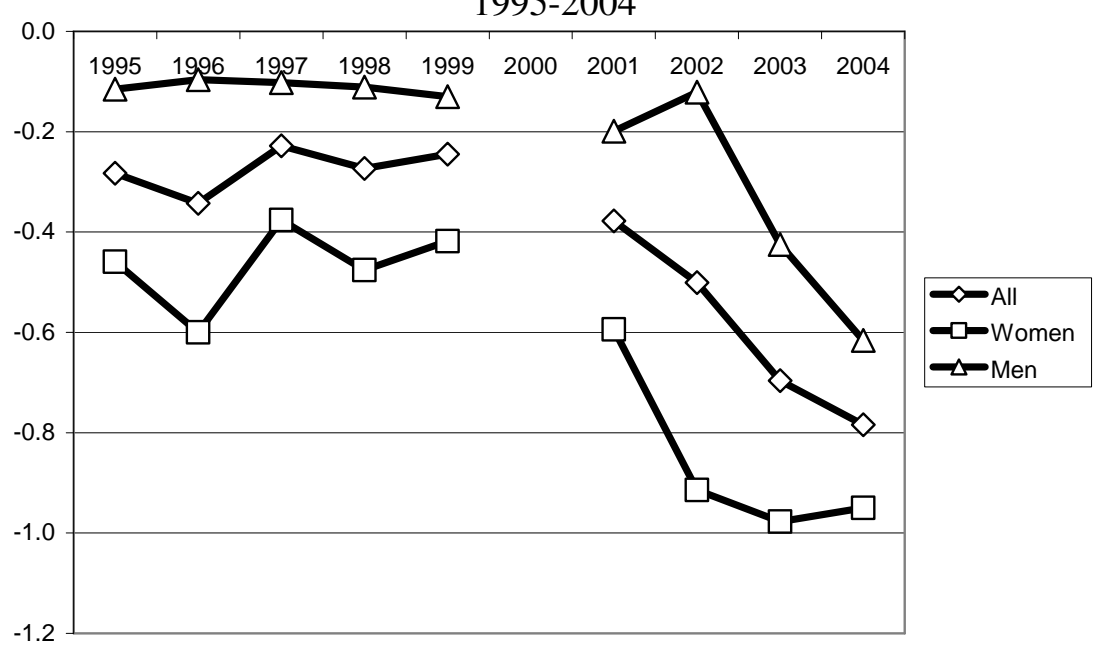

Source: DNB household survey 1995-1999, 2001-2004

Note: The graph depicts all estimated coefficients for MANAGE ('How well can you manage with the total income of your household?' with 1 very hard 5 very easy) in an OLS regression with BMI for all respondents and males and females separately as regressand, further including a full set of dummies for all combinations of age and sex.

people with low and high discount rates. ${ }^{13}$ Figure 5.8, 5.9 and 5.10 depict this diverging trend in an alternative way. We split the sample in two parts: one group representing noncognitive skills reflecting high time discounting (so high impulsiveness, low management skills, and low imagination) and the other group low time discounting. The graphs clearly show a steady increase in the BMI of those with high time discounting, while the BMI of those with low time discounting remains more stable.

\subsection{Discussion and conclusions}

In this paper we have analyzed (1) whether time discounting is related to BMI, (2) which noncognitive skills are related to time discounting, (3) whether these skills can explain differences in BMI between people at a certain point in time, and (4) whether a trend in the skills can account for the increase of BMI over time. To analyze these questions, we have used data from a survey among a sample of the Dutch population, for the period 1995-2004, which contains not only information about body weight and height, but also has a very large set of questions concerning the financial situation and attitude of the respondents. On the basis of the 2004 data, we have investigated the link between time discounting and BMI, and the corre-

\footnotetext{
${ }^{13} \mathrm{~A}$ model in which the utility in the second period is non-linearly related to A, could also generate such interaction effects.
} 
Figure 5.6: Development of coefficients for PLAN in annual regressions explaining BMI, 1995-2004

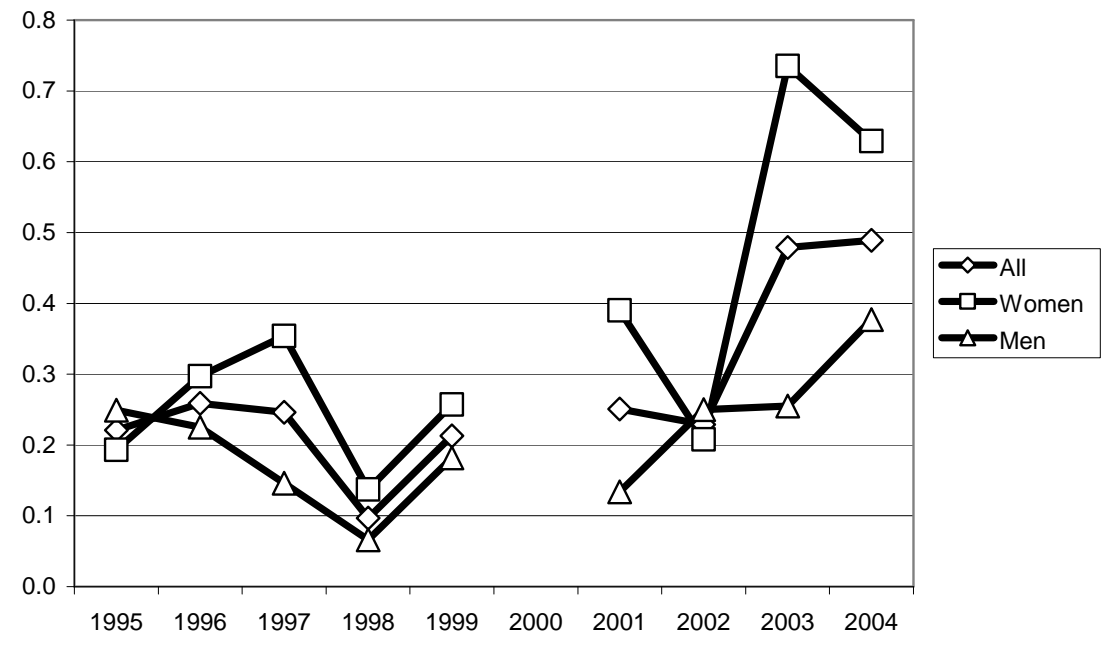

Source: DNB household survey 1995-1999, 2001-2004

Note: The graph depicts all estimated coefficients for PLAN ('Many people find it difficult to plan or control their expenditures. Do you find it difficult to control your expenditures?' with 1 no, very easy, , 7 yes, very difficult) in an OLS regression with BMI for all respondents and females and males separately as regressand, further including a full set of dummies for all combinations of age and sex.

Figure 5.7: Development of coefficients for FUTURE03 in annual regressions explaining BMI,

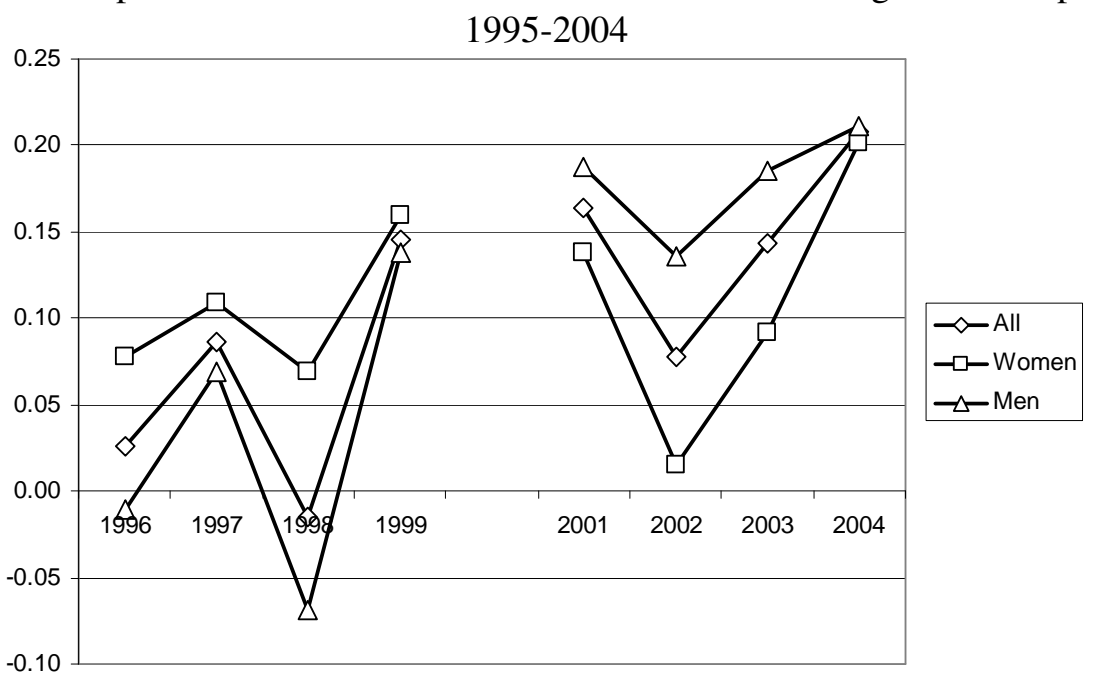

Source: DNB household survey 1995-1999, 2001-2004.

Note: The graph depicts all estimated coefficients for FUTURE03 ('I am only concerned about the present, because I trust that things will work themselves out in the future' with 1 totally disagree, , 7 totally agree) in an OLS regression with BMI for all respondents and females and males separately as regressand, further including a full set of dummies for all combinations of age and sex. 


\section{Imagination and Investments in Health: the Body Mass Index}

Figure 5.8: BMI for high and low budget managing skills (based on MANAGE variable), 1995-2004

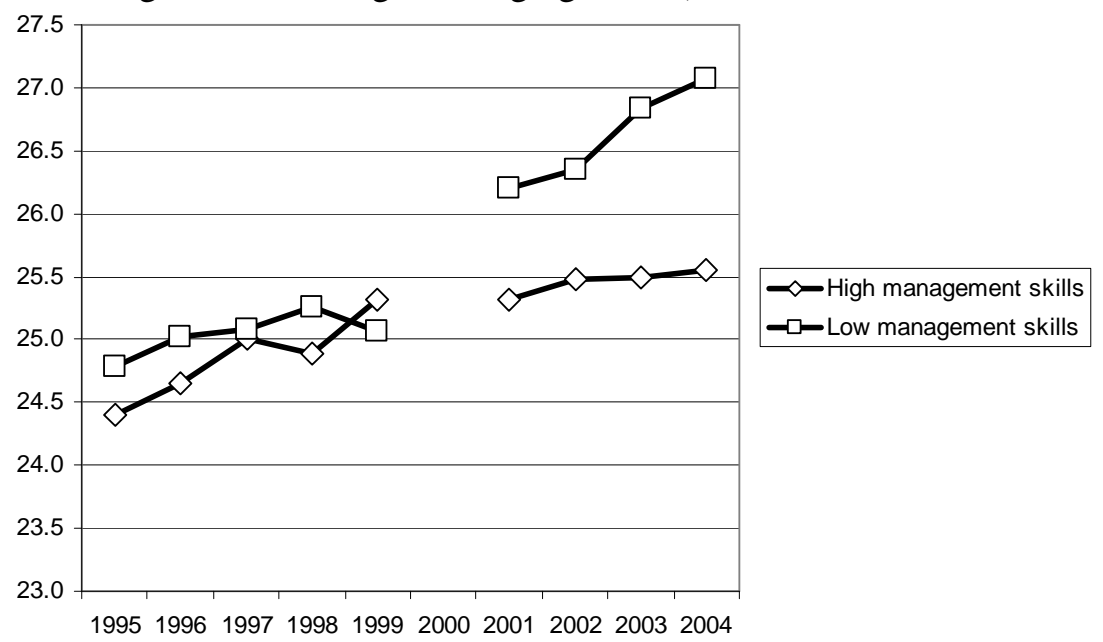

Source: DNB household survey 1995-1999, 2001-2004

Low management skills has been defined as values for MANAGE ('How well can you manage with the total income of your household?' with 1 very hard 5 very easy) less than 3 . Note: The maximum of the scale of the vertical axis is determined by adding 0.5 times the standard deviation to the mean BMI score. Similarly, the minimum of the scale is determined by subtracting 0.5 times the standard deviation of the mean score. The mean and standard deviation are averages of these values over the years.

Figure 5.9: BMI for high and low impulsiveness (based on PLAN variable), 1995-2004

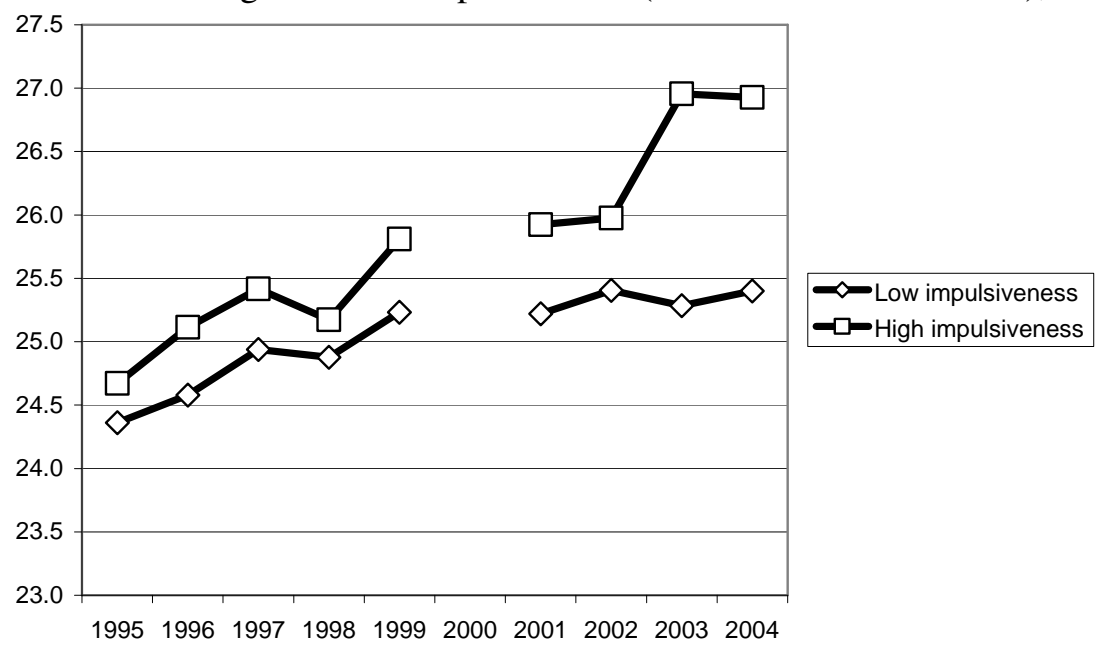

Source: DNB household survey 1995-1999, 2001-2004

High impulsiveness has been defined as values for PLAN ('Many people find it difficult to plan or control their expenditures. Do you find it difficult to control your expenditures?' with 1 no, very easy, , 7 yes, very difficult) larger than 4 . Note: The maximum of the scale of the vertical axis is determined by adding 0.5 times the standard deviation to the mean BMI score. Similarly, the minimum of the scale is determined by subtracting 0.5 times the standard deviation of the mean score. The mean and standard deviation are averages of these values over the years. 
Figure 5.10: BMI for high and low imagination (based on FUTURE03 variable), 1995-2004

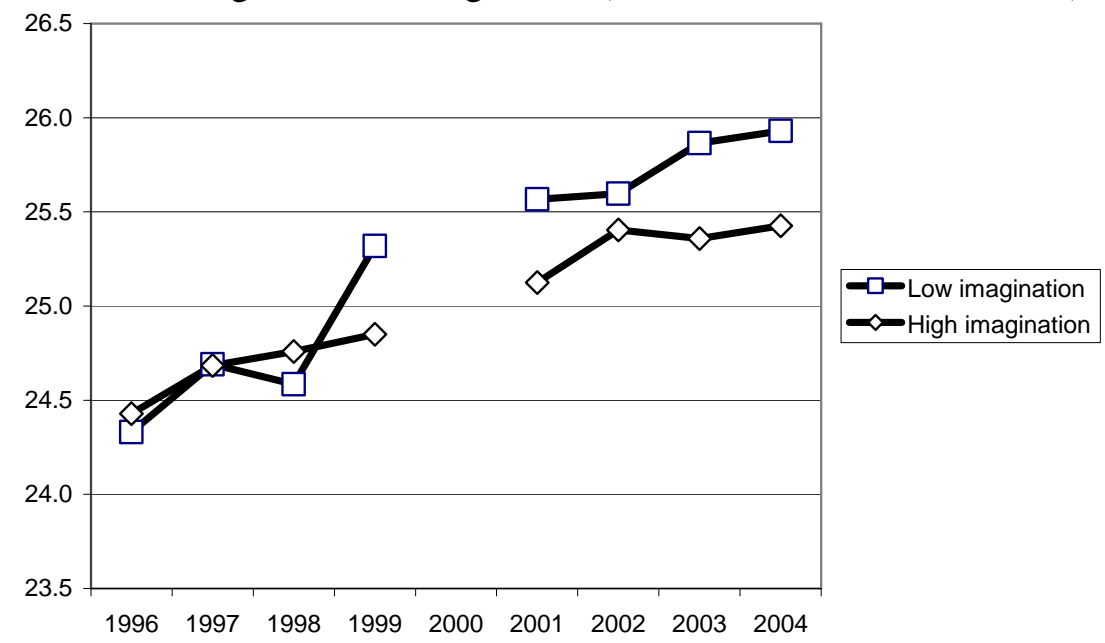

Source: DNB household survey 1995-1999, 2001-2004

Low imagination has been defined as values for FUTURE03 ('I am only concerned about the present, because I trust that things will work themselves out in the future' with 1 totally disagree , , 7 totally agree) larger than 4 . Note: The maximum of the scale of the vertical axis is determined by adding 0.5 times the standard deviation to the mean BMI score. Similarly, the minimum of the scale is determined by subtracting 0.5 times the standard deviation of the mean score. The mean and standard deviation are averages of these values over the years.

lation of proxies for noncognitive skills with time discounting and BMI. We have investigated the development of the proxies for noncognitive skills and its link with BMI over time in the Netherlands.

We find surprisingly little correlation between time discounting and BMI. Differences in BMI between people in a specific year in the sample are related to some of our proxies for noncognitive skills. Especially measures that are related to the ability to manage expenditures, impulsiveness and imagination are correlated with BMI. Comparing different years, however, it turns out that the average of the proxies for these skills did not change from 1995 - 2004. It is therefore unlikely that the upward trend in BMI can be accounted for by an increase in these skills. We find that with the increase of BMI, the difference in BMI between people with skills related to low and high time discounting has also increased, i.e. BMI may not have increased because impulsiveness increased or the ability to manage or imagine decreased, but because those with high impulsiveness, low imagination or low budget managing skills gained more weight.

On the basis of the model in Section 2, an alternative explanation left for a rise in BMI would be a fall in the price of calorie-rich food. Cutler, Glaeser, and Shapiro (2003) provide convincing evidence for this fall in the price. This price trend, however, does not explain the weak cross-sectional relationship between time discounting and BMI. It also leaves unexplained the remarkable differences between sex and age groups with respect to this link 
between time discounting and BMI.

We believe that for future research it is important to look in greater depth at the substitutability and complementarity between food consumption and other forms of risky behavior and investments in human capital. The extended model in Section 2 has shown that such interactions between different forms of human capital can influence time discounting-BMI relationship to a great extent. Both cross-sectional data and time series evidence provide examples to illustrate the interaction between food intake and other forms of risky behavior or investments in human capital. First, we indicated that people who invest in their career at school or work by learning might neglect their health, and eat more to increase mental concentration. In this case, leisure (not learning) and food intake are substitutes. A regression explaining BMI with apart from the usual variables (age-sex dummies) also the answer to the question "In my work people take care I get tasks of which I can learn a lot", gives indeed a significant parameter of .197 (st.dev.: .087).

A time-series example is provided by the data about smoking. Smoking rates have decreased considerably in the Netherlands in the past 10 years (our data indicate a decrease of about 9\%). Developments in time discounting alone cannot account for both this trend and the trend in BMI. Various policy measures to reduce smoking have clearly increased the price of smoking. Our hypothesis is that reductions in smoking behavior could also have caused the increase in BMI when smoking and eating are substitutes in period's 1 utility function. Since both behaviors can help to reduce distress, such substitutability seems not to be unlikely. We therefore think that such interactions in behavior provide interesting avenues for further research concerning the developments of obesity. 


\section{Implications and future research}




\subsection{Main findings}

The aim of this thesis has been to investigate whether people differ in the capacity to think about the future, and whether those who see the future less clearly will be more present oriented and will make less adequate investment decisions. The thesis consisted of four selfcontained chapters in which the consequences of having less imagination were investigated in a context of investments in human capital.

In chapter 2 we find that better imagination is related to a lower discount rate. If certain results are imagined more vividly than other results, different discount rates will apply for different situations. This result can explain the paradoxical empirical finding that a given person often applies different discount rates for different goods. We show in chapter 2 that an implication of this result is that people with less imagination take more time to finish educations with the same nominal duration. The second main finding is that imagination improves the quality of investment choices. Less imagination is related with more regret about the choice of an educational field, and with a larger probability to regret a longer stay in education.

In chapter 3 we find that many students who regret the choice of educational field attempt to correct their choice after graduation by studying in a different discipline. Spending time in education is costly in the sense that one foregoes income. These costs indicate the importance of imagination. We will elaborate on this result below by giving a back-of-the-envelope calculation on the size of the costs in several countries.

In chapter 4 we analyze whether imagination affects the quality of investment decisions after people left education. The chapter reports findings of an experiment in which we show that people with more imagination are more inclined to choose courses from which they can learn. The experimental character of the analysis provides important additional evidence on the relation between imagination and the ability to invest.

Chapter 5 investigates whether imagination affects the quality of investment decisions in health. We focus in this chapter on the Body Mass Index. Many obese people are trying to lose weight, suggesting that they regret having gained weight previously. For this reason, we expect a lack of imagination to be an important predictor for overweight. The analysis shows that people with more imagination indeed have a lower body mass index. Average imagination remained stable over the years, so the recent increase in the average BMI is not due to changes in imagination. 


\subsection{Implications}

\subsubsection{The case for interventions in behavior}

One of the central findings in this thesis is that a lack of imagination is related to less adequate investment decisions. Here, we will argue that this can provide a rationale for government interference in individuals' choices.

Governments typically intervene in intertemporal choices in various ways. ${ }^{1}$ An intervention may be "hard" in the sense that governments may coerce people into doing something or forbid them to do something. But interventions can also be "softer," in the sense that governments may engage in policy which changes behavior without limiting choice. Examples are giving information or changing defaults. Thaler and Sunstein (2003) term these soft interventions libertarian paternalism. By intervening in choices, governments stimulate people with high discount rates to care more about the future. Such interventions often seem to have good cause. For instance many will agree that it is imperative that children under a certain age should be prohibited to drink or smoke.

Economists have traditionally been sceptical about interference. People are assumed to be fully rational and to have perfect information about the future. Individuals with high discount rates are simply making conscious decisions in favor of the present. If so, there is no reason to discourage them from doing so. In economic theory, interventions are justifiable only in case of market failures. For instance, smoking in public places clearly has negative externalities for non-smokers which they are not compensated for by the smokers. From this perspective, banning or taxing smoking in public places therefore is justifiable but banning smoking alone at home is not.

The research in this thesis argues instead that many present oriented decisions occur because people cannot imagine the future consequences of their decisions very well. Once they are confronted with these consequences, they often state they would have made a different choice had they known this a priori. This idea can be seen in terms of externalities. Suppose that a person has a present self and a future self. A smoker pleases his present self, but harms his future self. If all costs of this harm are included in the present self's decision, there is no externality and no case for intervention. Our contribution is that we argue that the current self may not include all costs inflicted on the future self because some of the future costs will be very difficult to imagine for the present self. This lack of imagination represents a market failure which can justify intervention. Related to this Herings and Rohde (2006) suggest that

\footnotetext{
${ }^{1}$ We focus on governments here. Obviously, besides governments, parents, partners, friends, managers, and many others often attempt to intervene in choices.
} 
by treating the present self and the future self as two distinct persons, traditional arguments of Pareto improvements can be used to see whether intervention increases efficiency.

Following the conclusions in our research, a new insight can be provided about the type of intervention which could be applied. Interventions such as giving information, changing defaults, and coercion typically attempt to improve the quality of choices regarding specific matters. Our result stresses the importance of imagination for the quality of a great variety of decisions throughout life. For future research the question remains whether people can be taught to think more clearly about the future. If they can, teaching people to become more aware of the future in general can provide potentially substantial gains in many specific aspects of life.

We want to stress that while an imperfect imagination can provide a reason for interventions, there are several strong arguments against interference which should be considered. These arguments hinge on the fact that governments' decisions are also prone to error. Glaeser (2005) shows that consumers can be expected to face stronger incentives to get things right than governments who make decisions about unrelated individuals. His second argument is that paternalism may lead to societal losses because it is less costly for lobby groups to persuade a few government bureaucrats than millions of consumers.

An interesting observation with respect to justifications of interventions in behavior is that while it is generally accepted that young children cannot decide themselves about important intertemporal matters, adults are assumed to be able to make adequate decisions. The distinction between adults and children seems very ad hoc. It is unlikely that the ability to invest really changes the day one becomes an adult. We intend to investigate how the ability to invest changes over the life-cycle. In an ongoing research, we analyze this matter with respect to investments in courses (Borghans and Golsteyn 2007a). Our preliminary findings suggest that young children indeed do not choose the courses that could reduce their skill deficiencies. The tendency to choose courses from which one can learn rises with age, with the top at approximately age 30 . Then the tendency to choose a course from which one can learn drops substantially. Young children tend to choose courses in topics in which they are interested. From this evidence we conclude that children and young adults do not realize that they should invest.

\subsubsection{The costs of inadequate choices}

How large are the costs of inadequate choices? The importance of making adequate choices is manifested by the costs of regretting decisions. Chapter 3 showed that disappointing outcomes produce utility losses and people will have an incentive to try to correct their initial decisions. 
Here, we give a conservative estimate of the costs of correcting educational choices. Obviously, it would be interesting to extend this analysis to measuring the costs of corrections in other aspects in life. For instance, it is well-known that trying to quit smoking or to lose weight costs a tremendous amount of perseverance. Measuring this loss of energy and comparing it to other activities which cost energy would provide new insights in the costs of smoking or obesity.

Regarding educational choices, approximately $20 \%$ of the young graduates regret their choice of educational field. Many of them go back to school later to repair their inadequate educational choice. In addition, most people who acquire a qualification at a later age would - looking back at their career - have preferred to have done this when they were young.

Learning at a later age may play an important role in adjusting educational choices made earlier in life. The possibility to change educational field during a later career phase, makes the labor market more flexible. Individuals can adjust their educational choice if they notice that the education they chose when they were young does not fit them or gives them for instance a lower wage than they expected. This implies that there are not only possibilities to prevent discrepancies between demand and supply by helping young children to make the right educational choice but also to diminish them by retraining adults.

These adjustments are not without costs, however. If educations at a higher age are indeed followed to correct earlier choices, it would be more efficient to have followed this education as soon as possible. As a consequence of the adjustment, the total time in education will increase and the graduate will become available for the labor market later or will experience some breaks in the work career.

To give a back-of-the-envelope calculation, consider that with an average working life of 40 years, a one-year delay in education can be seen as a 2.5 percent capacity loss. Based on the international survey CHEERS among graduates 3 years after graduation (approximately 3.500 graduates per country) a conservative estimate of capacity losses can be calculated for different countries. ${ }^{2}$ Table 6.1 shows that the costs are highest in Italy, Austria and Finland while Japan, the Czech Republic, Sweden and France have relatively low capacity losses. The high capacity losses in Italy are due to the fact that students take too long time to graduate. In Italy, Germany, the Netherlands and the U.K. many students continue studying after they graduated from college education. This also reduces the number of years they will work on average considerably.

These conclusions regarding the consequences of making inadequate investment decisions provide a new insight into the reasons for learning at a later age. In an ongoing research,

\footnotetext{
${ }^{2}$ For an elaborate description of the method of measuring these costs, see Borghans and Golsteyn (2006a).
} 
Table 6.1: The costs of learning delay

\begin{tabular}{|c|c|c|c|c|}
\hline & $\begin{array}{l}\text { Length education } \\
\%\end{array}$ & $\begin{array}{c}\text { Second education } \\
\%\end{array}$ & $\begin{array}{c}\text { Started late or } \\
\text { delay during education } \\
\%\end{array}$ & $\begin{array}{c}\text { Total capacity loss } \\
\text { as percentage of GDP } \\
\%\end{array}$ \\
\hline Italy & 8.0 & 2.6 & 0.9 & 11.5 \\
\hline Spain & 2.4 & 1.3 & 0.8 & 4.5 \\
\hline France & 1.1 & 1.3 & 0.6 & 3.0 \\
\hline Austria & 7.6 & 1.1 & 1.2 & 9.9 \\
\hline Germany & 3.3 & 2.3 & 1.1 & 6.9 \\
\hline The Netherlands & 1.5 & 2.7 & 1.1 & 5.3 \\
\hline UK & 0.2 & 2.6 & 1.1 & 3.9 \\
\hline Finland & 5.4 & 0.2 & 1.9 & 7.5 \\
\hline Sweden & 2.4 & 0.4 & 0.4 & 3.2 \\
\hline Norway & 2.4 & 0.7 & 1.4 & 4.5 \\
\hline Czech-Republic & 2.3 & 0.3 & 0.5 & 3.1 \\
\hline Japan & 0.4 & 0.0 & 0.0 & 0.4 \\
\hline
\end{tabular}

we (Borghans and Golsteyn 2007b) argue that to understand lifelong learning, it is crucial to take into account the reasons why people tend to spread learning over their life span. We propose that there are three main reasons for adult learning: (1) Skills with a high level of depreciation might require regular updating. (2) Economic or technological shocks in the labor market can make it necessary to reinvest in other skills. (3) People might want to repair previous inadequate choices in initial or postinitial education. We find that the reparation motive is the most important reason people engage in learning at a later age. Therefore, in the discussion about lifelong learning a distinction has to be made between maintenance and reparation. Increases in the level of time spent on maintenance can reflect optimal reactions to new circumstances, but will mainly relate to specific knowledge characterized by high levels of depreciation. Reparation only reflects erroneous decisions in the past. People may regret their choice of educational discipline for instance when they find out after graduation that the position of their qualification on the labor market deteriorated and they are going to earn a lower wage than the wage they expected. A decrease of the wages of a specific qualification will only be a temporary reason to invest in education since it only applies to those who have already chosen an education. Once young people know the new wage structure, they may adjust ex ante their initial investment decisions, making later corrections abundant. If reparation is also characterized by a lack of understanding how important education and vocational choices can be for the career the phenomenon can be more persistent.

Helping people to choose their educational field by improving the quality of the image people have of the future will be important in combating the need for reparation of earlier investments. In a recent report for CEDEFOP, we show (using IV-estimates) that visiting a 
study counselor is an effective method to decrease the probability of regretting the education (Borghans and Golsteyn forthcoming). When reparation is the reason for adult learning, more help in making an adequate educational choice - when successful - will induce a shift from adult learning to investments in education at a younger age. 
6 Implications and future research 


\section{Bibliography}

Abadie, A., And S. Gay (2006): "The Impact of Presumed Consent Legislation on Cadaveric Organ Donation: A Cross Country Study," Journal of Health Economics, 25(4), 599-620.

Ainslie, G. (1992): Picoeconomics. Cambridge: Cambridge University Press.

Akerlof, G. A. (1991): "Procrastination and Obedience," American Economic review, Papers and Proceedings, 81(2), 1-19.

Allison, P. D., And N. A. Christakis (1994): "Logit Models for Sets of Ranked Items," Sociological Methodology, 24, 199-228.

Ameriks, J., A. CAPlin, ANd J. LeAhy (2003): "Wealth Accumulation and the Propensity to Plan," Quarterly Journal of Economics, 118(3), 1007-1047.

AzFAR, O. (1999): “Rationalizing Hyperbolic Discounting," Journal of Economic behavior and Organization, 38, 245-252.

Becker, G. (1964): Human Capital, A Theoretical and Empirical Analysis, with Special Reference to Education. New York: Columbia University Press.

Becker, G., And C. Mulligan (1997): “The Endogenous Determination of Time Preference," Quarterly Journal of Economics, 112(3), 729-758.

Becker, G., AND K. Murphy (1988): “A Theory of Rational Addiction,” Journal of Political Economy, 96(4), 675-700. 
Bell, D. (1982): "Regret in Decision Making under Uncertainty," Operations Research, 30(5), 961-981.

Ben-Porath, Y. (1967): "The Production of Human capital and the Life-Cycle of Earnings," Journal of Political Economy, 75(4), 352-365.

Bernheim, B. D., And A. Rangel (2004): "Addiction and Cue-Triggered Decision Processes," American Economic Review, 94(5), 1558-1590.

Bickel, W., A. Odum, And G. Madden (1999): "Impulsivity and Cigarette Smoking: Delay Discounting in Current, Never, and Ex-Smokers," Psychopharmacology, 146(4), 447454.

BILs, M. (1985): "Real Wages over the Business Cycle: Evidence from Panel Data," Journal of Political Economy, 93(4), 665-689.

Blaylock, J., S. Smallwood, K. Kassel, J. Variyam, and L. Aldrich (1999): "Economics, Food Choices, and Nutrition," Food Policy, 24, 269-286.

BöHm-BAWERK, E. V. (1891): The Positive Theory of Capital. William Smart, trans. Freeport, NY: Books for Library Press [reprint 1971].

Borghans, L., AND B. GOLSTEYN (2006a): "De kosten van uitgesteld leren," Kwartaalschrift Economie, 3, 291-300.

(2006b): "Time Discounting and the Body Mass Index, Evidence from the Netherlands," Economics and Human Biology, 4(1), 39-61.

(2007a): "Are People Able to Choose Their Own Training Courses? Experimental Evidence from 7 till 80," Mimeo, Maastricht University.

(2007b): "Human Capital Accumulation Over the Life-Cycle: Reasons for and Costs of Learning at a Higher Age," Mimeo, Maastricht University.

(2007c): “Skill Transferability, Regret and Mobility," Applied Economics, 39(13), $1663-1677$.

(forthcoming): "The Importance of information, advice and guidance over the lifecycle," in Modernising vocational education and training. Fourth report on vocational training research in Europe: background report, ed. by P. Descy, and M. Tessaring. Luxembourg: EUR-OP. (Cedefop reference series). 
Bowles, S., H. Gintis, And M. Osborne (2001): "The Determinants of Earnings: A behavioral Approach," Journal of Economic Literature, 39(4), 1137-1176.

BRUNELlO, G. (2004): "Labour market institutions and the complementarity between education and training in Europe," in Education, Training and Labour Market Policies in Europe, ed. by D. Checchi, and C. Lucifora, pp. 188-209. Basingstoke, UK: Palgrave Macmillan.

BÜChel, F., AND A. Mertens (2004): "Overeducation, Undereducation and the Theory of Career Mobility," Applied Economics, 36(8), 803-816.

Burton, S., And S. Tiffany (1997): "The Effects of Alcohol Consumption on Craving to Smoke," Addiction, 92, 15-26.

Busby, J., And T. Suddendorf (2005): "Recalling Yesterday and Predicting Tomorrow," Cognitive Development, 20, 362-372.

CAIRns, J. (1994): "Valuing Future Benefits," Health Economics, 3, 221-229.

Capen, E., R. Clapp, and W. Campbell (1971): "Competitive Bidding in High-Risk Situations," Journal of Petroleum Technology, 23, 641-653.

Caplin, A., And J. LeAhy (2001): "Psychological Expected Utility Theory And Anticipatory Feelings," Quarterly Journal of Economics, 116(1), 55-79.

CAWley, J. (2000): “Body Weights and Women's Labor Market Outcomes,” NBER Working Paper, 7841.

(2004): “The Impact of Obesity on Wages," Journal of Human Resources, 39(2), $451-474$.

Cawley, J., S. Markowitz, and J. Tauras (2004): “Lighting Up and Slimming Down: The Effects of Body Weight and Cigarette Prices on Adolescent Smoking Initiation," Journal of Health Economics, 23(2), 293-311.

Chaloupka, F. (1991): "Rational Addictive Behavior and Cigarette Smoking," Journal of Political Economy, 99(4), 722-742.

Chapman, G., And E. Coups (1999): “Time Preferences and Preventive Health Behavior: Acceptance of the Influenza Vaccine,” Medical Decision Making, 19, 307-314.

Chapman, G., And A. Elstein (1995): "Valuing the Future, Temporal Discounting of Health and Money," Medical Decision Making, 15(4), 373-386. 
Chapman, G., R. Nelson, and D. Hier (1999): "Familiarity and Time Preferences: Decision Making About Treatments for Migraine Headaches and Crohn's Disease," Journal of Experimental Psychology: Applied, 5(1), 17-34.

Chesson, H., And W. Viscusi (2000): “The Heterogeneity of Time-risk Tradeoffs," Journal of Behavioral Decision Making, 13, 251-258.

Chevalier, A., And I. WAlker (2001): "Education and Earnings in Europe: United Kingdom," in Education and Earnings in Europe: a Cross Country Analysis of the Returns to Education, ed. by C. Harmon, I. Walker, and N. Westergaard-Nielsen, pp. 302-330.

Choi, J., D. Laibson, B. Madrian, and A. Metrick (2005): "Optimal Defaults and Active Decisions," NBER Working Paper No. 11074.

Clayton, N. S., T. J. Bussey, and A. Dickinson (2003): "Can Animals Recall the Past and Plan for the Future?," Nature Reviews Neuroscience, 4(8), 685-691.

ColquitT, J., J. LePine, And R. NoE (2000): "Towards an Integrative Theory of Training Motivation: A Meta-Analytic Path Analysis of 20 Years of Research,' Journal of Applied Psychology, 85(5), 678-707.

Conti, G. (2005): “Training, Productivity and Wages in Italy," Labour Economics, 12(4), $557-576$.

Cutler, D., And E. Glaeser (2005): "What Explains Differences in Smoking, Drinking and Other Health-Related Behaviors?," American Economic Review Papers and Proceedings.

Cutler, D., E. Glaeser, And J. Shapiro (2003): "Why Have Americans Become More Obese?," Journal of Economic Perspectives, 17(3), 93-118.

D’Argembeau, A., And M. VAn Der Linden (2006): "Individual Differences in the Phenomenology of Mental Time Travel: The Effect of Vivid Visual Imagery and Emotion Regulation Strategies," Consciousness and Cognition, 15, 342-350.

DellaVigna, S., And M. PASERman (2005): “Job Search and Impatience," Journal of Labor Economics, 23(3), 527-588.

Dolton, P., And A. Vignoles (2000): “The Incidence and Effects of Overeducation in the U.K. Graduate Labour Market,” Economics of Education Review, 19(2), 179-198. 
Eraut, M. (2000): "Non-Formal Learning and Tacit Knowledge in Professional Work," British Journal of Educational Psychology, 70(1), 113-136.

Evans, W., And E. Montgomery (1994): "Education and Health: where there is smoke, there is an instument," NBER Working Paper 4949.

Fersterer, J., And R. Winter-Ebmer (2003): “Smoking, Discount Rates, and Returns to Education," Economics of Education Review, 22, 561-566.

FiELD, J. (2000): Lifelong Learning and the New Educational Order. Trentham Books, Stoke on Trent.

FISHBURn, P. (1970): Utility Theory and Decision Making. New York: Wiley.

(1982): “Nontransitive Measurable Utility," Journal of Mathematical Psychology, 26(1), 31-67.

FISHER, I. (1930): The Theory of Interest. New York: Macmillan.

Flegal, K., M. Carroll, R. Kuczmarksi, and C. Johnson (1998): “Overweight and Obesity Trends in the United States: Prevalence and Trends 1960-1994," International Journal of Obesity and Related Metabolic Disorders, 22(1), 39-47.

Frazis, H., And M. A. Loewenstein (2005): "Reexamining the Returns to Training; Functional Form, Magnitude, and Interpretation," Journal of Human Resources, 40(2), 453476.

Frederick, S. (2005): “Cognitive Reflection and Decision Making," Journal of Economic Perspectives, 19(4), 24-42.

Frederick, S., G. Loewenstein, And T. O’Donoghue (2002): “Time Discounting and Time Preference: A Critical Review,” Journal of Economic Literature, XL, 351-401.

FreEman, R. (1975): "Legal Cobwebs: A Recursive Model of the Market for New Lawyers," Review of Economics and Statistics, 57(2), 171-179.

Friedman, W. J. (2005): "Developmental and Cognitive Perspectives on Human's Sense of the Times of Past and Future Events," Learning and Motivation, 36, 145-158.

FuCHS, V. (1982): “Time Preference and Health: an Exploratory Study," in Economic Aspects of Health, ed. by V. Fuchs. Chicago, University of Chicago Press. 
Gafni, A., And G. Torrance (1984): "Risk Attitude and Time Preference in Health," Risk Analysis, 30(4), 440-451.

Glaeser, E. (2005): “Paternalism and Psychology,” NBER Working paper, 11789.

Green, D., K. Jacowitz, D. Kahneman, and D. McFadden (1998): "Referendum Contingent Valuation, Anchoring, and Willingness to Pay for Public Goods," Resource Energy Economics, 20, 85-116.

Groot, W. (1996): "The Incidence of, and Returns to Overeducation in the U.K.," Applied Economics, 28(10), 1345-1350.

Grossman, M. (1972): "On the Concept of Health Capital and the Demand for Heath," Journal of Political Economy, 80(2), 223-255.

Gulliver, S. (1995): "Interrelationships of Smoking and Alcohol Dependence, Use and Urges to Use," Journal of Studies on Alcohol, 56, 202-206.

HARRISON, J. R., AND J. G. MARCH (1984): “Decision Making and Postdecision Surprises," Administrative Science Quarterly, 29, 26-42.

Heckman, J. (2000): "Policies to Foster Human Capital," Research in Economics, 54(1), $3-56$.

Heckman, J., J. StixRUd, And S. URZUA (2006): “The Effects of Cognitive and Noncognitive Abilities on Labor Market Outcomes and Social Behavior," Journal of Labor Economics, 24(3), 411-482.

Heijke, H., C. Meng, And C. Ris (2003): "Fitting to the Job: the Role of Generic and Vocational Competencies in Adjustment and Performance," Labour Economics, 10(2), 215229.

HERINGS, P. J.-J., AND K. I. M. ROHDE (2006): “Time-inconsistent preferences in a general equilibrium model," Economic Theory, 29(3), 591-619.

HERSCH, J. (1991): "Education Match and Job Match," Review of Economics and Statistics, 73(1), 140-144.

HERSCH, J. (1996): “Smoking, Seat Belts, and Other Risky Consumer Decisions: Differences by Gender and Race," Managerial and Decision Economics, 17, 471-481. 
(2000): "Gender, Income Levels, and the Demand for Cigarettes," Journal of Risk and Uncertainty, 21(2), 263-282.

HERSCH, J., AND W. K. VISCUSI (1990): “Cigarette Smoking, Seatbelt Use and Differences in Wage-Risk Tradeoffs," Journal of Human Resources, 25(2), 202-227.

Johnson, E., S. Bellman, And G. Lohnse (2002): "Defaults, Framing and Privacy: Why Opting In-Opting Out," Marketing Letters, 13(1), 5-15.

Johnson, E., And D. Goldstein (2003): “Do Defaults Save Lifes?,” Science, 302, 13381339.

Johnson, E., J. Hershey, J. Meszaros, and H. Kunreuther (1993): “Framing, Probability Distortions, and Insurance Decisions," Journal of Risk an Uncertainty, 7(1), 35-53.

Jovanovic, B. (1979): "Job Matching and the Theory of Turnover," Journal of Political Economy, 87(5), 972-990.

Kirby, K., N. Petry, And W. Bickel (1999): "Heroin Addicts Have Higher Discount Rates For Delayed Rewards Than Non-Drug-Using Controls," Journal of Experimental Psychology: General, 128, 78-87.

Komlos, J., And M. BAur (2004): "From the Tallest to (one of) the Fattest: The Enigmatic Fate of the American Population in the 20th Century," Economics and Human Biology, 2(1), $57-74$.

Komlos, J., P. Smith, And B. Bogin (2004): "Obesity and the Rate of Time Preference: Is There a Connection?," Journal of Biosocial Science, 36(2), 209-219.

Koopmans, T. (1960): "Stationary Ordinal Utility and Impatience," Econometrica, 28, 287309.

LAIBSON, D. (1997): “Golden Eggs and Hyperbolic Discounting," Quarterly Journal of Eocnomics, 112(2), 443-477.

Lakdawalla, D., And T. Philipson (2002): "The Growth of Obesity and Technological Change: A Theoretical and Empirical Examination,” NBER Working Paper No. 8946.

LAnCAster, K. (1963): “An Axiomatic Theory of Consumer Time Preference," International Economic Review, 4, 221-231. 
Lawrance, E. (1991): "Poverty and the Rate of Time Preference: Evidence from Panel Data," Journal of Political Economy, 99(1), 54-77.

Levine, P., T. Gustafson, and A. Velenchik (1997): "More Bad News for Smokers? The Effects of Cigarette Smoking on Labor Market Outcomes," Industrial and Labor Relations Review, 50(3), 493-509.

LEVY, A. (2002): "Rational Eating: Can It Lead to Overweightness Or Underweightness?," Journal of Health Economics, 21, 887-899.

LEWIN, K. (1951): Field Theory in Social Science. New York: Harper.

Loewenstein, G. (1992): "The Fall and Rise of Psychological Explanation in the Economics of Intertemporal Choice," in Choice Over Time, ed. by G. Loewenstein, and J. Elster, pp. 3-34. New York: Russell Sage.

Loewenstein, G. (1996): "Out of Control: Visceral Influences on Behavior," Organizational Behavior and Human Decision Processes, 65, 272-292.

(2005): "Hot-cold Empathy Gaps and Medical Decision-Making," Health Psychology, 24(4), S49-S56.

Loewenstein, G., And D. Prelec (1992): “Anomalies in Intertemporal Choice: Evidence and Interpretation," Quarterly Journal of Economics, 107(2), 573-597.

Loewenstein, G., R. Weber, J. Flory, S. Manuck, and M. Muldoon (2001): “Dimensions on Time Discounting," Conference on Survey Research on Household Expectations and Preferences.

Loomes, G., And R. Sugden (1982): "Regret Theory: An Alternative Theory of Rational Choice under Uncertainty," The Economic Journal, 92(368), 805-824.

Madden, G., N. Petry, G. Badger, and W. Bickel (1997): "Impulsive and Self-Control Choices in Opiod-Dependent Patients and Non-Drug-Using Control Participants: Drug and Money Rewards," Experimental and Clinical Psychopharmacology, 5, 256-262.

MCGuinNESS, S. (2003): “Graduate Overeducation as a Sheepskin Effect: Evidence from Northern Ireland," Applied Economics, 35, 597-608.

MCLaughlin, J., And M. BiLs (2001): "Interindustry Mobility and the Cyclical Upgrading of Labor,” Journal of Labor Economics, 19(1), 94-135. 
Miller, R. (1984): “Job Matching and Occupational Choice," Journal of Political Economy, 92(6), 1086-1120.

Mokdad, A., M. Serdula, W. Dietz, B. Bowman, J. Marks, and J. Koplan (1999): "The Spread of the Obesity Epidemic in the United States, 1991-1998," Journal of the American Medical Association, 282(16), 1519-1522.

Mueser, P. R. (1979): "The Effects of Noncognitive Traits," in Who Gets Ahead? The Determinants of Economic Success in America, ed. by C. Jencks, pp. 122-158. New York: Basic Books.

MÜLleR, W., AND Y. SHAVIT (1998): “The institutional Embeddedness of the Stratification Process, a Comparative Study of Qualifications and Occupations in Thirteen Countries," in From School to Work, ed. by Y. Shavit, and W. Müller, pp. 1-48. New York: Clarendon Press.

Munasinghe, L., And N. Sicherman (2006): "Why Do Dancers Smoke? Smoking, Time Preference and Wage Dynamics," Eastern Economic Journal, 32(4), 595-616.

NEAL, D. (1998): “The Link between Ability and Specialization, An Explanation for Observed Correlations between Wages and Mobility Rates," Journal of Human Resources, 33(1), 173-200.

(1999): “The Complexity of Job Mobility among Young Men,” Journal of Labor Economics, 17(2), 237-261.

Nederkoorn, C., C. Braet, Y. V. Eijs, A. Tanghe, and A. Jansen (2006): "Why Obese Children Cannot Resist Food: the Role of Impulsivity," Eating Behaviors, 7, 315322.

NGISC (1999): "National Gambling Impact Study Commission. National Gambling Impact Study: Final Report," http://govinfo.library.unt.edu/ngisc/reports/finrpt.html.

Ogden, C., C. Frayer, M. Carroll, and K. Flegal (2004): "Mean Body Weight, Height and Body Mass Index, United States 1960-2000," Advance Data From Vital and Health Statistics No. 347, Hyattsville MD, National Center for Health Statistics.

Oosterbeek, H., W. Groot, and J. Hartog (1992): “An Empirical Analysis of University Choice and Earnings," De Economist, 140, 293-309. 
Orphanides, A., AND D. Zervos (1995): "Rational Addiction with Learning and Regret," Journal of Political Economy, 103(4), 739-758.

PARENT, D. (1999): "Wages and Mobility: The Impact of Employer-Provided Training," Journal of Labor Economics, 17(2), 298-317.

PARK, C., S. Yun, And D. MacInNis (2000): “Choosing What I want Versus Rejecting What I Do Not Want: An Application of Decision Framing to Product Option Choice Decisions," Journal of Marketing Research, 37(2), 187-202.

PARKER, J. (1999): "Spendthrifts in America? On two decades of decline in the U.S. saving rate," in NBER Macroeconomics Annual 1999, ed. by B. Bernanke, and J. Rotemberg, pp. 317-370. MIT Press, Boston.

PhILIPSON, T. (2001): "The World-Wide Growth in Obesity: An Economic Research Agenda," Health Economics, 10(1), 1-7.

Philipson, T., ANd R. Posner (1999): “The Long-Run Growth in Obesity as a Function of Technological Change," John M. Olin Program in Law and Economics Working Paper No. 78, University of Chicago Law School.

Picone, G., F. Sloan, And J. Trogdon (2004): “The Effect of the Tobacco Settlement and Smoking Bans on Alcohol Consumption," Health Economics, 13, 1063-1080.

Popkin, B., And C. DoAK (1998): “The Obesity Epidemic is a Worldwide Phenomenon," Nutrition Reviews, 56(4), 106-114.

Rachlin, H., A. Raineri, And D. Cross (1991): "Subjective Probability and Delay," Journal of the Experimental Analysis of Behavior, 55, 233-244.

RAE, J. (1835): The Sociological Theory of Capital. London: Macmillan [reprint 1905].

Robst, J. (1994): "Measurement Error and the Returns to Excess Schooling," Applied Economics Letters, 1(9), 142-144.

Rosen, S. (1976): “A Theory of Life Earnings,” Journal of Political Economy, 84(4), S45S67.

Ruhm, C. (2000): “Are Recessions Good for Your Health?,' Quarterly Journal of Economics, $115(2), 617-650$. 
RyAN, P. (2001): "The School-to-Work Transition: A Cross-National Perspective," Journal of Economic Literature, 39(1), 34-92.

Samuelson, P. (1937): "A Note on the Measurement of Utility," Review of Economic Studies, IV, 151-161.

Sargant, N., And F. Aldridge (2002): Adult Learning and Social Division: A Persistent Pattern, Vol. 1. NIACE, Leicester.

SAUER, R. (1998): "Job Mobility and the Market for Lawyers," Journal of Political Economy, 106(1), 147-171.

SHAW, K. (1984): "A Formulation of the Earnings Function using the Concept of Occupational Investment," Journal of Human Resources, 19(3), 319-340.

SHIELDS, M. (1998): "Changes in the determinants of employer-funded training for full-time employees in Britain," Oxford Bulletin of Economics and Statistics, 60, 189-214.

Sicherman, N., AND O. GALOR (1990): “A Theory of Career Mobility,” Journal of Political Economy, 98(1), 169-192.

Siow, A. (1984): “Occupational Choice Under Uncertainty,” Econometrica, 52(3), 631-645.

Sloane, P., H. BAtTU, And P. SeAman (1999): "Overeducation, Undereducation and the British Labour Market,” Applied Economics, 31(11), 1437-1453.

Smith, P., B. Bogin, And D. Bishai (2005): "Are Time Preference and Body Mass Index Associated? Evidence from the National Longitudinal Survey of Youth," Economics and Human Biology, 3, 259-270.

Strotz, R. (1956): “Myopia and Inconsistency in Dynamic Utility Maximization,” Review of Economic Studies, 23(3), 165-180.

Suddendorf, T., And J. Busby (2005): "Making Decisions with the Future in Mind: Developmental and Comparative Identification of Mental Time Travel," Learning and Motivation, 36, 110-125.

SyKeS, D., A. EvAns, ANd E. MCCRUM (1990): "Psychological risk profile of smokers compared with non-smokers and past smokers: a population based study," in Proceedings of the 7th World Conference on Tobacco and Health, ed. by B. Durston, and K. Jamrozik. Perth: Health Department of Western Autralia. 
Thaler, R. (1981): "Some Empirical Evidence on Dynamic Inconsistency," Economic Letters, 8, 201-207.

(1985): "Mental Accounting and Consumer Choice," Management Science, 4, 199_ 214.

Thaler, R. H., And C. R. Sunstein (2003): "Lbertarian Paternalism," American Economic Review, Papers and Proceedings, 93(2), 175-179.

TOPEL, R., AND M. WARD (1992): “Job Mobility and the Careers of Young Men," Quarterly Journal of Economics, 107(2), 439-479.

Trope, Y., And N. Liberman (2003): “Temporal Construal,” Psychological Review, 110(3), $403-421$.

VAn DiJK, E., AND M. ZeElenberg (2003): “The Discounting of Ambiguous Information in Economic Decision Making," Journal of Behavioral Decision Making, 16, 341-352.

Viscusi, W., AND J. Hersch (2001): “Cigarette Smoking as Job Risk Takers," Review of Economic and Statistics, 83(2), 269-280.

Vuchinich, R., and C. Simpson (1998): "Hyperbolic Temporal Discounting in Social Drinkers and Problem Drinkers," Experimental and Clinical Psychopharmacology, 6, 292305.

WeISS, Y. (1971): "Investment in Graduate Education," American Economic Review, 61(5), $833-852$.

Wilkinson, B. (1966): "Present Values of Lifetime Earnings for Different Occupations," Journal of Political Economy, 74(2), 132-157.

ZARKIN, G. (1985): “Occupational Choice: An Application to the Market for Public School Teachers," Quarterly Journal of Economics, 100(2), 409-446. 


\section{Summary in Dutch}

\section{Samenvatting}

In de theorie van het menselijk kapitaal zijn kennis en gezondheid uitkomsten van bewuste investeringsbeslissingen. Veel van de keuzes hieromtrent lijken in de praktijk echter niet weldoordacht. Een belangrijke uiting hiervan is dat mensen achteraf vaak aangeven spijt te hebben van hun keuzes. Dit roept de vraag op of een lage investeringsbereidheid in menselijk kapitaal een voorkeur is of dat deze lage investeringsbereidheid samenhangt met een minder groot vermogen om een helder beeld van de toekomst te scheppen.

Het doel van dit proefschrift is te onderzoeken of mensen verschillen in hun voorstellingsvermogen, en of degenen die een beter beeld van de toekomst hebben meer bereid zijn om te investeren in menselijk kapitaal en minder spijt hebben van hun investeringsbeslissingen.

De belangrijkste bevindingen uit de analyse zijn allereerst dat studenten met een slechter voorstellingsvermogen op verschillende gebieden minder willen investeren in de toekomst: ze doen langer over hun studie, wanneer zij werken kiezen ze minder vaak voor leerzame cursussen, en ze hebben gemiddeld een hoger lichaamsgewicht. Daarnaast geven deze studenten vaker aan spijt te hebben van keuzes met betrekking tot hun investeringen. Een belangrijke consequentie is dat studenten die spijt hebben vaak doorstuderen om hun eerdere keuze te corrigeren. Dit kan erg kostbaar zijn.

Het onderzoek heeft een belangrijke implicatie voor overheidsbeleid. Als mensen bewust het heden verkiezen boven de toekomst is er vanuit economische optiek geen reden voor overheidsingrijpen, maar als mensen het heden verkiezen omdat zij de gevolgen van hun keuzes 
niet goed doorzien, dan is overheidsingrijpen wel te rechtvaardigen.

\section{Opbouw proefschrift}

Dit proefschrift bestaat uit vier hoofdstukken waarin wordt onderzocht welke consequenties een verminderd voorstellingsvermogen heeft in de context van investeringen in menselijk kapitaal.

\section{Discontovoet, Voorstellingsvermogen en Investeringen in Menselijk Kapitaal}

In hoofdstuk 2 laten we in een model allereerst zien dat mensen die zich de toekomst minder goed voor kunnen stellen, minder bereid zullen zijn om in de toekomst te investeren. Heterogeniteit in het voorstellingsvermogen verklaart deels waarom mensen verschillen in hun discontovoet. Als iemand zich een bepaald aspect in de toekomst beter kan voorstellen dan een ander aspect, kan de theorie daarnaast ook verklaren waarom iemand verschillende discontovoeten kan hebben voor verschillende situaties. Ten tweede laten we met behulp van het model zien dat mensen met een slechter voorstellingsvermogen vaker spijt zullen hebben van investeringsbeslissingen.

Een consequentie hiervan is dat studenten die zich het leven op de arbeidsmarkt niet goed kunnen voorstellen het studieleven relatief hoog zullen waarderen. Daarom hebben ze een stimulans om langer in de opleiding te blijven. Wanneer zij gaan werken hebben zij een grotere kans op spijt van het uitstellen van hun arbeidsmarktintrede.

We meten het voorstellingsvermogen en de discontovoet in drie Nederlandse datasets. We vinden een robuuste negatieve correlatie tussen deze concepten en bevestigen de voorspellingen dat studenten met een slechter voorstellingsvermogen langer in de opleiding blijven en na afloop meer spijt hebben van het uitstellen van de arbeidsmarktintrede. Mensen met een slechter voorstellingsvermogen hebben ook meer spijt van de studiekeuze. ${ }^{3}$

\section{De Overdraagbaarheid van Vaardigheden, Spijt en Mobiliteit}

In het derde hoofdstuk, onderzoeken we de consequentie van het hebben van spijt van de studiekeuze. Na afstuderen beginnen veel studenten te werken in sectoren die niet gerelateerd zijn aan hun studie of participeren ze in training gericht op werk in andere sectoren. In dit

\footnotetext{
${ }^{3}$ We meten spijt van de studiekeuze na afsluiten van de studie. Uit andere analyses blijkt dat mensen met een slechter voorstellingsvermogen ook vaker tijdens de opleiding van studie wisselen.
} 
hoofdstuk bekijken we de mobiliteit tussen sectoren vanuit het perspectief dat studiekeuzes gemaakt worden op het moment dat studenten nog weinig of geen ervaring hebben met het feitelijke werk in de beroepen gerelateerd aan hun opleiding.

We ontwikkelen een model waarin studenten menselijk kapitaal accumuleren maar op de universiteit en gedurende de eerste jaren op de arbeidsmarkt ook leren over hun voorkeuren met betrekking tot hun studie en beroep. Een consequentie van de nieuw verworven inzichten is dat deze jongeren zich zouden kunnen realiseren dat werk in een andere beroepssector beter bij hun voorkeuren past. Wanneer zij dit zich realiseren, hebben ze een stimulans om hun sector te verlaten. Echter, doorstuderen in een ander vakgebied is erg kostbaar vanwege de opportuniteitskosten van de extra studietijd. Deze kosten geven het belang aan van een goede studiekeuze.

Naast spijt wordt de keuze om door te studeren in een ander vakgebied vergroot naarmate meer kennis van het ene vakgebied in het andere kan worden gebruikt. Als de overdraagbaarheid van kennis klein is dan is de kans dat de afgestudeerde switcht kleiner. Als de afgestudeerde met een lage overdraagbaarheid van vaardigheden toch switcht, zal hij meer in de opleiding investeren. Met behulp van gegevens van Nederlandse afgestudeerden uit de CHEERS data hebben we ons model getoetst. Consistent met ons model vinden we dat conditioneel op spijt - er meer geswitcht wordt als de overdraagbaarheid van kennis groter is. Daarnaast reduceert een hogere overdraagbaarheid het loonverlies bij doorsturen en de duur van de training na de initiële opleiding.

\section{Voorstellingsvermogen en Investeringen in Kennistekorten}

Hoofdstuk 4 rapporteert de bevindingen van een experiment waarin we onderzoeken of mensen met een beter voorstellingsvermogen meer geneigd zijn om cursussen te kiezen waarvan zij kunnen leren. Het experimentele karakter van de analyse levert belangrijk additioneel bewijs voor de relatie tussen het voorstellingsvermogen en de kwaliteit van investeringen.

De participanten in het experiment zijn werkenden. Het doel van het onderzoek is om te bekijken of zij cursussen kiezen om tekorten in hun vaardigheden weg te werken, en of ze de cursussen op een weloverwogen manier kiezen. We analyseren welke persoonskenmerken de uitkomst van hun keuzes bepalen.

We meten het tekort aan kennis voor zes vaardigheden en doen een experiment waarin werkenden wordt gevraagd om (hypothetisch) deel te nemen aan een programma waarin drie cursussen door de werkgever worden aangeboden die gerelateerd zijn aan de vaardigheden. De participanten kunnen de cursussen accepteren maar ook inruilen voor andere cursussen. Door het pakket aan cursussen dat wordt aangeboden te randomiseren, identificeren we hoe 
weloverwogen de keuze wordt gemaakt. Het idee is dat mensen de cursussen die worden aangeboden zien als een advies van de werkgever met betrekking tot de keuze. De feitelijke keuze wordt gebaseerd op een combinatie van deze impliciete informatie en de perceptie van de respondent.

De respondenten kiezen vaker cursussen die in het standaard pakket worden aangeboden, met name wanneer deze overeenkomen met hun tekorten aan vaardigheden. Echter, wanneer de werkenden zelf kiezen, nemen zij over het algemeen geen cursussen waarmee ze hun tekorten weg kunnen werken. Dit suggereert dat managers een belangrijke rol kunnen hebben in de efficiënte ontwikkeling van het menselijk kapitaal van werkenden. Werknemers met een beter voorstellingsvermogen investeren meer in hun kennistekorten. Een beter voorstellingsvermogen, minder angstigheid, een lagere risico aversiteit en meer cognitieve vaardigheden zijn gerelateerd aan een hogere kans op het maken van een weloverwogen keuze.

\section{Voorstellingsvermogen en Investeringen in Gezondheid: De Body Mass Index}

Hoofdstuk 5 onderzoekt of het voorstellingsvermogen investeringen in gezondheid beïnvloedt. In veel westerse landen heeft het gemiddelde gewicht van mensen (relatief aan hun lengte) gemeten door de Body Mass Index (BMI) - veel aandacht gekregen omdat het in de afgelopen jaren substantieel is toegenomen. Een hoge BMI wordt vaak gerelateerd aan een hoge discontovoet. Komlos, Smith en Bogin (2004) argumenteren dat de gemiddelde discontovoet is toegenomen in de afgelopen jaren en zij denken dat dit de oorzaak geweest zou kunnen zijn voor een toename in BMI.

We analyseren deze claim vanuit het perspectief dat de discontovoet een aggregaat is van verschillende psychologische eigenschappen. Veel zware mensen proberen gewicht te verliezen. Dit suggereert dat zij spijt hebben van hun eerdere gewichtstoename. Vanwege het eerder gevonden verband tussen spijt en voorstellingsvermogen, verwachten we dat het voorstellingsvermogen ook een belangrijke voorspeller kan zijn van overgewicht. Andere kenmerken die we bekijken zijn impulsiviteit, risico aversiteit, en het vermogen om rond te komen met inkomsten. We verwachten dat BMI en deze persoonskenmerken gerelateerd zijn, maar tegelijkertijd denken we dat het erg onwaarschijnlijk is dat psychologische kenmerken zoals het voorstellingsvermogen snel kunnen veranderen over een tijdsperiode van slechts enkele jaren.

De aanpak in dit hoofdstuk bestaat uit vier stappen. Ten eerste analyseren we of BMI gerelateerd is aan de discontovoet. Dan onderzoeken we welke noncognitieve vaardigheden 
gerelateerd zijn aan de discontovoet en of deze verschillen in BMI kunnen verklaren. Ten slotte analyseren we of een trend in de noncognitieve vaardigheden de veranderingen in BMI over de tijd kan verklaren.

We vinden verrassend weinig bewijs voor een positieve correlatie tussen de standaard maat van de discontovoet en BMI. De verklaring die wij hiervoor aanvoeren is dat de discontovoet gevormd is door verschillende noncognitieve vaardigheden die op verschillende manieren gecorreleerd kunnen zijn met BMI. We vinden dat er een significante correlatie is tussen bepaalde noncognitieve vaardigheden en de discontovoet en tussen deze noncognitieve vaardigheden en verschillen in BMI tussen mensen. De hoogste correlaties worden gevonden met proxies voor het voorstellingsvermogen en impulsiviteit hoewel de relatie sterk afhangt van de keuze van de proxy.

Vervolgens bekijken we de ontwikkeling van de proxies die het sterkst aan BMI gerelateerd zijn. Hiermee geven we de hypothese dat noncognitieve vaardigheden veranderingen in het gemiddelde van de BMI hebben veroorzaakt de beste kans. We vinden geen bewijs voor een verandering van deze proxies over de tijd. Onze belangrijkste bevinding is dus dat overgewicht gerelateerd zou kunnen zijn aan het voorstellingsvermogen of aan impulsiviteit, maar dat de toename in BMI van de afgelopen jaren verklaard moet worden door verschuivingen in andere parameters. Voorbeelden hiervan zouden veranderingen in de prijs van voedsel en een afname van lichaamsbeweging kunnen zijn.

In hoofdstuk 6 bespreken we ten slotte de belangrijkste bevindingen van het proefschrift en de implicaties van de conclusie dat het voorstellingsvermogen een belangrijke psychologische eigenschap is voor het maken van adequate investeringsbeslissingen. We beargumenteren dat deze conclusie een reden geeft voor overheidsingrijpen in het gedrag van individuen. We nemen beslissingen met betrekking tot de studie als voorbeeld en laten zien dat de potentiële baten van het helpen van mensen om adequate beslissingen te maken zeer groot zijn. 
Summary in Dutch 


\section{Biography}

Bart Hendricus Hubertus Golsteyn was born in Sittard, the Netherlands, on May 7, 1976. He graduated from high school (Gymnasium) at the Bisschoppelijk College Sittard in 1994.

He studied economics at Maastricht University from 1994 until 1999, specializing in labor economics and social-security. In the academic year 1997/1998 he studied at Trinity College Dublin. His master thesis contained an analysis of female labor supply in the Netherlands and Sweden. After graduation he worked in Stockholm for one year.

In October 2000, he started working as a researcher at the Research Centre for Education and the Labour Market (ROA) at Maastricht University. His work at the ROA involved research projects for the European Commission, national and regional governments and various interest groups. Major themes throughout the various projects were educational choices and graduates' labor supply.

In May 2004 he obtained a grant from ROA to write a $\mathrm{PhD}$ thesis which resulted in the present study. Part of the thesis was written at the Institute for International Economic Studies at Stockholm University where he stayed for half a year in 2006.

From August 2007 onward Bart is employed as assistant professor at the Department of Economics of Maastricht University. He is research fellow at IZA and at ROA. 
Biography

162 


\section{ROA Dissertation Series}

1. Lex Borghans (1993), Educational Choice and Labour Market Information, Maastricht, Research Centre for Education and the Labour Market

2. Frank Cörvers (1999), The Impact of Human Capital on International Competitiveness and Trade Performance of Manufacturing Sectors, Maastricht, Research Centre for Education and the Labour Market

3. Ben Kriechel (2003), Heterogeneity Among Displaced Workers, Maastricht, Research Centre for Education and the Labour Market

4. Arnaud Dupuy (2004), Assignment and Substitution in the Labour Market, Maastricht, Research Centre for Education and the Labour Market

5. Wendy Smits (2005), The Quality of Apprenticeship Training, Conflicting Interests of Firms and Apprentices, Maastricht, Research Centre for Education and the Labour Market

6. Judith Semeijn (2005), Academic Competences and Labour Market Entry: Studies Among Dutch Graduates, Maastricht, Research Centre for Education and the Labour Market

7. Jasper van Loo (2005), Training, Labor Market Outcomes and Self-Management, Maastricht, Research Centre for Education and the Labour Market

8. Christoph Meng (2005), Discipline-Specific or Academic? Acquisition, Role and Value of Higher Education Competencies, Maastricht, Research Centre for Education and the Labour Market 
9. Andreas Ammermüller (2007), Institutional Effects in the Production of Education: Evidence from European Schooling Systems, Maastricht, Research Centre for Education and the Labour Market

10. Bart Golsteyn (2007), The Ability to Invest in Human Capital, Maastricht, Research Centre for Education and the Labour Market 